\title{
Social threat hurts! : the influence of social threat on pain
}

Citation for published version (APA):

Peeters, P. A. M. (2013). Social threat hurts! : the influence of social threat on pain. [Doctoral Thesis, Maastricht University]. Maastricht University. https://doi.org/10.26481/dis.20131018pp

Document status and date:

Published: 01/01/2013

DOI:

10.26481/dis.20131018pp

Document Version:

Publisher's PDF, also known as Version of record

\section{Please check the document version of this publication:}

- A submitted manuscript is the version of the article upon submission and before peer-review. There can be important differences between the submitted version and the official published version of record.

People interested in the research are advised to contact the author for the final version of the publication, or visit the DOI to the publisher's website.

- The final author version and the galley proof are versions of the publication after peer review.

- The final published version features the final layout of the paper including the volume, issue and page numbers.

Link to publication

\footnotetext{
General rights rights.

- You may freely distribute the URL identifying the publication in the public portal. please follow below link for the End User Agreement:

www.umlib.nl/taverne-license

Take down policy

If you believe that this document breaches copyright please contact us at:

repository@maastrichtuniversity.nl

providing details and we will investigate your claim.
}

Copyright and moral rights for the publications made accessible in the public portal are retained by the authors and/or other copyright owners and it is a condition of accessing publications that users recognise and abide by the legal requirements associated with these

- Users may download and print one copy of any publication from the public portal for the purpose of private study or research.

- You may not further distribute the material or use it for any profit-making activity or commercial gain

If the publication is distributed under the terms of Article $25 \mathrm{fa}$ of the Dutch Copyright Act, indicated by the "Taverne" license above, 
Pim A. M. Peeters

Social threat
hurts!

\section{The influence of} social threat on pain 
Cover design Lay-out and design

Printed by
Proefschrift-aio.nl Proefschrift-aio.nl DPP

\title{
ISBN
}

\author{
(C) 2013 Pim Peeters
}




\section{Social threat hurts!}

\section{The influence of social threat on pain}

\section{PROEFSCHRIFT}

ter verkrijging van de graad van doctor aan de Universiteit Maastricht en Katholieke Universiteit Leuven, op gezag van de Rector Magnificus,

Prof. Dr. Luc Soete

volgens het besluit van het College van Decanen, in het openbaar te verdedigen

op 18 oktober 2013 om 12:00 uur

door

Pim Antonius Maria Peeters 


\section{Promotor:}

Prof. Dr. Johan Vlaeyen

\section{Copromotor:}

Prof. Dr. Madelon Peters

\section{Beoordelingscommissie:}

Prof. Dr. Arnoud Arntz (Voorzitter)

Prof. Dr. Ilse Van Diest (KU Leuven)

Prof. Dr. Liesbet Goubert (UGent)

Dr. Linda Vancleef

Dr. Carolien Martijn

Deze dissertatie werd financieel mogelijk gemaakt door een Toptalent beurs van de Nederlandse Organisatie voor Wetenschappelijk Onderzoek (NWO). 
Chapter 1:

Introduction

Chapter 3:

The effects of a social safety cue and threat of pain on pain report and facial pain expression

Chapter 5:

Feeling more pain, yet showing less: The influence of social threat on pain P. 56

Chapter 7:

The impact of a social threat to psychosocial integrity on reported pain intensity and facial pain expression

Chapter 2:

A topical review on the influence of social threat on pain experience and pain expression

P. 12

Chapter 4:

The effect of available communication channels on pain expression

\section{P. 44}

Chapter 6:

Taking into account social threat: A vignette study of pain assessment

P. 72

Chapter 8:

General Discussion
Summary

P. 118

Samenvatting

P. 124

About the author

P. 130

Dankwoord 
1 
The effect

of available

communication

channels on pain

expression

Pim A. M. Peeters, Sandy de Groof, Johan W. S. Vlaeyen 


\section{Introduction}

With several influential articles about the fear avoidance model of pain $[13 ; 6 ; 1]$ and an exposure therapy based on this model proving to be highly effective for chronic pain patients that are fearful of pain ${ }^{[2 ; 7]}$ it can be safely stated that the effects of threatening pain appraisals on pain experience and behaviour is becoming more widespread knowledge. As the expected harmfulness of pain increases, so does it's experience become more aversive $^{[5]}$, and safety behaviour more elaborate ${ }^{[12]}$.

Threat, however, has more than one face. While appraisals of the intrapersonal threat value of pain have been thoroughly researched, little is known about how interpersonal threats influence the experience and expression of pain. What happens when not the pain itself, but the social context in which it occurs is experienced as threatening? The social environment can present various threats to an individual, ranging from having to suffer negative comments by others, to chronic bullying or physical assault.

Increasing evidence from social and health psychology demonstrate that threats to our integrity from a social source, such as bullying or harm inflicted by another, can have a severe impact on our physical and psychological health ${ }^{[9]}$. Head and stomach pains are amongst the most commonly observed somatic problems associated with bullying $[3 ; 4 ; 10]$. However, aside from studies on negative spouse interactions of chronic pain patients ${ }^{[8]}$, no systematic effort has been made to investigate the influence of social threats on pain and possible underlying mechanisms.

It is very well possible that interpersonal or social threats play an important role in the influence that others have on the pain experience and behaviour of someone suffering from pain. Since very little is known about the influence of social threats on pain, this dissertation presents an exploratory investigation of social threat effects on pain experience and expression and their underlying mechanisms. 


\section{Research questions}

The main research question of this dissertation is:

What is the effect of social threat on pain report and facial expression?

Relevant sub-questions are:

1. What are the effects of a pain-specific social threat?

2. What are the effects of a social threat unrelated to pain?

3. Are social threat effects different for people who catastrophize about pain?

4. Are social threat effects taken into account when judging pain in others?

\section{Outline}

First a topical review about social threat in the context of pain is presented in chapter two. A case is made to distinguish four subtypes of social threat on a theoretical basis. Existing models of pain and/or social threat are related to these four subtypes and empirical evidence for these relations is considered.

For the purpose of further organizing this dissertation in a logical order, the studies have been split into studies dealing with the methodology of social threat research and studies dealing with the research questions about social threat influences on pain. In the methodological sections two studies are described. In chapter three a study is presented that is largely a replication of Sullivan, Adams, and Sullivan ${ }^{[11]}$, investigating the influence of an observer being present during a painful task. Additionally, it was investigated whether it mattered if the observer was able to exert influence over the pain task or not.

In chapter four, the second methodological study, the influence of an observer on pain report and facial pain expression was further investigated by manipulating the communication channels through which the participants were in contact with the observer. The observer had either only a visual means of observing the participant, only an auditory means of observing the participant, both means, or no means of observing the participant.

Whereas the studies in the methodological section mainly deal with the factors determining a participant's response to observer presence in general, several studies were conducted that specifically deal with the influence of social threat on pain. In chapter five a study is presented in which participants were administered five painful electrical stimuli by an alleged fellow student. This fellow student was however an accomplice to the study. These five painful stimuli were framed as a friendly, a neutral, or a hostile choice of the fellow student in three conditions. 
Chapter six presents a study in which participants had to estimate the painfulness and expression of pain of a character described in a vignette. While injuries were kept constant, the social context in which these injuries were sustained was varied from positive to negative. This way it became possible to investigate the degree to which social context variables are taken into account when making pain judgments about others.

The final study is presented in chapter seven. In this study two participants played a quiz for money. By overtly favouring one of the participants over the other, the experimenter aimed to become a threatening person to one of the participants, while representing a safe person for the other. By having the experimenter be present while the participants were subjected to a painful task, the influence of social threat on pain report and expression could be investigated.

This dissertation closes in chapter eight with a discussion of the presented studies and the research questions. Implications for clinical practice and future research are discussed. 


\section{References}

[1] Crombez G, Eccleston C, Van Damme S, Vlaeyen JWS, Karoly P. Fearavoidance model of chronic pain: The next generation. Clinical Journal of Pain 2012;28:475-483.

[2] de Jong JR, Vlaeyen JWS, Onghena P, Goossens MEJB, Geilen M, Mulder H. Fear of movement/(re)injury in chronic low back pain. Education or exposure in vivo as mediator to fear reduction? Clinical Journal of Pain 2005;21(9-17).

[3] Fekkes M, Pijpers FIM, Fredriks AM, Vogels T, Verloove-Vanhorick SP. Do bullied children get ill, or do ill children get bullied? A prospective cohort study on the relationship between bullying and health-related symptoms. Pediatrics 2006;117(5):1568 - 1574.

[4] Gini G, Pozzoli T. Association between bullying and psychosomatic problems: a meta-analysis. Pediatrics 2009;123(3):1059 - 1065.

[5] Jackson T, Pope L, Nagasaka T, Fritch A, Iezzi T, Chen H. The impact of threatening information about pain on coping and pain tolerance. British Journal of Health Psychology 2005; 10:441-451.

[6] Leeuw M, Goossens MEJB, Linton SJ, Crombez G, Boersma K, Vlaeyen JWS. The fearavoidance model of musculoskeletal pain: current state of scientific evidence. Behavioural Medicine 2007;30:77-94.

[7] Leeuw M, Goossens MEJB, van Breukelen GJ, de Jong JR, Heuts PHTG, Smeets RJ, Köke AJ, Vlaeyen JWS. Exposure in vivo versus operant graded activity in chronic low back patients: results of a randomized controlled trial. Pain 2008;138:192-207.

[8] Leonard MT, Cano A, Johansen AB. Chronic pain in a couples context: a review and integration of theoretical models and empirical evidence. Journal of Pain 2006;7(6):377-390.

[9] Miller GE, Chen E, Parker KJ. Psychological stress in childhood and susceptibility to the chronic diseases of aging: moving toward a model of behavioral and biological mechanisms. Psychological Bulletin 2011;137(6):959-997.

[10] Saastamoinen P, Laaksonen M, Leino-Arjas P, Lahelma E. Psychosocial risk factors of pain among employees. European Journal of Pain 2009; 13(1):102-108.

[11] Sullivan MJL, Adams H, Sullivan ME. Communicative dimensions of pain catastrophizing: social cueing effects on pain behaviour and coping. Pain 2004;107:220-226.

[12] Tang NK, Salkovskis PM, Poplavskaya E, Wright KJ, Hanna M, Hester J. Increased use of safety-seeking behaviors in chronic back pain patients with high health anxiety. Behavior Research and Therapy 2007;45(12).

[13] Vlaeyen JWS, Linton SJ. Fear-avoidance and its consequences in chronic musculoskeletal pain: A state of the art. Pain 2000;85(3):317-332. 
2 


\section{A topical review on the influence of social threat on pain experience and pain expression}

Pim A. M. Peeters, Ken Ceulemans, Johan W. S. Vlaeyen 


\begin{abstract}
In the field of pain research, the intrapersonal threat of pain has been widely investigated. As the threat value of pain increases, so does pain appear to become more aversive. Much less is known however about how interpersonal/social threats impact pain experience and expression. Evidence from social and health psychology suggests that social threat can have a severe impact on health. In this article different forms of social threat are related to existing models of pain. Four forms of social threat are distinguished on the basis of the target and nature of the social threat. The evidence for an effect of each form of social threat effects on pain are reviewed in the light of the existing models. Suggestions are made for alternative models from other fields of research that may prove useful in investigating and explaining social threat effects on pain.
\end{abstract}




\section{Introduction}

Pain that is appraised as threatening is experienced as more intense [23], but what happens when not the pain itself, but the social context in which it occurs is experienced as threatening? While some research has been conducted on social support in the context of pain ${ }^{[5,16,34]}$, the investigation of threat has mostly focused on the intrapersonal threat of pain itself and its relation to catastrophic interpretations of pain ${ }^{[40]}$, attention and hypervigilance ${ }^{[9]}$, fear avoidance ${ }^{[8,28,47]}$ and motivation ${ }^{[8,44]}$. Social threat generally has no place in the models of pain. However, increasing evidence from social and health psychology suggests that social threats can have a severe impact on our physical and psychological health ${ }^{[31]}$. Therefore, in this review we investigate whether hypotheses about social threat effects on pain can be derived from existing models of pain and pain communication, and the available empirical evidence for these hypotheses.

The lack of attention to social threats in the field of pain is surprising given that the social communication of pain has been a topic of structured research for almost two decades already. In 1995, Prkachin and Craig ${ }^{[36]}$ formulated a communication model of pain, later refined by Hadjisavropoulos and Craig ${ }^{[20,21]}$, that still serves as the model on which most social pain research is based. According to this model, the communication of pain takes place in various steps. First an individual experiences pain. This pain is encoded by the individual into overt pain behaviours, which are perceived by other individuals who have to decode these pain behaviours to get an understanding of the experience of the pain sufferer.

Since each step depends on the result of the previous step, factors that influence any of these levels will therefore impact the resulting understanding of an individual's pain. Such factors include personality traits and beliefs about pain for both the sufferer and observer, but could also comprise the relationship between the sufferer en observer ${ }^{[21]}$. Research on the communication model of pain has lead to valuable insights into how inter- and intrapersonal factors influence another persons' attention to and assessment of pain expressed by the sufferer.

Unfortunately, the way that the communication model of pain is usually explained implies a unidirectional model. The model starts with the experience and encoding of pain, leading finally to other persons' understanding of the pain. In reality, communication is rather a repetitive loop in which communication may be adapted to the responses of others. This implies that an individuals encoding of pain, and possibly also its experience, may be influenced by his/her interpretation of the behaviours of those other individuals that are currently in his/her vicinity. The reciprocal influence of other individuals on the pain experience and expression of the sufferer has received relatively little attention. Knowledge about the influences of others on pain experience and expression would complement the pain communication model as a feedback loop from assessor behaviour to the experience of the sufferer. 


\section{The impact of social threat}

Many studies in the last few decades have found compelling evidence for the negative impact that social threats can have on psychological but also physical functioning and health. For example, research on ostracism, rejection and exclusion has shown that these can lead to feelings of anger and sadness on the short term, but also depression, hopelessness and feelings of unworthiness on the long term ${ }^{[51]}$.

Social threat can also impair task performance as has been demonstrated by research into stereotype threat; the threat of confirming a negative stereotype against one's group ${ }^{[26]}$. One way in which stereotype threat is often induced in the laboratory is by having a group perform a task for the purpose of performance evaluation in the presence of another group to which their performance is stereotypically inferior. Through increased physiological stress responding, distraction, adoption of performanceavoidance goals and negative thoughts and feelings such as anxiety, stereotype threat has been found to decrease performance on various tasks [27].

The fear of negative evaluation, induced in the Trier social stress test, where participants have to give a presentation before a small (expert) audience after a minimal preparation time, has been demonstrated to cause endocrine and immunological responses, which when chronic are associated with negative health consequences ${ }^{[25]}$. One of the most severe forms of social threat that one can endure, childhood maltreatment, has consistently been related with adult mental health problems such as depression and anxiety, but also with physical health problems such as coronary heart and autoimmune diseases ${ }^{[49]}$. These latter are likely to be caused by pervasive changes to biological systems and behaviour in response to the stress ${ }^{[31]}$.

While examples listed above are just a selection from many more studies on the topic of social threat, they demonstrate the overall finding that social threat appears to have a negative impact on health and functioning. They also demonstrate that 'social' and 'threat' are both very broad concepts. This in turn has lead to different operationalizations of social threat, which poses problems for comparability between studies. We believe that this may in part explain the lack of social threat research in the field of pain. Most studies on the effects of different kinds of social threat on pain either stand alone or are part of a research project on other topics. This underlines the lack of a systematic approach in the investigation of the impact of social threat in the field of pain.

\section{Different forms of social threat}

The most encompassing definition of social threat would be any social source of (impending) harm to integrity. Based on this definition of social threat, there are at least four ways in which social threat can act upon well being in 
the context of pain. First, integrity encompasses physical integrity, but also psychosocial integrity. This will be referred to as the target of the social threat. While a threat to physical integrity would take the form of damage to the body and possibly death, a threat to psychosocial integrity could take the form of losing face, being rejected by others, or being stigmatized. It is likely that the influence of a social threat on pain-related outcomes will depend on the target of the social threat.

Secondly, the social source of impending harm, referred to as the nature of the social threat, may also present itself in different forms. The nature of the social threat may be one of a direct harm or an indirect harm. A direct harm encompasses such situations where the integrity of the individual is damaged directly by the act of another. This could take the form of intentionally inflicted injury, but also bullying or a very negative evaluation by a superior. Indirect harm refers to situations where the act of another does not damage integrity directly, but hinders prevention of or alleviation from harm. This could take the form of being denied medical care, or losing social support.

Based on the theoretical distinctions between two targets and two natures of social threat, a $2 \times 2$ matrix can be created that yields four forms of social threat (see Fig. 1).

\begin{tabular}{|ll|ll|}
\cline { 2 - 3 } \multicolumn{1}{c|}{} & Nature & \\
\hline \multirow{2}{*}{\multicolumn{1}{c|}{}} & Direct threat & Indirect threat \\
\hline Target & Physical integrity & Direct physical threat & Indirect physical threat \\
& Psychosocial integrity & Direct psychosocial threat & Indirect psychosocial threat \\
\hline
\end{tabular}

Fig. 1

\section{The influence of social threat on pain}

Direct harm to physical integrity

In the context of pain, a social threat of direct harm to physical integrity is probably the most straightforward kind of social threat. Examples include injury resulting from a car accident, physical assault and torture. However, few models make any explicit prediction about whether inflicted pain should or should not lead to a different pain experience than pain suffered from a non-social source.

It has been suggested on the basis of a cognitive appraisal model of pain (CAM), that social contextual factors could influence pain experience through their impact on the threat value of the pain ${ }^{[46]}$. The central tenet of the CAM is that the experienced intensity of pain depends largely on the appraised threat value of the pain, where higher experienced threat leads to a more intense pain experience ${ }^{[37]}$. Social threats are hypothesized to increase the threat value of the pain, thereby increasing the intensity of the pain experience itself as well. 
Two experimental studies indeed found evidence for social threat causing increased pain intensity. A study by Grey and Wegner ${ }^{[18]}$ demonstrated that pain stimuli that were perceived as intentionally rather than unintentionally administered by a confederate were reported to be more painful. Similarly, Peeters and Vlaeyen ${ }^{[35]}$ found that the experienced social threat caused by someone intentionally administering more pain stimuli than necessary lead to higher reported pain intensity for high pain catastrophizers specifically. Remarkably, in this latter study facial pain expression decreased in response to the social threat, resulting in a dissociation between verbal and non-verbal pain behaviour.

These results appear to fit with the CAM, however in the first study by Grey and Wegner ${ }^{[18]}$ no underlying mechanisms were investigated, while the study by Peeters and Vlaeyen ${ }^{[35]}$ that did include measures of pain threat, found no evidence for its mediating role suggested by the CAM. This led the authors to suggest that appraisal processes related to other aspects of pain than its threat value may be responsible for social influences on pain ${ }^{[35]}$. Pain that is judged to be unfair may for example become more aversive, without becoming more physically threatening.

While not making any predictions about the experienced pain, an evolutionary account of pain expression ${ }^{[50]}$ and a communal coping model of pain catastrophizing ${ }^{[40]}$ do imply that socially inflicted pain should affect the communication of pain experience differently than pain originating from other sources. Based on an evolutionary account of pain ${ }^{[50]}$, non-verbal pain behaviour mostly serves to signal the need for help to protagonists. In the case of a social threatening context, such as the presence of an antagonist, the expression of pain is expected to be suppressed as signaling vulnerability is in this situation counterproductive to the individual's survival.

A similar prediction with a slightly different rationale can be found in the communal coping model of pain catastrophizing (CCM $)^{[39,40]}$. This model posits that pain behaviour to solicit support is a coping strategy that is mostly employed by individuals who catastrophize about pain. As with the evolutionary model, the CCM appears to imply that increased pain expression of high pain catastrophizers should not occur when the social context is threatening rather than supportive. The evolutionary model assumes that the tendency to suppress pain in threatening contexts is an evolved, automatic tendency, whereas the CCM assumes a goal directed effort being made by the individual in pain to communicate more or less pain.

The decrease in facial pain expression as a result of social threat in the study by Peeters and Vlaeyen ${ }^{[35]}$ appears to support the basic prediction of these models. Contrary to the CCM, no differential effect was found for low or high pain catastrophizers. Whether this decrease in facial pain expression stems from automatic suppression or a goal directed effort cannot be concluded on the basis of these data. Determining the automaticity of facial pain expression modulation remains a challenge for future research. 
The studies discussed above focus mainly on the acute results of inflicted pain. However, the perception that pain is being suffered at the hand of someone else also appears to be deleterious to recovery from long term pain. Ferrari and Russell ${ }^{[14]}$ presented data demonstrating that patients with whiplash complaints recover more poorly when the car accident causing the whiplash had been the fault of someone else, rather than being the fault of the patient him/herself. It has been suggested that the poor recovery from inflicted whiplash is linked to litigation status ${ }^{[19]}$. Pursuing litigation for injury compensation appears to be associated with poorer recovery. Based on a motivational perspective this could mean that litigation goals may conflict with and take priority over pain coping goals. While this could take the form of an explicit conflict of interest, poor recovery perhaps being the basis for greater financial compensation, a motivational account does not rule out more subtle goal conflicts, such as time lost at pursuing litigation going at the expense of active rehabilitation. It should be noted that explanations for this association remain highly speculative.

\section{Indirect harm to physical integrity}

Social threat of indirect harm to physical health integrity may be a less obvious form of social threat, which is most likely to be relevant to sufferers of chronic pain. As for many instances of chronic pain, when no medical explanation can be found, chronic pain patients will often find themselves in situations where they are or feel to be rejected by medical professionals despite the feeling that something must by medically wrong.

In patient caretaker communication, invalidation may cause patients to feel misunderstood and lose faith in the caretaker. Invalidation refers to a lack of understanding and empathy towards the other and the experiences that he/she voices. This can occur when a caretaker focuses on trying to reassure the patient that nothing is medically wrong, while not paying attention to how the pain affects the patients life. Experimental studies have demonstrated that invalidation may actually decrease pain ratings compared to a validation condition for experimentally induced pain [29], and increase pain ratings for chronic low back pain ${ }^{[45]}$. These effects on pain are likely to be mediated (in part) by the negative effects of invalidation on emotions. As patients feel worse about the communication with the caretaker, this negative mood may increase pain

Aside from mismatched communication, chronic pain patients may experience that there is nobody to turn to with their problem. Conceptually the threat of losing options to prevent or alleviate of pain is closely related to a loss of control. Individuals experience that while previously pain was under control of others, being prevented or alleviated, or at least efforts being made to control the pain, this sense of control is now lost. While control over pain is generally accepted to be beneficial [1], there is some evidence that losing this control may have even more negative consequences for pain than never to have controlled pain at al ${ }^{[1,7]}$. According to a motivational perspective, repeated efforts to bring pain 
back under control may be a misdirected attempt to deal with the pain, which takes precedence over other more effective strategies of dealing with the pain, such as acceptance ${ }^{[44]}$. On the long term such continued failure to control could lead to learned helplessness, resulting in depression.

While the mentioned studies placed pain under the direct control of the sufferer, similar processes may also occur when pain is experienced to be under control of others. Attempts of control will then likely take the form of trying to get the attention of the potential pain controller and convincing him/her that action is required to alleviate or prevent the pain. This ties into the evolutionary account and CCM of pain expression. Unfortunately, to the knowledge of the authors no studies on this topic have been conducted.

\section{Direct harm to psychosocial integrity:}

Social threat of a direct harm to psychosocial integrity as opposed to the physical integrity threats is likely to be a much more common experience, also for those who are not suffering from chronic pain. Everyone is likely to have experienced risking a negative evaluation, unfair treatment, discrimination or perhaps even stigmatization. These experiences may be more frequent to sufferers of chronic pain ${ }^{[6,38]}$.

Unlike the social threats to physical integrity, which are likely to be more often than not related to the source of the pain, social threats to psychosocial integrity result from social interactions that are not in itself the cause of the pain. This does not mean that this form of social threat may not be associated with pain, as social exclusion and stigmatization may very well occur in relation to chronic pain complaints. This distinction does imply that other mechanisms may play a more prominent role for social threats to psychosocial integrity.

The distinction between direct and indirect harm while relatively clear for psychical integrity, is more blurred for psychosocial integrity. Instances of direct harm to psychosocial integrity, such as negative interactions in the context of bullying, are likely to be associated with the experience of or actual instances of indirect harm such as ostracism as well. Therefore mechanisms pertaining to one form of social threat to physical integrity may be relevant for the other form as well.

The research on stereotype threat effects on task performance ${ }^{[26,27]}$ is especially interesting in this context. One of the main working mechanisms through which stereotype threat reduces task performance appears to be its effects on attention; by causing the mind to wander ${ }^{[32]}$ and negative thoughts and feelings distracting attention. Similar mechanisms may play a role in the context of pain, causing rumination, and distraction away from effective task performance despite pain. Motivational aspects are also likely to play a role. The adoption of performance-avoidance goals (wanting to avoid demonstrating incompetence), rather than performance approach goals (wanting to demonstrate competence), can lead to negative task experience and behaviour, thereby reducing performance ${ }^{[27]}$. Stereotype threat mechanisms may also offer a partial explanation for gender effects 
on pain thresholds and tolerance, as women are typically regarded to be more sensitive to pain than men. Systematic investigation would be needed to make any claims as to the consequences stereotype threats for pain.

Many forms of social threat to psychosocial integrity are likely to lead to a dilemma for the sufferer, as he/she has to deal both with pain and the psychosocial injury that is (potentially) inflicted. The solutions for both issues may often be in conflict with each other, such as taking it easy on a physically straining task to reduce pain, or continuing on the task to prevent or reduce stigmatization by coworkers. There is evidence that this goal conflict is itself stressful, taxing the suffering regardless of the goal he chooses to prioritize.

In the cases of more long lasting social threats such as bullying, sensitization to pain may be the result of processes delineated in the biological embedding of childhood adversity model of Miller, Chen and Parker ${ }^{[31]}$. This model posits that childhood adversity can cause changes at the biological level such as hormonal deregulation and the release of increased proinflammatory cytokines. These changes are especially likely when social threat is experienced in childhood, when the body is still calibrating certain bodily systems. Behaviourally, chronic social threat may lead people to become biased towards interpreting social situations as threatening, creating mistrust of others. This may in turn cause its own social difficulties, making conflict and rejection more likely than warm and supportive social relationships. While mostly linking childhood maltreatment to coronary heart disease and autoimmune diseases in their model, hormonal dysregulation have also been associated with other social threats ${ }^{[25]}$ and chronic pain ${ }^{[3]}$, making this model a promising model for the investigation of pain sensitization through chronic social threat. These biological and behaviour changes may explain the consistent associations between childhood maltreatment $[4,15,22,24,41,42,48]$ or bullying ${ }^{[17,43]}$ and chronic pain.

\section{Indirect harm to psychosocial integrity}

To be clear on the nature of indirect harm in the context of psychosocial integrity, the definition indirect harm does not imply that this form of social threat does not directly impact wellbeing. Indirect harm means that wellbeing is impacted through the hindering of prevention from or alleviation of psychosocial injury, such as losing a social support network. This distinguishes it from direct harm, where psychosocial integrity is impacted directly such as when one is being unjustly treated. As has been noted earlier this distinction is theoretically based and likely to be less clear in practice.

Social threats of indirect harm to psychosocial integrity have recently received increased attention in the form of research on social exclusion, rejection and ostracism. The model that structures most of the current research on social exclusion, rejection and ostracism is the need-threat model [51]. This model distinguishes between three phases in the consequences of social exclusion. First is the immediate/reflexive phase in which four 
fundamental needs are threatened by the exclusion; belongingness, control, self-esteem, and meaningful existence. This has a negative impact on the individual, regardless of the exact nature of the exclusion and the context in which it occurs. Then follows the coping/reflective phase in which the individual attempts to compensate for the threat to their needs either by trying to get socially included again or find other sources for their needs. If coping attempts are unsuccessful and social exclusion goes into the long-term/resignation phase, coping resources become depleted and individuals start feeling depressed, unworthy and hopeless.

Many studies have shown relations between the experiences of social exclusion and pain and overlapping brain activation ${ }^{[12,13,30,33]}$. Eisenberger, Jarcho, Lieberman, and Naliboff ${ }^{[11]}$ found a direct effect of social exclusion on pain, by demonstrating that social distress caused by being excluded during participation in a virtual ball tossing game was related to increased report of pain unpleasantness in response to heat stimuli at the end of the game. On the other hand DeWall and Baumeister ${ }^{[10]}$ found that a different social exclusion manipulation based on telling participants that they would end up lonely in the future resulted in decreased pain experience and increased pain tolerance. Both these results were replicated by Bernstein and Claypool ${ }^{[2]}$, who showed that the opposite results are most likely due to an intensity effect, with low intensity social exclusion such as the ball tossing game leading to pain sensitization, while high intensity social exclusion such as a future alone manipulation is likely to lead to a numbing for pain. It would be interesting to investigate whether increased pain is mostly related to the initial immediate phase and numbing is the result of unsuccessful coping in resignation phase, especially in the context of chronic pain where individuals continually need to cope with pain and are therefore much more likely to reach the resignation phase.

\section{Conclusion}

By proposing four ways in which social threat can act upon well being in the context of pain, the present paper hopes to structure and stimulate research into social threat effects on pain experience and expression. Although few models make specific predictions about how social threat should impact pain, many models imply that appraisal processes, coping, and goal directed behaviour are likely to play an important role. Especially in the case of social threats to psychosocial integrity, dual appraisal and coping processes may be in play, to deal with pain as well as with the psychosocial injury. This is likely to give rise to goal conflicts as an additional stressor to the pain sufferer.

By necessity all measures of pain rely on behaviour of the pain sufferer, be it verbal or non-verbal behaviour, which should be viewed as a form of communication rather than a direct reflection of the internal experience ${ }^{[20]}$. Aside from possibly influencing the experience of pain, social threat is also likely to affect the communication of pain. Using multiple measures of 
pain and taking into account their communicative nature is therefore very important when investigating social threat effects on pain.

While there are several hypotheses about the role of social threat on pain report and non-verbal pain expression, the empirical data is presently lacking. Overall, it appears that social threats increase the experienced intensity of pain, although there are several cases known in which the opposite was observed or could be theoretically predicted. Systematic investigation of social threat effects on pain is therefore necessary to be able to understand how social threats impact pain and how this should be best dealt with by the sufferer. In this context it is also essential to investigate the underlying mechanisms and the moderators of these effects, such as individual sensitivities and timeframe of the social threat and of pain (acute vs. chronic). We believe that with the lack of empirical studies, the current theories on pain and social threat should be used as a starting point for the investigation of social threat effects on pain. Additional data will show whether the existing theories of pain are able to adopt social threats as well, or that new models will be necessary to explain the empirical findings. 


\section{References}

[1] Arntz, A, Schmidt, AJM. Perceived control and the experience of pain. In A Steptoe and A Appels. Stress, personal control and health.

Chichester:Wiley, 1989. pp. 131-162

[2] Bernstein, MJ, Claypool, HM. Social Exclusion and Pain Sensitivity: Why Exclusion Sometimes Hurts and Sometimes Numbs. Psychological Bulletin. 2011:1-12

[3] Blackburn-Munro, G. Hypothalamo-Pituitary-Adrenal Axis Dysfunction As a Contributory Factor to Chronic Pain and Depression. Current Pain and Headache Reports. 2004;8:116-124

[4] Brown, J, Berenson, K, Cohen, P. Documented and self-reported child abuse and adult pain in a community sample. Clinical Journal of Pain. 2005;21(5):374-377

[5] Brown, JL, Sheffield, S, Leary, MR, Robinson, ME. Social support and experimental pain. Psychosomatic Medicine. 2003;65:276-283

[6] Cohen, M, Quintner, J, Buchanan, D, Nielsen, M, Guy, L. Stigmatization of Patients with Chronic Pain: The Extinction of Empathy. Pain Medicine. 2011;12:1637-1643

[7] Crombez, G, Eccleston, C, De Vlieger, P, van Damme, S, De Clercq, A. Is it better to have controlled and lost than never to have controlled at all? An experimental investigation of control over pain. Pain. 2008;137:631-639

[8] Crombez, G, Eccleston, C, Van Damme, S, Vlaeyen, JWS, Karoly, P. Fear-avoidance model of chronic pain: The next generation. Clinical Journal of Pain. 2012;28:475-483

[9] Crombez, G, van Damme, S, Eccleston, C. Hypervigilance to pain: an experimental and clinical analysis. Pain. 2005; 116:4-7

[10] DeWall, CN, Baumeister, RF. Alone but feeling no pain: Effects of social exclusion on physical pain tolerance and pain threshold, affective forecasting and interpersonal empathy. Journal of Personality and Social Psychology. 2006;91(1):1 - 15

[11] Eisenberger, NI, Jarcho, JM, Lieberman, MD, Naliboff, BD. An experimental study of shared sensitivity to physical pain and social rejection.

Pain. 2006; 126:132-138

[12] Eisenberger, NI, Lieberman, MD. Why it hurts to be left out: The neurocognitive overlap between physical and social pain. In KD Williams, JP Forgas and W von Hippel. The social outcast: Ostracism, social exclusion, rejection, and bullying. New York:Psychology Press, 2005. pp.

[13] Eisenberger, NI, Lieberman, MD, Williams, KD. Does rejection hurt? An fMRI study of social exclusion. Science. 2003;302:290 - 292

[14] Ferrari, R, Russell, A. Why blame is factor in recovery from whiplash injury. Medical Hypotheses. 2001;56:372-375

[15] Finestone, HM, Stenn, P, Davies, F, Stalker, C, Fry, R, et al. Chronic pain and health care utilization in women with a history of childhood sexual abuse. Child Abuse \& Neglect. 2000;24(4):547-556

[16] Gil, KM, Keefe, FJ, Crisson, JE, Van Dalfsen, PJ. Social support and pain behavior. Pain. 1987;29(2):209-217 


\section{A TOPICAL REVIEW ON THE INFLUENCE OF SOCIAL THREAT ON PAIN EXPERIENCE AND PAIN EXPRESSION}

[17] Gini, G, Pozzoli, T. Association between bullying and psychosomatic problems: a meta-analysis. Pediatrics. 2009;123(3):1059 - 1065

[18] Gray, K, Wegner, DM. The sting of intentional pain. Psychological Science. 2008;19(12):1260-1262

[19] Gun, RT, Osti, OL. Risk factors for prolonged disability after whiplash injury: a prospective study. Spine. 2005;30:386-391

[20] Hadjistavropoulos, T, Craig, KD. A theoretical framework for understanding self-report and observational measures of pain: A communications model. Behaviour Research and Therapy. 2002;20:551-570

[21] Hadjistavropoulos, T, Craig, KD, Duck, S, Cano, A, Goubert, L, et al. A biopsychosocial formulation of pain communication. Psychological Bulletin. 2011;137(6):910-939

[22] Imbierowicz, K, Egle, UT. Childhood adversities in patients with fibromyalgia and somatoform pain disorder. European Journal of Pain. 2003;7(2):113-119

[23] Jackson, T, Pope, L, Nagasaka, T, Fritch, A, Iezzi, T, et al. The impact of threatening information about pain on coping and pain tolerance. British Journal of Health Psychology. 2005; 10:441-451

[24] Jones, GT, Power, C, Macfarlane, GJ. Adverse events in childhood and chronic widespread pain in adult life: Results from the 1958 British Birth Cohort Study. Pain. 2009;143((1-2)):92-96

[25] Kirschbaum, C, Pirke, KM, Hellhammer, DH. The 'Trier Social Stress Test'--a tool for investigating psychobiological stress responses in a laboratory setting. Neuropsychobiology. 1993;28(1-2):76-81

[26] Kit, KA, Tuokko, HA, Mateer, CA. A Review of the Stereotype Threat Literature and Its Application in a Neurological Population. Neuropsychological Review. 2008;18:132-148

[27] L., SJ. Understanding the Process of Stereotype Threat: A Review of Mediational Variables and New Performance Goal Directions. Educational Psychology Review. 2004;16(3):177-206

[28] Leeuw, M, Goossens, MEJB, Linton, SJ, Crombez, G, Boersma, K, et al. The fearavoidance model of musculoskeletal pain: current state of scientific evidence. Behavioural Medicine. 2007;30:77-94

[29] Linton, SJ, Boersma, K, Vangronsveld, K, Fruzzetti, A. Painfully reassuring? The effects of validation on emotions and adherence in a pain test. European Journal of Pain. 2012;16(4):592-599

[30] MacDonald, G, Kingsbury, R, Shaw, S. Adding insult to injury: Social pain theory and response to social exclusion. In KD Williams, JP Forgas and W von Hippel. The social outcast: Ostracism, social exclusion, rejection, \& bullying. New York:Psychology Press, 2005. pp. 77-90

[31] Miller, GE, Chen, E, Parker, KJ. Psychological stress in childhood and susceptibility to the chronic diseases of aging: moving toward a model of behavioral and biological mechanisms. Psychological Bulletin. 2011;137(6):959-997

[32] Mrazek, MD, Chin, JM, Schmader, T, Hartson, KA, Smallwood, J, et al. Threatened to distraction: Mind-wandering as a consequence of stereotype threat. Journal of Experimental Social Psychology. 2011;47:1243-1248 
[33] Nelson, EE, Panksepp, J. Brain substrates of infant-mother attachment: Contributions of opiods, oxytocin, and norepinephrine. Neuroscience and Biobehavioral Reviews. 1998;22:437-452

[34] Patrick, L, D’Eon, J. Social support and functional status in chronic pain patients. Canadian Journal of Rehabilitation. 1996;9(4):195-201

[35] Peeters, PAM, Vlaeyen, JWS. Feeling more pain, yet showing less: The influence of social threat on pain. Journal of Pain. 2011:

[36] Prkachin, KM, Craig, KD. Expressing pain: The communication and interpretation of facial pain signals. Journal of Nonverbal Behavior. 1995;19(4):191-205

[37] Severeijns, R, Vlaeyen, JWS, van den Hout, MA. Do we need a communal coping model of pain catastrophizing? An alternative explanation. Pain. 2004;111(3):226-229

[38] Slade, SC, Molloy, E, Keating, JL. Stigma experienced by people with non-specific chronic low back pain. Pain Medicine. 2009; 10:143-154

[39] Sullivan, MJL, Adams, H, Sullivan, ME. Communicative dimensions of pain catastrophizing: social cueing effects on pain behaviour and coping. Pain. 2004; 107:220-226

[40] Sullivan, MJL, Thorn, B, Haythornthwaite, JA, Keefe, F, Martin, M, et al. Theoretical perspectives on the relation between catastrophizing and pain. The Clinical Journal of Pain. 2001;17:52-64

[41] Tietjen, GE, Brandes, JL, Peterlin, BL, Eloff, A, Dafer, RM, et al. Childhood maltreatment and migraine (part I). Prevalence and adult revictimization: a multicenter headache clinic survey. Headache. 2010;50(1):20-31

[42] Tietjen, GE, Brandes, JL, Peterlin, BL, Eloff, A, Dafer, RM, et al. Childhood maltreatment and migraine (part III). Association with comorbid pain conditions. Headache. 2010;50(1):42-51

[43] Undheim, AM, Sund, AM. Prevalence of bullying and aggressive behavior and their relationship to mental health problems among 12- to 15-year-old Norwegian adolescents. Eur Child Adolesc Psychiatry. 2010;19(11): $803-811$

[44] van Damme, S, Crombez, G, Eccleston, C. Coping with pain: A motivational perspective. Pain. 2008;139:1-4

[45] Vangronsveld, KL, Linton, SJ. The effect of validating and invalidating communication on satisfaction, pain and affect in nurses suffering from low back pain during a semi-structured interview. European Journal of Pain. 2012;16(2):239-346

[46] Vlaeyen, JWS, Hanssen, MMP, Dautzenberg, A, Peters, ML, Goubert, L, et al. Threat of pain influences social context effects on verbal pain report and facial expression. Behaviour Research and Therapy. 2009;47(9):774-782

[47] Vlaeyen, JWS, Linton, SJ. Fear-avoidance and its consequences in chronic musculoskeletal pain: A state of the art. Pain. 2000;85(3):317-332

[48] Walsh, CA, Jamieson, E, Macmillan, H, Boyle, M. Child abuse and chronic pain in a community survey of women. Journal of Interpersonal Violence. 2007;22(12):1536-1554 
[49] Wegman, HL, Stetler, C. A meta-analytic review of the effects of childhood abuse on medical outcomes in adulthood. Psychosomatic Medicine. 2009; 71:805-812

[50] Williams, ACdC. Facial expression of pain: An evolutionary account. Behavioral and Brain Sciences. 2002;25:439-488

[51] Williams, KD. Ostracism: The power of silence. New York:

Guilford Press., 2001 
3. 


\section{The effects of a}

social safety cue

and threat of pain

on pain report

and facial pain

expression

Pim A. M. Peeters, Tine Vervoort, Madelon L. Peters, Johan W. S. Vlaeyen 


\begin{abstract}
Although accumulating evidence suggests that social context influences pain expression, relatively little is known about the underlying mechanisms. According to a communal coping model, pain expression is used to solicit social support from others specifically by high pain catastrophizers. However, a social safety cueing hypothesis predicts that others can serve as a safety signal, thereby reducing pain expression. The present study aimed to investigate the communal coping and social safety cueing hypotheses by examining the roles of observer presence and the threat value of pain. Participants $(\mathrm{N}=92)$ completed a one minute cold pressor task, either alone or in the presence of an observer who explicitly stated to be able to control the painfulness of the cold pressor task when necessary (observer/control condition) or who would not interfere with the task (observer/no control condition). Contrary to the social safety cueing hypothesis, the effects of observer presence on pain expression were not mediated by perceived threat of pain. High pain catastrophizers reported more pain than low pain catastrophizers, and independently, participants in the observer conditions reported less pain than those in the alone condition. Further analyses indicated that high pain catastrophizers displayed more facial pain expression than low pain catastrophizers, however no social context effects were found. These results contrast with earlier studies on social context effects on pain and are not adequately explained by the communal coping or social safety cueing hypotheses, stressing the need for more elaborate studies and models of social context effects on pain.
\end{abstract}




\section{Introduction}

While most psychological research on pain has focused on intrapersonal influences on pain-related outcomes, such as personality, affect, and beliefs, there is mounting evidence that interpersonal influences, such as social context variables, also influence the experience and expression of pain ${ }^{[10 ; 6 ; 11]}$. One of the social context effects that has been examined is the effect of the absence or presence of another person/observer during pain induction on verbal and non-verbal pain expression. However, studies on this topic have yielded contrasting results.

The first comparison between pain expression when alone or in the presence of an observer was made by Sullivan, Adams, and Sullivan ${ }^{[15]}$. They demonstrated that specifically individuals scoring high on pain catastrophizing, the tendency to experience pain as disproportionately negative, expressed more verbal and non-verbal pain behaviour in the presence of an observer than when alone. This was interpreted on the basis of a communal coping model of pain catastrophizing (CCM) ${ }^{[17]}$, which interprets the increased pain expression of the high pain catastrophizers as an attempt of these individuals to solicit social support from the observer. Other studies have, however, failed to replicate these findings, even yielding results opposite to those of Sullivan et al. ${ }^{[15]}$. In a study on the effects of social support on pain report during a cold pressor task, Brown, Sheffield, Leary, and Robinson ${ }^{[3]}$ included a condition which they referred to as passive social support, which was operationalized as the presence of a trusted observer. Pain report was significantly lower in this passive social support condition than in the alone condition. In a similar line, Vlaeyen et al. ${ }^{[19]}$ demonstrated that when cold pressor pain was manipulated to be threatening, the presence of an observer decreased verbal and non-verbal pain expression, which was mediated by a decrease in the threat value of the pain. This was the basis for a social safety cueing hypothesis, which suggests that simply the presence of an observer may already serve as a safety cue, reducing the threat of pain and thereby its expression.

The contrasting findings between the studies on observer presence may be due to the limited attention paid to the experienced meaning of the observer. While in the study of Brown et al. ${ }^{[3]}$ the observer is very likely to have had a high reassuring value, this was not explicitly measured, nor was non-verbal pain expression investigated. In the studies of Sullivan et al. ${ }^{[15]}$ and Vlaeyen et al. ${ }^{[19]}$ the reassuring value of the observer is even less clear. Increased pain expression in the study by Sullivan et al. ${ }^{[15]}$ may also be due to participants feeling more uncomfortable in the presence of the observer, while likewise the observer in the study by Vlaeyen et al. ${ }^{[19]}$ may have distracted the participants from the threat value of the pain by making them feel more uncomfortable of his/her presence.

The present study aimed to investigate the effects of social presence or absence on verbal and non-verbal pain expression during a cold pressor task, while checking the reassuring value of the observer. To investigate the prediction of the CCM, pain catastrophizing was investigated as a 
moderator of this effect ${ }^{[17 ; 15]}$. In accordance with the social safety cuing hypothesis, the threat value of pain was investigated as a mediator ${ }^{[14 ; 19]}$.

\section{Methods}

\section{Participants}

One hundred healthy participants were recruited through flyers at the university and university hospital. All participants were aged between 18 and 65 years, and were screened for exclusion criteria which included low/high blood pressure, ischemic heart problems, and hyperventilation. Participants were randomly assigned to the social context conditions, prestratifying for gender and pain catastrophizing around a cut-off score of 16 on the Pain Catastrophizing Scale ${ }^{[\mathrm{PCS} ; 16]}$, the average score of a large student population in a previous study ${ }^{[18]}$.

\section{Apparatus}

A cold pressor apparatus was used to induce pain. Cold pressor pain is considered to be an analogue for various naturally occurring acute pains [s]. The cold pressor apparatus consisted of a refrigerated unit filled with circulating water $(30 \mathrm{~h}-50 \mathrm{l}-30 \mathrm{~d} \mathrm{~cm})$ that maintained the water temperature at $2^{\circ}$ to $4^{\circ}$ Celsius. Prior to the cold pressor test, participants immersed their hand in a unit that contained water at approximately room temperature $\left(21^{\circ}\right.$ Celsius) for 5 minutes in order to assure comparable baseline skin temperatures across participants.

\section{Social context manipulations}

To investigate the effect of social presence on pain expression, initially three social context conditions were constructed in which the role of the observer was experimentally manipulated. Firstly, the experimenter would either leave the room during the cold pressor task (alone condition) or stay in the room, sitting opposite to the participant (observer conditions). Secondly, in order to make an extra contrast between a low and high reassuring observer, an attempt was made to manipulate the control the observer appeared to have over the cold pressor task. The observer would state either to be able to control the painfulness of the cold pressor task when necessary (observer/control condition) or to not interfere with the task under any circustances (observer/no control condition).

\section{Measures}

\section{Threat appraisal of the pain}

After completing the cold pressor task, participants completed a questionnaire consisting of 8 items describing threatening pain appraisals related to the cold pressor task ${ }^{[19]}$. Participants rated their threat appraisals on an 11-point scale from 0 (completely disagree) to 10 (completely agree). Reliability analysis on the items of the threat questionnaire yielded a good internal consistency (Cronbach's Alpha $=.87$ ), supporting its reliability as 
a measure of the threat appraisal of pain.

\section{Pain catastrophizing}

Pain catastrophizing was measured with the Dutch version of the Pain Catastrophizing Scale ${ }^{[16 ; 7]}$. The PCS is a 13 -item self-report questionnaire that targets different thoughts and feelings associated with the experience of pain. The PCS has shown to be a valid and highly reliable instrument (Cronbach's alpha between 0.85 and 0.91$)^{[18]}$.

\section{Manipulation checks}

After completion of the cold pressor task, all participants in the observer conditions rated the degree of reassurance that was experienced as a result of the social context condition on three items (e.g. in the alone condition: "I was glad to be alone during the cold water immersion" or in the observer conditions "I was glad there was someone with me during cold water immersion"). Similar to the threat questionnaire, items were rated on an 11-point scale from 0 (completely disagree) to 10 (complete agree). Participants expressed the reverse scored items on the alone condition scale to be difficult to fill in (e.g. "I would have felt more secure if someone had been present"), and as these items also showed to lower the scales' reliability, they were removed from the scale. This yielded a one item reliability manipulation check for the alone condition and a three item reliability check for the observer conditions with a satisfactory internal consistency (Cronbach's alpha $=0.88$ ). In the conditions where an observer was present three questions were included about the control that the participants believed the observer could exert over the cold pressor task (e.g. "I had the feeling that the experimenter had the task under control"). Reliability analysis of the control manipulation check yielded satisfactory internal consistency (Cronbach's alpha $=0.82$ ).

\section{Reported pain intensity}

Pain intensity was measured by having participants verbally report the intensity of the pain they experienced, giving it a rating between 0 and 10 . At 20,40, and 60 seconds after immersing their arm into the cold pressor tank, participants were prompted by an audiotape to verbally report on the intensity of their pain. These ratings were averaged into a single mean pain intensity report.

\section{Facial pain expression}

Facial pain expression was measured using an abridged version of the Child Facial Coding System ${ }^{[\mathrm{CFCS} ; 4]}$. The CFCS is derived from the Facial Action Coding System ${ }^{[8]}$ and distinguishes between 13 discrete facial actions; brow lowering, eye squint, eye squeeze, blink, flared nostrils, nose wrinkle, nasolabial furrow, cheek raiser, upper lip raise, open lips, lip corner pull, vertical mouth stretch, horizontal mouth stretch. Ten of these actions are coded for intensity ( 0 for no action, 1 for slight action, 2 for distinct/maximal action), while the remaining three (blink, flared nostrils 
and open lips) are only coded for presence ( 0 for no action, 1 for action). The CFCS has shown good reliability and validity in coding children's facial pain expressions ${ }^{[9 ; 2]}$. and has been successfully used with adults as well ${ }^{[19]}$.

Each one-second fragment of the 60 second video sessions made during the cold pressor task was coded separately by a single coder who had received extensive training in the CFCS. Fragments during which the participant's face was poorly visible because the head was turned and fragments during which participants reported on pain intensity were coded as invalid and excluded from the analyses. A second coder trained in the CFCS coded a random sample of $20 \%$ of the video sessions to determine inter-rater reliability. Inter-rater reliability, calculated in accordance with the formula provided by Ekman and Friesen ${ }^{[8]}$, was 0.66 overall, with inter-rater reliability for individual facial actions ranging from 0.49 (brow lowering) to 1.00 (nose wrinkling). An average facial pain expression score was calculated by dividing the sum of all action units by the number of valid fragments.

While the CFCS distinguishes between 13 facial actions, studies on the facial expression of pain ${ }^{[12 ; 13]}$ have pointed out that lowering of the brows, wrinkling of the nose, raising of the cheeks, raising of the upper lip and closing or narrowing of the eyelids are the most consistently associated with pain expression. Since all CFCS units were coded it was possible to compare the full CFCS set with an abridged set, which contained only those facial actions that correspond with the facial movements most consistently related to pain (brow lowering, eye squint, eye squeeze, nose wrinkle, cheek raiser, upper lip raise ${ }^{[13]}$ ). The correlation between the total scores of both sets proved to be high $(r=0.92)$ and the abridged set yielded the same results on all the analyses as the full CFCS set. Based on these results, it was decided to only report the results for the abridged set.

\section{Procedure}

Prior to the experiment, participants were told that the experiment aimed at investigating thoughts and feelings of people when experiencing painful stimuli. After participants had been informed about the nature of the experiment, they were requested to complete the screening assessment questionnaires. Participants who met all the inclusion criteria were invited to take part in the study.

At the beginning of the experiment, the experimenter, who would also be the observer in the observer conditions, briefly explained the set-up of the experiment, after which participants were asked to read and sign the informed consent form and complete a filler questionnaire. Participants were then asked to immerse their non-dominant arm in a tank filled with water at room temperature $\left( \pm 20^{\circ} \mathrm{C}\right)$ for 5 minutes to ensure equal baseline temperatures across participants. During the room temperature immersion, all participants received instructions about the remaining part of the experiment.

After the 5 minutes of room temperature immersion, the experimenter 
started an instruction audiotape in all three conditions and left the room in the alone condition, or took place in the chair opposite to the participant in the observer/no control and observer/control conditions. At 20,40 and 60 seconds after immersing their arm into the cold pressor tank, participants were prompted by the tape to verbally report on the intensity of their pain using the pain thermometer positioned in front of them. After completion of the CPT, participants rated the perceived threat, social reassurance, and the control that they believed the observer could exert over the cold pressor task. They were then debriefed and rewarded with one course credit or a 5 euro monetary compensation.

\section{Statistical analyses}

First, it was investigated whether the condition had an effect on the participants' reassurance caused by the social context and the degree of control the participants believed the observer to have. Regression analyses were conducted with the total scores on the manipulation checks as the dependent variable and condition as the independent variable. To enter 'condition' as an independent variable in the regression analyses, the three conditions used in this study were dummy coded, with the alone condition being the constant, while separate dummies were created for the observer/ no control and observer/control conditions.

Further regression analyses were conducted for reported pain intensity and facial pain expression as dependent variables, with condition, pain catastrophizing and the interaction terms between condition and pain catastrophizing as independent variables. Interaction terms were created by multiplying the dummy for condition with the centred PCS scores. Mediation analyses were conducted to investigate whether any condition effects were mediated by the threat appraisal of the pain in accordance with the steps outlined by Baron and Kenny ${ }^{[1]}$. The total score on the threat questionnaire was centred for all analyses. All regression analyses used a forward strategy, with gender being entered first to correct for gender differences, followed by pain catastrophizing, the dummy variable for condition in the next step and the interaction in the final step. Standardized beta's are reported.

\section{Results}

\section{Participant descriptives}

A total sample of 100 participants completed the study, of whom 2 participants removed their arm from the cold pressor tank prematurely, one earlier than 40 seconds, (excluded from the analyses) and one longer than 40 seconds (missing third pain rating was replaced with the last available pain rating). Data from an additional 7 participants were excluded because of incomplete facial expression data, either caused by the participant looking away from the camera for more than 10 coding fragments or because of technical problems with the recording equipment. 
The total sample that was included into the analyses contained 92 participants, 76 women and 16 men. The alone condition included 29 participants, the observer/no control condition included 32, and the observer/control condition 31 participants. The mean age of the sample was 24.27 year $(S D=9.26)$ ranging from 18 to 64 years old (see Table 1.).

Table 1.

\begin{tabular}{|c|c|c|c|c|c|c|c|c|}
\hline \multirow[b]{2}{*}{ Variables } & \multicolumn{2}{|c|}{$\begin{array}{l}\text { Overall } \\
\mathrm{N}=92\end{array}$} & \multicolumn{2}{|c|}{$\begin{array}{c}\text { Alone } \\
N=29\end{array}$} & \multicolumn{2}{|c|}{$\begin{array}{c}\text { Observer } \\
\text { No Control } \\
\mathrm{N}=32\end{array}$} & \multicolumn{2}{|c|}{$\begin{array}{c}\text { Observer } \\
\text { Control } \\
\mathrm{N}=31\end{array}$} \\
\hline & M & SD & M & SD & M & SD & M & SD \\
\hline Experienced threat & 21,14 & 14,68 & 22,17 & 16,40 & 20,81 & 16,01 & 20,52 & 11,69 \\
\hline Pain catastrophizing & 13,54 & 7,38 & 13,17 & 7,48 & 13,91 & 6,31 & 13,52 & 8,46 \\
\hline Reported pain intensity & 5,52 & 2,08 & 6,24 & 1,89 & 5,33 & 2,00 & 5,10 & 2,23 \\
\hline Facial pain expression & 1,98 & 1,43 & 1,92 & 1,50 & 2,16 & 1,68 & 1,84 & 1,07 \\
\hline
\end{tabular}

Table 1: Means and standard deviations for participant descriptives and the independent and dependent variables in the study

\section{Manipulation checks}

Regression analyses for the manipulation checks with condition as independent variable yielded a significant difference in reassurance between the alone and observer conditions $(B=0.326$; $p<0.05$ and $B$ $=0.476, \mathrm{p}<0.001)$, but no difference in reassurance was observed between both observer conditions $(B=0.192 ; \mathrm{p}<0.131)$. The analysis for the control manipulation check similarly yielded no difference between the observer conditions ( $B=0.049$; $p<0.703)$, which suggests that the perceived control manipulation failed to influence participants' belief about the observers control over the cold pressor task. Means of both observer conditions $(\mathrm{M}=26.50 ; \mathrm{SD}=3.89$ and $\mathrm{M}=26.97$; $\mathrm{SD}=$ 5.66 respectively) lie very close to the maximum score on the scale (30), suggesting a ceiling effect for perceived control in both conditions. Due to the lack of difference between the observer conditions, it was decided to combine both conditions into a single observer condition for further analyses $(\mathrm{N}=63)$. This combined observer condition yielded significantly higher scores on reassurance than the alone condition $(B=0.381$; $<<$ $0.001)$.

\section{The impact of social context on verbal and facial pain expression: the moderating role of pain catastrophizing}

Two regression analyses were performed to investigate the moderating impact of pain catastrophizing for the relationship between condition and verbal pain reports and facial pain expression respectively. Within each analysis, pain catastrophizing and condition, as well as their statistical interaction were entered as independent variables. 
For the analysis with verbal pain report, a significant main effect was found for pain catastrophizing $(B=0.292$; $p<0.005)$, such that higher pain catastrophizing was associated with higher pain reports. A main effect was also found for condition $(B=-0.244$; $p<0.05)$, with less pain being reported in the observer condition. The interaction between pain catastrophizing and condition did not reach statistical significance $(B=$ $-0.025 ; \mathrm{p}=0.814$ ).

For the analysis with facial pain expression, a significant main effect was found for pain catastrophizing $(B=0.280 ; \mathrm{p}<0.01)$, with higher pain catastrophizing associated with increased pain expression. The main effect for condition ( $B=0.019 ; p=0.850)$ nor the interaction between pain catastrophizing and condition $(B=0.103 ; \mathrm{p}=0.351)$ reached statistical significance. The small effect size for condition suggests that the lack of statistical significance is not simply due to a lack of power.

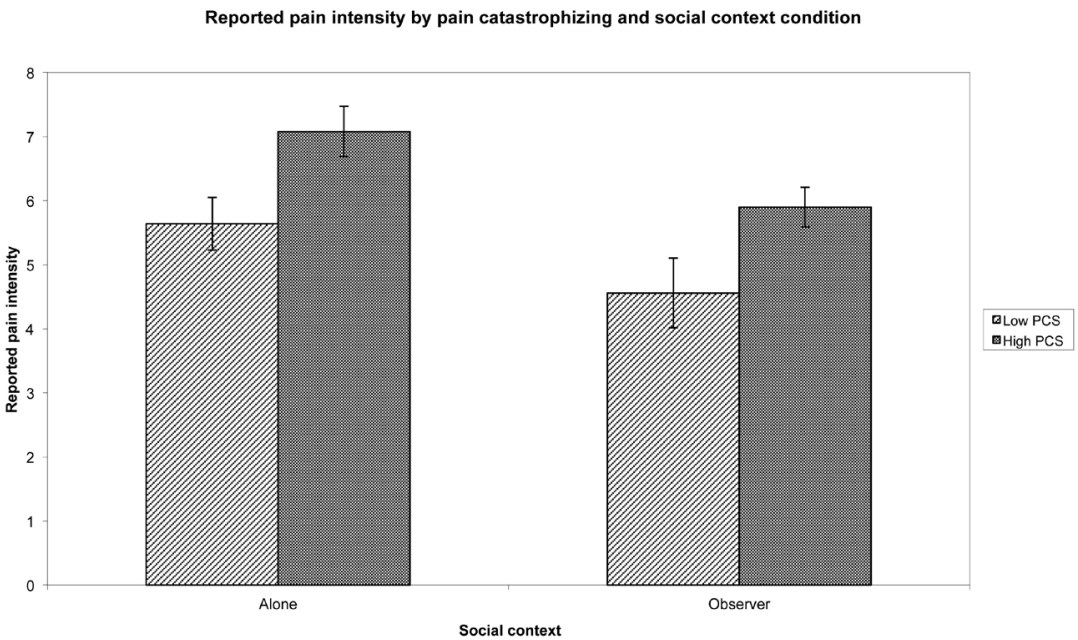

Figure 1: Average reported pain intensity during the cold pressor task as a function of condition and pain catastrophizing dichotomized around a score of 16 . 


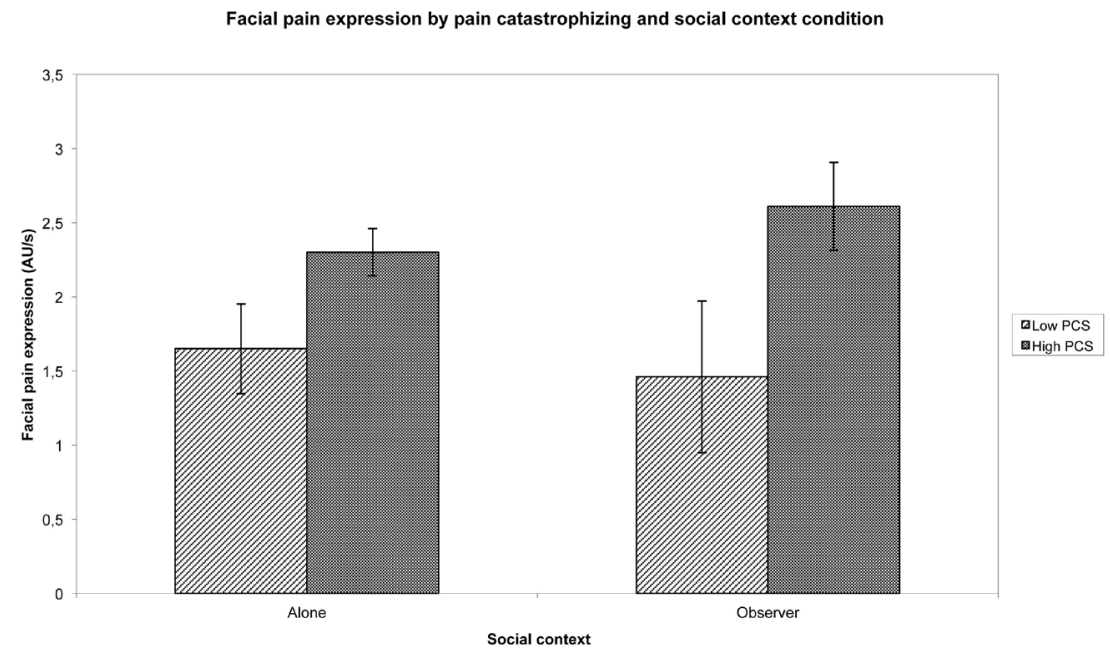

Figure 2: Average facial pain expression per second as a function of condition and pain catastrophizing dichotomized around a score of 16 .

\section{The impact of social context upon verbal and facial pain expression: the mediating role of the threat value of pain}

The first step to demonstrate mediation, according to Baron and Kenny [1], is to investigate whether the independent variable has a significant effect on the mediator. Results of a regression analysis indicated that there was no effect for condition on the experienced threat value of the pain $(B=-0.048 ; p=0.652)$. This lack of a condition effect on the experienced threat of pain disqualifies threat as a potential mediator of the association between condition and pain expression, making the other steps of the mediation analysis unnecessary. This suggests that the experienced threat of the pain is not influenced by the social context.

\section{Discussion}

This study was designed to investigate the influence of the absence/ presence of an observer on pain expression during a cold pressor task. Additionally, pain catastrophizing was tested as a moderator, as suggested by the communal coping model ${ }^{[17]}$. Furthermore, the perceived threat value of the cold pressor task pain was investigated as a mediator of the social context effects, as suggested the social safety cueing hypothesis ${ }^{[19]}$. The results indicate that participants reported less intense pain in the observer conditions than in the alone condition, while facial pain expression was not influenced by the social context condition. While main effects of pain catastrophizing were found, indicating higher pain reports and more display of pain behaviour, these associations were not further moderated by the social context condition, contrary to the findings of 
Sullivan et al. ${ }^{[15]}$. In contrast with the study by Vlaeyen et al. ${ }^{[19]}$, the social context manipulation did not impact on the experienced threat value, also ruling out mediation.

The results on reported pain intensity demonstrate that while high pain catastrophizers reported more pain than low pain catastrophizers, both low and high pain catastrophizers reported less pain in the presence of an observer than when alone. This pattern is similar to the one found by Brown et al. ${ }^{[3]}$ and Vlaeyen et al. ${ }^{[19]}$, rather than that of Sullivan et al. ${ }^{[15]}$. The effect was however not mediated by the experienced threat value of the pain. Hence, the social safety cueing hypothesis put forward by Vlaeyen et al. ${ }^{[19]}$, that the social context influences pain expression through its effect on the experienced threat of the pain, is not supported by these results. The higher reassurance scores in the observer condition compared to the alone condition, coupled with lower pain ratings, seems to fit with the beneficial effects of passive social support found by Brown et al. ${ }^{[3]}$. If not caused by a reduction in the threat value of the pain, this effect may perhaps have been caused by a more general feeling of safety, assuring the participants that all in all they will be fine, rather than changing the beliefs about the pain stimulus itself. This possibility warrants further examination in future studies.

Contrary to reported pain intensity, no effect of the social context condition was found for facial pain expression. Only a main effect of pain catastrophizing was found, with high pain catastrophizers displaying more facial pain expression than low pain catastrophizers. The lack of a social context effect on facial pain expression in spite of significant differences in reassurance between the alone and observer conditions is striking, since previous studies examining facial pain expression have found non-verbal pain ratings to be as sensitive as or even more sensitive than verbal pain ratings to social context effects ${ }^{[15 ; 19]}$.

Overall the findings of the present study contrasts with the results of several other studies. Most notably, Sullivan et al. ${ }^{[17]}$ found that high pain catastrophizers expressed more pain in the presence of an observer than when alone, while low pain catastrophizers did not. However, in the present study no interaction effect of pain catastrophizing and the social context was found for facial pain expression nor for verbal pain ratings. Additionally, an overall decrease in pain report was observed in the presence of an observer rather than an increase. These differences with the study by Sullivan et al. ${ }^{[15]}$ are especially striking, given the similarities between the pain inducing procedure and the roles of the observers. It appears that both verbal and non-verbal pain expression are sensitive to other (subtle) social context properties that currently remain unknown. The meaning that participants ascribe to the observer is likely to be one of these properties.

Unfortunately, the interpretation of the results remains somewhat limited by the lack of a difference in perceived control and reassurance between both observer conditions. To adequately investigate the mechanisms through which the social context impacts pain expression, 
more elaborate and reliable social context manipulations and measures will have to be employed in future studies. Another interesting alternative may be to ask participants directly whether they experience others as supporting or threatening and influencing their pain behaviour.

In sum, the reduction in reported pain intensity in the observer conditions together with higher reassurance ratings in the observer conditions, suggests that participants benefitted from the presence of another individual during the pain task. At the same time, facial pain expression appeared to be insensitive to the social context manipulation. These findings cannot be explained by the communal coping model ${ }^{[17 ; 15]}$ or social safety cue hypothesis ${ }^{[19]}$, stressing the need for further research to expand models on how the social context and personal characteristics interact in their effect on pain expression. By extending the investigation from the effects of mere social presence to different qualities of the social context, a more complete understanding of pain expression may be achieved. 


\section{References}

[1] Baron RM, Kenny DA. The moderator-mediator variable distinction in social psychological research: Conceptual, strategic and statistical considerations. Journal of Personality and Social Psychology 1986;51:1173-1182.

[2] Breau LM, McGrath PJ, Craig KD, Santor D, Cassidy KL, Reid GJ. Facial expression of children receiving immunizations: a principal components analysis of the Child Facial Coding System. Clin J Pain 2001;17:178-186.

[3] Brown JL, Sheffield S, Leary MR, Robinson ME. Social support and experimental pain. Psychosomatic Medicine 2003;65:276-283.

[4] Chambers CT, McGrath PJ, Gilbert CA, Craig KD. Child Facial Coding System - revised manual. Halifax: IWK-Grace Health Centre, Dalhousie University \& University of British Columbia, 1996.

[5] Chen ACN, Dworkin SF, Haug J, Gehrig J. Human responsivity in a tonic pain model: psychological determinants. Pain 1989;37(2):143-160.

[6] Craig KD. The social communication model of pain. Canadian Psychology 2009;50(1):22-32.

[7] Crombez G, Vlaeyen JWS, Heuts PHTG, Lysens R. Pain-related fear is more disabling than pain itself: evidence on the role of pain-related fear in chronic low back pain disability. Pain 1999;80:329-339.

[8] Ekman P, Friesen W. Investigator's guide to the Facial Action Coding System. Palo Alto, CA: Consulting Psychologists Press, 1978.

[9] Gilbert CA, Lilley CM, Craig KD, McGrath PJ, Court CA, Bennett SM, Montgomery CJ. Postoperative pain expression in preschool children: validation of the Child Facial Coding System. Clin J Pain 1999;15:192-200.

[10] Hadjistavropoulos T, Craig KD. A theoretical framework for understanding self-report and observational measures of pain: A communications model. Behaviour Research and Therapy 2002;20:551-570.

[11] Hadjistavropoulos T, Craig KD, Duck S, Cano A, Goubert L, Jackson PL, Mogil JS, Rainville P, Sullivan MJ, Williams CdC, Vervoort T, Fitzgerald TD. A biopsychosocial formulation of pain communication. Psychological Bulletin 2011;137(6):910-939.

[12] Prkachin KM. The consistency of facial expressions of pain: a comparison across modalities. Pain 1992;51(3):297-306.

[13] Prkachin KM, Craig KD. Expressing pain: The communication and interpretation of facial pain signals. Journal of Nonverbal Behavior 1995; 19(4):191-205.

[14] Severeijns R, Vlaeyen JWS, van den Hout MA. Do we need a communal coping model of pain catastrophizing? An alternative explanation. Pain 2004;111(3):226-229.

[15] Sullivan MJL, Adams H, Sullivan ME. Communicative dimensions of pain catastrophizing: social cueing effects on pain behaviour and coping. Pain 2004;107:220-226.

[16] Sullivan MJL, Bishop S, Pivik J. The pain catastrophizing scale: development and validation. Psychological Assessment 1995;7:52-64. 
[17] Sullivan MJL, Thorn B, Haythornthwaite JA, Keefe F, Martin M, Bradley LA, Lefebvre JC. Theoretical perspectives on the relation between catastrophizing and pain. The Clinical Journal of Pain 2001;17:52-64.

[18] Van Damme S, Crombez G, Vlaeyen JWS, Goubert L, Van den Broeck A, Van Houdenhove B. De Pain Catastrophizing Scale: psychometrische karakteristieken en normering. Gedragstherapie 2000;3:211-222.

[19] Vlaeyen JWS, Hanssen MMP, Dautzenberg A, Peters ML, Goubert L, Sullivan ML, Morley S. Threat of pain influences social context effects on verbal pain report and facial expression. Behaviour Research and Therapy 2009;47(9):774-782. 
THE EFFECTS OF A SOCIAL SAFETY CUE AND THREAT OF PAIN ON PAIN REPORT AND FACIAL PAIN EXPRESSION. 
4 


\section{The effect \\ of available \\ communication \\ channels on \\ pain expression}

Pim A. M. Peeters, Sandy de Groof, Johan W. S. Vlaeyen 


\begin{abstract}
According to communicative models of pain expression, pain expression serves to communicate pain with the purpose to solicit certain behaviours from others. This suggests that the way pain is expressed should vary as a function of the efficacy and availability of communication channels. The present study aimed to investigate the hypothesis that the way pain is expressed depends on which form of pain expression most effectively communicates pain to others in the specific situation. Healthy subjects $(\mathrm{N}=82)$ completed a one minute cold pressor task during which they verbally reported pain intensity. The available communication channels were manipulated by telling the subjects that they could or could not be heard by the experimenter (auditory channel) and could or could not be seen by the experimenter (visual channel). The faces of participants were recorded in all conditions and scored for facial pain expression. In contrast with the hypothesis, the analyses yielded no significant results for the conditions on either reported pain intensity and facial pain expression. These results suggest that the availability of communication channels does not have a (large) influence on the way in which pain is expressed. Implications for communicative models of pain and research on social context effects are discussed.
\end{abstract}




\section{Introduction}

A growing body of studies has demonstrated that social factors influence the expression of pain ${ }^{[9 ; 3]}$. According to communicative models of pain expression, pain expression serves to communicate pain with the purpose to solicit certain behaviours from others ${ }^{[17 ; 3]}$. Whether the soliciting of help is intentional and conscious or not, pain expression has been hypothesized to be a goal-directed behaviour ${ }^{[16]}$. The hypothesis that pain expression is goal-directed implicates that pain expression may vary as a function of the availability and efficacy of the communication channels that are available. Hence under some conditions, the possibility to report about pain could reduce the facial expression of pain and visa versa. Whether this occurs or not could have implications for conducting pain measurements both in clinical practice and in pain research.

Relatively little is known about the mechanisms that drive facial pain expression and pain report. Many consider facial pain expression to be mostly communicative in nature ${ }^{[14 ; 6]}$, although in some cases it is used as a direct measure of pain experience ${ }^{[9]}$. Pain report is often considered to be the most accurate reflection of the subjective pain experience ${ }^{[9]}$; however it cannot be seen independently from the interpersonal context in which pain report takes place ${ }^{[6]}$. Some have noted that facial pain expression and pain reports are likely to have different adaptive functions ${ }^{[6]}$, which is supported by generally moderate correlations ${ }^{[10]}$ and the findings that both forms of pain expression can be differentially influenced by social context manipulations ${ }^{[1 ; 12]}$. In contrast, other studies have found similar effects of social context manipulations on both pain report and facial pain expression ${ }^{[14 ; 22]}$, supporting the notion that both forms of pain expression could serve to solicit support from others.

Following from the hypothesis that pain expression is goal-directed, one form of pain expression is likely to be favoured over the other when this form of pain expression is more likely to effectively communicate pain. In many studies pain report and facial pain expression were measured at the same time ${ }^{[14 ; 11 ; 12 ; 22]}$. This means that aside from the manipulations employed in these studies, the fact that both forms of pain expression were included at the same time could have influenced the outcomes. The pain expression deemed the most effective communicator could reduce the expression of the other.

The present study aimed to investigate the hypothesis that the way pain is expressed depends on which form of pain expression most effectively communicates pain to others in the specific situation. Healthy subjects completed a one minute cold pressor task during which they verbally reported pain intensity. The available communication channels were manipulated by telling the subjects that they could or could not be heard by the experimenter (auditory channel) and could or could not be seen by the experimenter (visual channel). The faces of participants were recorded in all conditions and scored for facial pain expression. 


\section{Methods}

\section{Participants}

All participants that applied for the study were administered a screening questionnaire to check for the presence of exclusion criteria. To be included, all participants had to be between the ages of 18 years and 65 years old and report no pain-related condition or medical condition that might be adversely affected by the experimental pain procedure, such as ischemic heart problems.

Participants were randomly assigned to one of the context conditions. In addition, all participants were asked to complete the Dutch version of the Pain Catastrophizing Scale (PCS) ${ }^{[15 ; 5]}$. Participants were divided into a low and a high pain catastrophizing group based on a cut-off score of 16, the mean score for the PCS' Dutch version in a previous student population ${ }^{[19]}$. The randomization process was stratified for both the pain catastrophizing groups and gender, to ensure equal distributions across all conditions.

\section{Apparatus}

A cold pressor apparatus was used to induce pain. The cold pressor apparatus consisted of a refrigerated unit filled with circulating water $(30-50-30 \mathrm{~cm})$ that maintained the water temperature at approximately $2^{\circ}$ Celsius. Prior to the cold pressor test, participants immersed their hand in a unit that contained water at approximately body temperature (37\% Celsius).

\section{Communicative context manipulations}

The availability of auditory and visual communication was manipulated, creating a $2 \times 2$ factorial design. The availability of auditory communication was manipulated by explaining the subjects that during the cold pressor task they could either not be heard by the experimenter, or they could be heard by the experimenter through a ceiling mounted microphone. In the case that the subject was told he could be heard, an audio test was done prior to the cold pressor task, where the subjects were alone in the room and communicated verbally with the experimenter through the microphone.

The availability of visual communication was manipulated by telling the subjects that during the cold pressor task they either could not be seen by the experimenter, or they could be seen by the experimenter through a wall-mounted camera. Subjects that were told that they were seen through the camera saw the wall mounted camera being aimed at them remotely and were asked to wave to the camera after which the experimenter responded to the gesture by confirming that the subject was visible. After the cold pressor task each subject filled in two 10-point likert scale items asking the subject to which degree he experienced being watched (visual manipulation check) and heard (auditory manipulation check) during the task as a manipulation check. 


\section{Measures}

\section{Manipulation check}

A brief manipulation check questionnaire was included to check whether participants believed that they were or were not seen and/or heard. The manipulation check consisted of two 11 point Likert scale items on which participants had to rate the degree to which they felt that they were being watched and the degree to which they felt they were being heard by the experimenter.

\section{Pain catastrophizing}

Pain catastrophizing was measured with the Dutch version of the Pain Catastrophizing Scale (PCS) ${ }^{[4]}$. The PCS is a 13 -item self-report questionnaire that targets different thoughts and feelings associated with the experience of pain. The 13 items can be subdivided over three factors ${ }^{[18]}$; rumination ( 4 items), magnification ( 3 items) and helplessness (6 items). In the current study, only the total score was used. The PCS has shown to be a valid and highly reliable instrument (Cronbach's alpha between .85 and .91) ${ }^{[20]}$.

\section{Reported pain intensity}

In the appropriate conditions, verbal pain report of the intensity of the pain that participants experienced was requested three times during the cold pressor task at 20, 40 and 60 seconds. Participants had to verbally rate their pain experience by saying out loud a number between 0 and 10 . This process was aided by providing participants with an 11-point rating scale in the form of a pain thermometer with the endpoints "no pain at all" (0) and "the most extreme pain" (10) that was shown on a monitor facing them.

\section{Facial pain expression}

Facial pain expression was coded using an abridged version of the Child Facial Coding System (aCFCS) ${ }^{[2]}$. The aCFCS codes for 6 facial actions; brow lowering, eye squint, eye squeeze, nose wrinkle, cheek raiser and upper lip raise. These actions are coded for intensity ( 0 for no action, 1 for slight action, 2 for distinct/maximal action). The aCFCS has shown to be highly comparable to the full CFCS $(r=0,92)^{[11]}$, which has shown good reliability and validity in coding children's ${ }^{[8 ; 1]}$ and adult's ${ }^{[22]}$ facial pain expressions.

Coding was conducted for each second fragment of the one-minute cold pressor task. Fragments during which the participant's face was poorly visible because the head was turned or fragments during which the participant was speaking were coded as invalid. All fragments were coded by a single coder. A second coder coded a random sample of $20 \%$ of the video sessions to determine inter-rater reliability. Inter-rater reliability was calculated in accordance with the formula provided by Ekman and Friesen [7], yielding a good inter-rater reliability of 0.87 ranging from 0.67 (squint) to 1.00 (eye squeeze) on the individual facial actions. 


\section{Procedure}

Prior to the experiment, participants were told that the experiment aimed at investigating thoughts and feelings of people when experiencing painful stimuli. At the beginning of the experiment, the experimenter briefly explained the set-up of the experiment, after which participants were asked to read and sign the informed consent form. The subjects were then asked to immerse their non-dominant arm in a tank filled with water at room temperature $\left( \pm 37^{\circ} \mathrm{C}\right)$ for 5 minutes to ensure equal baseline temperatures across participants. During the room temperature immersion, they received basic instructions about the cold pressor task, followed by the communicative context manipulations.

After the 5 minutes of room temperature immersion, the experimenter started an instruction video on a monitor facing the subject and left the room. At 20, 40 and 60 seconds after immersing their arm into the cold pressor tank, participants were prompted by the video to verbally report on the intensity of their pain using the pain thermometer positioned in front of them. The subjects faces were recorded with a video camera positioned next to the instruction monitor. After completion of the CPT, participants completed the manipulation check questionnaires, after which they were debriefed and rewarded with one course credit or a 5 euro monetary compensation.

\section{Statistical analyses}

First it was verified that the communication manipulations were successful. This was done via two regression analyses with auditory condition and visual condition as independent variables and either the auditory manipulation check score or the visual manipulation check as dependent variables.

Further analysis consisted of two regression analyses with auditory condition, visual condition, pain catastrophizing and all their interactions as independent variables and reported pain intensity and facial pain expression as dependent variables. A backwards strategy was adopted, starting with the full model and taking out the highest order interaction with the highest $\mathrm{p}$-value at each step until only significant predictors $(\mathrm{p} \leq$ 0.05 ) were left in the final model. All variables were centred for the purpose of the analyses. Variable Inflation Factors (VIF's) for all the analyses did not exceed 2, indicating that there was no problem of multicollinearity. 


\section{Results}

\section{Participant descriptives}

A total of 82 participants completed the experiment. Data from one participant was excluded as she failed to keep her hand in the cold pressor tank for the required time. Due to technical problems with videorecording, data of another 3 individuals were incomplete and therefore unfit for analyses. The total sample that was included in the analyses contained 78 participants, 32 male and 46 female (see Table 1).

Table 1: Participant descriptives

\begin{tabular}{llllll}
\hline \multicolumn{5}{c}{ Condition } \\
& All conditions & $\begin{array}{l}\text { Not Seen } \\
\text { Not Heard }\end{array}$ & $\begin{array}{l}\text { Seen } \\
\text { Not Heard }\end{array}$ & $\begin{array}{l}\text { Not Seen } \\
\text { Heard }\end{array}$ & $\begin{array}{l}\text { Seen } \\
\text { Heard }\end{array}$ \\
& & & & \\
Age & $21.40(1.54)$ & $21.19(1.21)$ & $21.81(1.66)$ & $21.30(1.75)$ & $21.30(1.53)$ \\
Pain catastrophizing & $19.04(6.41)$ & $18.43(7.53)$ & $18.52(5.46)$ & $19.95(7.07)$ & $19.30(5.70)$ \\
Seen experienced & $5.07(3.65)$ & $2.71(2.76)$ & $7.52(2.73)$ & $2.10(2.45)$ & $7.95(2.06)$ \\
Heard experienced & $5.65(3.96)$ & $2.95(2.66)$ & $2.52(3.50)$ & $8.70(2.41)$ & $8.70(1.56)$ \\
Reported pain & $4.90(1.73)$ & $5.43(1.64)$ & $4.48(1.75)$ & $4.98(1.75)$ & $4.68(1.77)$ \\
Facial pain expression & $0.53(0.55)$ & $0.31(0.36)$ & $0.58(0.63)$ & $0.59(0.45)$ & $0.66(0.68)$ \\
\hline
\end{tabular}

\section{Manipulation checks}

Regression analyse demonstrated no significant interaction between the auditory and visual manipulation on the experience of being seen $(B=0.072, p=0.353)$, nor a main effect of the auditory manipulation $(B=-0.013, p=0.866)$. A significant main effect for the visual manipulation $(B=0.732, p<0.001)$ confirms that the manipulation successfully induced the feeling of being seen by the experimenter.

Regression analyses on the feeling of being heard demonstrated no significant interaction between the auditory and visual manipulation on the experience of being seen $(B=0.027, p=0.714)$, nor a main effect of the visual manipulation $(B=-0.028, p=0.706)$. A significant main effect for the auditory manipulation $(B=0.756, p<0.001)$ confirms that the manipulation successfully induced the feeling of being heard by the experimenter.

\section{Reported pain intensity}

To investigate the effects of the available communication channels on reported pain intensity a regression analysis was conducted. No main effects for either manipulation or pain catastrophizing were observed, nor for any of their interactions. Table 2 shows the standardized $B$ and $p$-value of each variable before being deleted from the model, with higher order variables already deleted. 


\section{Facial pain expression}

A regression analyses for facial pain expression with auditory and visual manipulation and pain catastrophizing as independent variables yielded no significant main or interaction effects (see Table 2.)

Table 2: Regression coefficients for the main analyses

\begin{tabular}{|c|c|c|c|c|}
\hline & \multicolumn{2}{|c|}{ Reported pain intensity } & \multicolumn{2}{|c|}{ Facial pain expression } \\
\hline & B & $\mathrm{p}$-value & B & $p$-value \\
\hline PCS & 0.143 & 0.203 & 0.012 & 0.917 \\
\hline Seen & -0.186 & 0.101 & 0.153 & 0.185 \\
\hline Heard & -0.047 & 0.674 & 0.158 & 0.172 \\
\hline Seen * Heard & 0.108 & 0.333 & -0.082 & 0.483 \\
\hline Seen $*$ PCS & -0.209 & 0.071 & -0.137 & 0.258 \\
\hline Heard * PCS & -0.037 & 0.543 & -0.073 & 0.535 \\
\hline Seen * Heard * PCS & -0.028 & 0.808 & -0.028 & 0.821 \\
\hline
\end{tabular}

\section{Discussion}

In order to investigate whether the way pain is expressed depends on which form of pain expression most effectively communicates, the present study manipulated the possibility of auditory and visual communication during a cold pressor task. No effect of auditory, nor visual communication availability was observed on either reported pain intensity or facial pain expression. Pain catastrophizing which was investigated as a possible moderator also yielded no significant effects.

It is hard to draw any firm conclusions on the basis of non-significant findings, as an effort to empirically prove the absence of an effect requires sample sizes that would be considered enormous to experimental standards ${ }^{[13]}$. Given the present data the mostly very small $\beta^{\prime}$ 's and the fact that other studies on social context effects on pain typically employ similar sample sizes lead us to conclude that even though pain behaviour may be adapted depending on the most effective communication means, such changes in pain behaviour appear to be minor and irrelevant for clinical practise or experimental research. There also appears to be no noticeable difference between low and high pain catastrophizing participants.

The lack of a significant difference between the seen/heard versus the not seen/not heard condition is somewhat surprising. The latter condition is essentially similar to the alone condition in studies investigating the effects of observer presence ${ }^{[1 ; ; 21]}$, which have often showed a difference in reported pain and non-verbal pain behaviour between the alone and observer conditions. While the manipulation checks confirm that participants in the seen/heard condition did experience a sense of being 
observed by the experimenter both visually and auditorily, there is apparently something about the actual presence of the observer within sight and hearing of the participant that impacts pain behaviour more strongly than just the factual knowledge of being observed. That factual knowledge does not appear to drive pain report and facial pain expression seems to argue against the instrumental use of either pain behaviour to explicitly communicate pain.

One possibility for the different findings for this study and the studies in which an observer was physically present is that people experience a present observer as a more potent source of help or threat, than an observer who is not present in the same room. Another explanation for the difference between the observer presence studies and this study is that in the presence of an observer the reaction of the observer, or the lack thereof, to the participants pain behaviour creates an experienced interaction between the observer and the participant that is absent in the current study. It may be the interaction between an observer and participant, rather than just the observer presence, which is crucial for the pain behaviour of the participant.

In sum, information about the availability of effective ways to communicate pain does not appear to influence pain report and facial pain expression in a sample size commonly used in studies on social context effects. While on the basis of the present results it cannot be stated that the availability of communication channels does not influence pain expressions at all, it appears that any effects are too small to be of practical or clinical significance. This also implies that in studies where the goal is to manipulate the social context, this is likely to be most effective when the social agent that is manipulated is present in the same room as the study participant. 


\section{References}

[1] Breau LM, McGrath PJ, Craig KD, Santor D, Cassidy KL, Reid GJ. Facial expression of children receiving immunizations: a principal components analysis of the Child Facial Coding System. Clinical Journal of Pain 2001; 17:178-186.

[2] Chambers CT, Cassidy KL, McGrath PJ, Gilbert CA, Craig KD. Child Facial Coding System

[3] Craig KD. The social communication model of pain. Canadian Psychology 2009;50(1):22-32.

[4] Crombez G, Vlaeyen JWS, Heuts PH, Lysens R. Pain-related fear is more disabling than pain itself: evidence on the role of pain-related fear in chronic back pain disability. Pain 1999;80(1-2):329-339.

[5] Crombez G, Vlaeyen JWS, Heuts PHTG, Lysens R. Pain-related fear is more disabling than pain itself: evidence on the role of pain-related fear in chronic low back pain disability. Pain 1999;80:329-339.

[6] de C Williams AC, Craig KD. A science of pain expression? Pain 2006;125(3):202-203.

[7] Ekman P, Friesen W. Investigator's guide to the Facial Action Coding System. Palo Alto, CA: Consulting Psychologists Press, 1978.

[8] Gilbert CA, Lilley CM, Craig KD, McGrath PJ, Court CA, Bennett SM, Montgomery CJ. Postoperative pain expression in preschool children: validation of the Child Facial Coding System. Clinical Journal of Pain 1999; 15:192-200.

[9] Hadjistavropoulos T, Craig KD. A theoretical framework for understanding self-report and observational measures of pain: A communications model. Behaviour Research and Therapy 2002;20:551-570.

[10] Labus JS, Keefe FJ, Jensen MP. Self-reports of pain intensity and direct observations of pain behavior: when are they correlated? Pain 2003;102:109-124.

[11] Peeters PAM, Peters ML, Vlaeyen JWS. The effects of pain control 'by proxy' on pain expression are moderated by the experienced threat value of pain. In preparation.

[12] Peeters PAM, Vlaeyen JWS. The influence of social threat on pain: Feeling more pain while showing less. In preparation.

[13] Quertemont E. How to statistically show the absence of an effect. Psychologica Belgica 2011;51(2):109-128.

[14] Sullivan MJL, Adams H, Sullivan ME. Communicative dimensions of pain catastrophizing: social cueing effects on pain behaviour and coping. Pain 2004;107:220-226.

[15] Sullivan MJL, Bishop S, Pivik J. The pain catastrophizing scale: development and validation. Psychological Assessment 1995;7:52-64.

[16] Sullivan MJL, Thibault P, Savard A, Catchlove R, Kozey J, Stanish WD. The influence of communication goals and physical demands on different dimensions of pain behavior. Pain 2006;125:270-277. 
[17] Sullivan MJL, Thorn B, Haythornthwaite JA, Keefe F, Martin M, Bradley LA, Lefebvre JC. Theoretical perspectives on the relation between catastrophizing and pain. The Clinical Journal of Pain 2001;17:52-64.

[18] Van Damme S, Crombez G, Bijttebier P, Goubert L, Van Houdenhove B. A confirmatory factor analysis of the Pain Catastrophizing Scale: invariant factor structure across clinical and non-clinical populations. Pain 2002;96(3):319-324.

[19] Van Damme S, Crombez G, Vlaeyen JWS, Goubert L, Van den Broeck A, Van Houdenhove B. De Pain Catastrophizing Scale: psychometrische karakteristieken en normering. Gedragstherapie 2000;3:211-222.

[20] Van Damme S, Crombez G, Vlaeyen JWS, Goubert L, Van den Broeck A, Van Houdenhove B. De Pain Catastrophizing Scale: psychometrische karakteristieken en normering. Gedragstherapie 2000;3:211-222.

[21] Vlaeyen JWS, Hanssen MMP, Dautzenberg A, Peters ML, Goubert L, Sullivan ML, Morley S. Threat of pain influences social context effects on verbal pain report and facial expression. Behaviour Research and Therapy 2009;47(9):774-782.

[22] Vlaeyen JWS, Hanssen MMP, Dautzenberg A, Peters ML, Goubert L, Sullivan ML, Morley S. Experienced threat of pain moderates and mediates the social cueing effects on pain intensity and communicative pain behavior. Behaviour Research and Therapy In Press. 
5. 


\section{Feeling more pain,}

yet showing less:

The influence

of social threat

on pain

Pim A. M. Peeters \& Johan W. S.

Vlaeyen

Based on:

P.A.M. Peeters, J.W.S. Vlaeyen (2012):

Feeling more pain, yet showing less:

The influence of social threat on pain.

Journal of Pain, 12, 1255-1261 


\begin{abstract}
The present study investigated the effects of social threat to physical integrity on reported pain and facial pain expression. Predictions of a cognitive appraisal model and a communicative perspective on pain expression were compared. Participants $(\mathrm{N}=67)$ received five electric pain stimuli administered by a confederate. They were lead to believe that five pain stimuli were the minimum, a fixed amount, or the maximum number of pain stimuli allowed, thereby varying the social threat posed by the confederate. Reported pain and facial pain expression were recorded during the delivery of pain stimuli. Increased perceived social threat lead to an increase of reported pain, specifically for high pain catastrophizing participants, while it lead to a reduction of facial pain expression. This is the first study to demonstrate that a social threat manipulation has opposite effects on reported pain and facial expression, suggesting differences in adaptive function for both forms of pain expression.
\end{abstract}




\section{Introduction}

There is a growing number of studies demonstrating that social context factors, such as the presence or absence of others, influence the reported experience and non-verbal behaviour of individuals in pain. Most of these studies have focused on social support ${ }^{[2]}$, spouse solicitousness ${ }^{[10]}$ or simply the presence of others ${ }^{[19]}$. However, individuals in pain may also experience social situations as threatening, either to physical integrity, such as intentionally inflicted pain, or to psychosocial integrity, such as stigmatization or social exclusion. The experimental research on the effects of social threats on the verbal or non-verbal expression of pain is currently lacking, which limits our knowledge of pain expression and its underlying mechanisms.

Based on a cognitive appraisal model of pain ${ }^{[18 ; 21]}$, social safety cueing ${ }^{[24]}$ is one mechanism that may underlie social context effects on pain expression. According to the cognitive appraisal model, the degree to which pain is experienced as aversive largely depends on how threatening pain is perceived to be. What the social safety cueing hypothesis adds to this model is the prediction that this threat value of pain can be influenced by the social context; it serving as a cue that signals safety or threat. Based on this hypothesis, it would be expected that social threat increases pain expression, caused by an increase in experienced threat of pain. For example, Gray and Wegner ${ }^{[12]}$ demonstrated that pain stimuli that were perceived as intentionally rather than unintentionally administered, were indeed reported to be more painful. However, it remains to be shown that this increase in pain report resulted from an increase in the threat value of the pain.

Another mechanism that could underlie social context effects on pain expression is the communicative goals of the individual in pain. According to communicative approaches, pain expression primarily serves to solicit social support from others ${ }^{[5]}$. More specifically, an evolutionary perspective of pain expression ${ }^{[26]}$ suggests that pain expression is likely to be suppressed when the social context signals threat, such as the presence of an antagonist, and expressing pain may be harmful rather than helpful. In a similar line, the communal coping model of pain catastrophizing proposes that specifically individuals who catastrophize about pain use pain expression to solicit social support ${ }^{[21]}$. Contrary to the social safety cueing hypothesis, these models predict that social threat reduces pain expression rather than increasing it, since social threat signals a decreased likelihood of social support.

The present study aimed to investigate the influence of a social threat to physical integrity on reported pain intensity and facial expression. The predictions of both the social safety cueing hypothesis and the communicative models of pain expression were compared, by introducing a confederate who intentionally administered less or more pain stimuli to the participant than required. The confederate was present in the same room while administering the pain stimuli, creating a context in which 
communication was possible. In accordance with the communal coping model, pain catastrophizing was investigated as a possible moderator. Experienced threat of pain was measured to investigate its mediating role proposed by the social safety cueing hypothesis.

\section{Materials and Methods}

\section{Ethical approval}

Approval for the study was granted by the Ethical Committee Psychology from the Maastricht University Faculty of Psychology and Neuroscience.

\section{Design}

A 2 (low/high pain catastrophizing) x 3 (low/neutral/high social threat) between-subjects design was used in this study. Participants were randomly assigned to one of three social threat conditions; low (LST), neutral (NST) and high (HST) social threat. Furthermore, participants were split in low and high pain catastrophizers around a cut-off score of 16 on the Pain Catastrophizing Scale, the mean score in a previous student population Van Damme ${ }^{[22]}$.

\section{Participants}

Eighty-two healthy participants were recruited by spreading flyers through the university. Exclusion criteria were chronic pain states, cardiovascular risk factors and mental disorders. All participants read and signed an informed consent form prior to participating in the experiment.

\section{Electrical pain stimuli}

Using a constant current stimulator (Model DS7, Digitimer, UK), electrocutaneous pain stimuli, $50 \mathrm{~Hz}$ block pattern waveforms of 3 seconds duration were generated at the press of a button. Participants received the stimuli through $2 \mathrm{Ag} / \mathrm{AgCl}$ electrodes spaced at $2 \mathrm{~cm}$, placed just below the inside of the wrist. The function generator was present in the same room as the participants, who were thus able to see that pressing the button initiated a painful stimulus. At the beginning of the experiment, the stimuli were individually calibrated by starting stimulation at $1 \mathrm{~mA}$, and building up with $1 \mathrm{~mA}$ until participants reported a subjective pain intensity of 8 on a scale from 0 to 10 . A suitable level of painful stimulation was reached for all participants, under the safety cut-off point of $20 \mathrm{~mA}$.

\section{Social threat manipulation}

The threat value of the social context was experimentally manipulated by varying the perceived willingness of a confederate to inflict pain on the participant. Participants entered the experiment with a confederate (Caucasian female, age 21 years) whom they believed was another participant. They were told that for the purpose of the study, one of them would have to administer pain stimuli to the other. 
Through a bogus randomization procedure the confederate would be assigned to administer pain stimuli to the participant. While the confederate administered 5 pain stimuli to the participant in all conditions, the crucial manipulation in this procedure was the way these 5 stimuli were framed. In the NST condition, the participants were explained that the confederate was instructed by the experimenter to administer 5 pain stimuli and that no personal choice of the confederate was involved. In the LST condition, participants were told that the confederate was allowed to deliver between 5 and 20 pain stimuli at his own choice, 5 thus being the lowest number allowed. Finally, in the HST condition participants received the information that the confederate had the choice to administer 1 to 5 pain stimuli, 5 thus being the highest number allowed. An audiotape would prompt the confederate to state out loud the number of stimuli she had chosen in the presence of the participant, while again framing the limits of the condition (for example in the HST condition: "How many stimuli are you going to administer between 5 and 20"), in response of which the confederate would always answer "Five".

\section{Measures}

\section{Demographic characteristics and screening}

At the beginning of the experiment, participants were asked to complete a screening questionnaire asking about their gender, age, level of education, and possible exclusion citeria.

\section{Perceived social threat}

A social threat questionnaire (STQ) consisted of 12 statements describing aspects of the relation between the participant and the confederate, which were rated on the degree to which participants experienced such a relationship on an 11-point scale from 0 (completely disagree) to 10 (completely agree). To ensure a general measurement of perceived social threat, each item referred to one of three conceptions of social threat; Specific social threat (e.g. "I had the feeling the other participant enjoyed hurting me", social proximity (e.g. "I feel close to the other participant") and social likeability (e.g. "the other participant is honest").

On the basis of a reliability analysis two items were removed. These two items were formulated more negatively than the other items, which may have lead to a floor-effect of the scores. The remaining scale consisting of 12 items with a high internal reliability (Cronbach's alpha $=0.85$ ). In order to check whether the sum score of the STQ reflects one construct of social threat, a Principal Factor Analysis of the 12 items was conducted. This analysis yielded a one factor solution that accounted for $46.5 \%$ of the total variance. While the sample size of the present study is too small to consider this result as a reliable validation of the social threat questionnaire, it justifies the use of the STQ sum score as a measure of social threat. 


\section{Pain catastrophizing}

Pain catastrophizing, the extent to which pain is habitually experienced as threatening, was measured with the Dutch version of the Pain Catastrophizing Scale ${ }^{[20]}$. The PCS is a 13-item self-report questionnaire that targets rumination, magnification and feelings of helplessness associated with the experience of pain. The PCS has shown to be a valid and highly reliable instrument (Cronbach's alpha between 0.85 and $\left.0.91^{[23]}\right)$.

\section{Positive and negative affect}

Trait positive and negative affect were measured to correct for possible confounding for the effects of pain catastrophizing. Additionally, state positive and negative affect were measured before and after the social threat manipulation to correct for possible confounding for the effects of social threat. Affect measures were taken with the trait and state versions of the Positive and Negative Affect Schedule (PANAS-t/-s ${ }^{[25]}$ ) respectively. Both versions of the PANAS contain 10 positive and 10 negative affect items that have to be scored on 5-point Likert scales. Items are summed to obtain positive affect and negative affect scores. While the PANAS-t asks participants to rate the affect items with reference to how they usually feel, the PANAS-s asks the participants to describe how they are feeling at the moment of completing the questionnaire.

\section{Perceived threat value of pain}

The perceived threat value of the pain inflicted during the experimental manipulation was measured with a pain threat questionnaire consisting of 6 items describing threatening pain appraisals ${ }^{[24]}$, which the participants rated on the degree to which they agreed to having made that particular threatening appraisal, on an 11-point scale from 0 (completely disagree) to 10 (complete agree). Reliability analysis yielded a good internal consistency (Cronbach’s Alpha $=0.91$ )

\section{Reported pain intensity}

Pain intensity was measured by having participants verbally report the intensity of the pain they experienced after each pain stimulus that was administered, by giving it a rating between 0 (no pain at all) and 10 (the most extreme pain) on a numerical rating scale in the form of a thermometer. Verbal report of pain intensity was chosen over written report of pain intensity, because verbal report is more likely to be open to both cognitive and communicative influences than written report. This makes for a more fair comparison between the cognitive appraisal and communicative models. All pain reports were averaged for each individual to create a reported pain intensity score.

\section{Facial pain expression}

Facial pain expression was coded using an abridged version of the Child Facial Coding System (CFCS ${ }^{[3]}$ ). The abridged CFCS consists of the 
6 facial actions of the CFCS that are most consistently related to pain expression ${ }^{[16 ; 17]}$; brow lowering, eye squint, eye squeeze, nose wrinkle, cheek raiser and upper lip raise. These actions were coded for three levels of intensity. The abridged version has shown to be highly comparable to the full CFCS (Peeters, 2010), which has shown good reliability and validity in coding adults' facial pain expressions ${ }^{[24]}$.

Coding was conducted for each electrocutaneous stimulus that was administered, starting at 1 second before the shock, 3 seconds during the shock and 2 seconds afterwards, for a total of 6 one-second coding fragments for each shock. Fragments during which the participant's face was poorly visible because the head was turned, or fragments during which the participant was speaking were coded as invalid. All fragments were coded by a trained coder blind to the experimental condition, who achieved satisfactory inter-rater reliability according to the formula of Ekman and Friesen ${ }^{[9]}$ ( 0.70 or higher for each individual action unit) on an extensive, full CFCS training. No inter-rater reliability was specifically calculated for the present study. An average facial pain expression score was calculated for each individual by dividing the sum of all action units by the number of valid fragments.

\section{Procedure}

At the beginning of the experiment, both the participant and the confederate entered the laboratory together and were seated facing each other at a table. After being informed on the procedures of the experiment, they were asked to complete the demographics and screening questionnaires, after which only participants who reported no exclusion criteria were allowed to continue with the study. Subsequently, both the participants and confederate were asked to read and sign the informed consent form and complete the PANAS-t, PANAS-s and PCS. Following the questionnaires, the bogus-randomisation procedure was shown, assigning the participant the role of receiving the pain stimuli administered by the confederate.

At this point, the experimenter brought the confederate to another room to ensure that the calibration of the pain stimulus was done in the most neutral social context possible. The experimenter stayed in the lab to calibrate the electric pain stimulus for the participant. The calibrated intensity of the electric stimuli was maintained for the painful stimuli administered by the confederate. After stimulus calibration, the pain threat questionnaire was completed with reference to the most intense stimuli they had just experienced.

Subsequently, the experimenter brought the confederate back to the lab and provided additional instructions to the confederate on how to administer pain stimuli. The experimenter then left the lab and started an audio-recording with task instructions. First, information was given to the participant about the range of pain stimuli from which the confederate was requested to choose (LST: 5 to 20, NST: 5, HST: 1 to 5). The confederate always responded to this request by overtly stating that she was going to deliver 5 stimuli. These first instructions were followed by 5 auditory cues 
signaling the confederate when to deliver the pain stimulus by pressing the button. Nine seconds after each pain stimulus, the participant was cued to verbally report the experienced pain intensity of the stimulus in the presence of the confederate. During this procedure, the participant's face was videotaped to code for facial pain expression.

Following the final pain intensity report, the experimenter returned to the lab and brought the confederate to the other room again. Participants were asked to complete the second pain threat questionnaire, PANAS-s and the social threat measures. When finished, they were debriefed, thanked, and received a small remuneration for their participation.

\section{Statistical analyses}

Three statistical analyses were used to test the hypotheses put forward by the communicative and cognitive appraisal models; two regression analyses and one mediation analysis. First two linear regression analyses were used to investigate the influences of social threat, pain catastrophizing and their interaction (the variables of interest) on both reported pain intensity and facial pain expression (the dependent variables). Several covariates were entered to control for various other influences on reported pain intensity and facial pain expression.

Both regression analyses used a forward strategy, with reported pain and experienced threat of pain at calibration entered as covariates in the first step, in order to correct for small baseline differences in electrocutaneous stimulus perception still present after calibration. Next, trait negative and positive affect, and change in state positive and negative affect were entered in order to correct for any confounding effects of mood for the social context manipulation. Finally, pain catastrophizing, the social threat measure, and their interaction were entered as the independent variables of interest. To investigate whether any social threat effects were mediated by the experienced threat value of the pain, the last analysis consisted of a mediation analyses conducted according to the steps described by Baron and Kenny ${ }^{[1]}$.

All variables were centred for the purpose of these analyses. In the case of a significant interaction effect, the simple effects of social threat per level of pain catastrophizing were investigated. For these simple effect analyses, pain catastrophizing was dichotomized around a cut-off score of 16 , the mean score for the PCS' Dutch version in a previous student population Van Damme et al. ${ }^{[22]}$, and dummy coded with the lowest scoring group being the constant. Variable Inflation Factors (VIF's) for all the analyses did not exceed 2 , indicating that there was no problem of multicollinearity.

Initially the intention was to use the three separate social context conditions as independent variable. However, a manipulation check indicated no significant differences between the LST and NST conditions, mostly due to the large spread in scores within all conditions. Leaving out the NST condition resulted in too small a sample size for reliable analyses; hence alternatively to using the conditions, the individual scores on the social threat measure were used as the independent variable in the 
analyses. While this approach had no noticeable effects on the effect sizes of social threat, pain catastrophizing and their interaction as compared to an analysis with the LST and HST conditions, it increased statistical power sufficiently to conduct reliable analyses.

\section{Results}

\section{Participant descriptives}

A total sample of 82 participants completed the study. Thirteen participants were excluded for analyses because they expressed suspicion about the role of the confederate. Data of another 2 participants had to be excluded from the study because no pain report or facial pain expression data were available, due to technical problems with videotaping. The total sample that was included into the analyses contained 67 participants, 49 women and 18 men (see Table 1 and 2).

Table 1 .

\begin{tabular}{lllll}
\hline & $\begin{array}{l}\text { Total } \\
\text { Mean (SD) }\end{array}$ & $\begin{array}{l}\text { LST condition } \\
\text { Mean (SD) }\end{array}$ & $\begin{array}{l}\text { NST condition } \\
\text { Mean (SD) }\end{array}$ & $\begin{array}{l}\text { HST condition } \\
\text { Mean (SD) }\end{array}$ \\
\hline Pain catastrophizing (PCS) & $15.12(7.97)$ & $15.43(7.36)$ & $15.42(8.22)$ & $14.50(8.56)$ \\
Pain threat pre-measure & $10.05(10.64)$ & $12.33(12.89)$ & $7.83(9.65)$ & $10.29(9.12)$ \\
Pain threat post-measure & $8.00(10.02)$ & $9.90(11.61)$ & $6.29(9.70)$ & $8.05(8.80)$ \\
Social threat questionnaire & $53.17(18.06)$ & $64.50(13.76)$ & $58.75(11.26)$ & $36.27(15.58)$ \\
Pain rating & $6.61(1.37)$ & $6.32(1.41)$ & $6.67(1.40)$ & $6.82(1.32)$ \\
Facial pain expression & $0.57(0.81)$ & $0.78(0.88)$ & $0.70(0.94)$ & $0.23(0.43)$ \\
\hline
\end{tabular}

Table 1: Means and standard deviations on the studies most important measures.

Table 2 .

\begin{tabular}{llllll}
\hline & $\begin{array}{l}\text { Pain threat } \\
\text { pre-measure }\end{array}$ & $\begin{array}{l}\text { Pain threat } \\
\text { post-measure }\end{array}$ & $\begin{array}{l}\text { Social threat } \\
\text { questionnaire }\end{array}$ & Pain rating & $\begin{array}{l}\text { Facial pain } \\
\text { expression }\end{array}$ \\
\hline Pain catastrophizing & 0.476 & 0.458 & -0.107 & .222 & .124 \\
Pain threat pre-measure & & 0.915 & -0.177 & 0.365 & 0.238 \\
Pain threat post-measure & & & -0.169 & 0.352 & 0.224 \\
Social threat questionnaire & & & & -0.225 & 0.235 \\
Pain rating & & & & 0.236 \\
\hline
\end{tabular}

Table 2: Correlations between the studies most important measures 


\section{Reported pain intensity}

Regression analyses on the reported pain intensity yielded a statistically significant social threat $\mathrm{x}$ pain catastrophizing interaction $(B=-0.252 ; \mathrm{p}<$ 0.05: see Fig. 1). Analyses of the simple effects showed that increased social threat only significantly increased pain ratings for high pain catastrophizers (STQ: $\beta=-0.461 ; p<0.05$ ) and not for low pain catastrophizers (STQ: $\beta$ $=0.013 ; \mathrm{p}=0.955)$.

\section{Facial pain expression}

Regression analyses on the facial pain expression with the total score on the social threat questionnaire, pain catastrophizing and their interaction as independent variables yielded a significant main effect for social threat $(B=0.359 ; p<0.01$; see Fig. 2 .), with increased social threat leading to reduced facial expression. No significant interaction effect $(B=0.079 ; \mathrm{p}=$ $0.550)$ or main effect for pain catastrophizing $(B=0.012$; $p=0.935)$ was found.

\section{Social cueing hypothesis}

To examine whether the social context influences may have been mediated by the perceived threat value of the pain, mediation analyses were conducted. Having already produced the total effect $\left(c+a^{*} b\right)$ in the previous analyses, the second step of the mediation analyses (path $a)^{[1]}$ included the same independent variables but now with perceived threat of the pain (after the pain task) as dependent variable. These analyses yielded no significant effects for the social threat measure $(B=-0.003 ; p=0.956)$ or interaction between the social threat measure $\mathrm{x}$ pain catastrophizing ( $B$ $=-0.055 ; \mathrm{p}=0.368)$, demonstrating that the experienced threat of pain was not influenced by social threat, and hence did not mediate the effects of social threat on reported pain intensity or facial pain expression.

Table 3.

\begin{tabular}{lllllll}
\hline & \multicolumn{3}{c}{ Reported pain } & \multicolumn{3}{c}{ Facial pain expression } \\
Variables & $\beta$ & $\mathrm{t}$ & Sig. & $\beta$ & $\mathrm{t}$ & Sig. \\
\hline Baseline pain after calibration & .273 & 2.483 & $.016^{*}$ & -.149 & -1.159 & .251 \\
Trait positive mood & -.134 & -1.198 & .236 & .091 & .742 & .461 \\
Trait negative mood & -.329 & -3.034 & $.004^{*}$ & -.008 & -.061 & .952 \\
Positive mood change & -.059 & -.503 & .617 & .184 & 1.473 & .146 \\
Negative mood change & .236 & 2.018 & $.048^{*}$ & .184 & 1.473 & .146 \\
Pain catastrophizing & .214 & 0.130 & .897 & -.009 & -.064 & .949 \\
Social threat & -.165 & -1.496 & .140 & .359 & 2.817 & $.007^{*}$ \\
Social threat x Pain catastrophizing & -.252 & -2.036 & $.046^{*}$ & - & - & - \\
\hline
\end{tabular}

* $=$ significant at $\mathrm{p}=0.05$ 


\section{Discussion}

The present study investigated the influence of social threat on reported pain intensity and facial expression of pain. Intriguingly, social threat was found to influence reported pain intensity and facial expression in opposite manners, increasing the pain report of high pain catastrophizers, but at the same time decreasing the facial pain expression of all participants. These results are notable as they point to particular conditions in which the report of pain and the non-verbal expression of pain are dissociated in the same individuals at one single instance. So far, no such findings have been reported.

Figure 1.

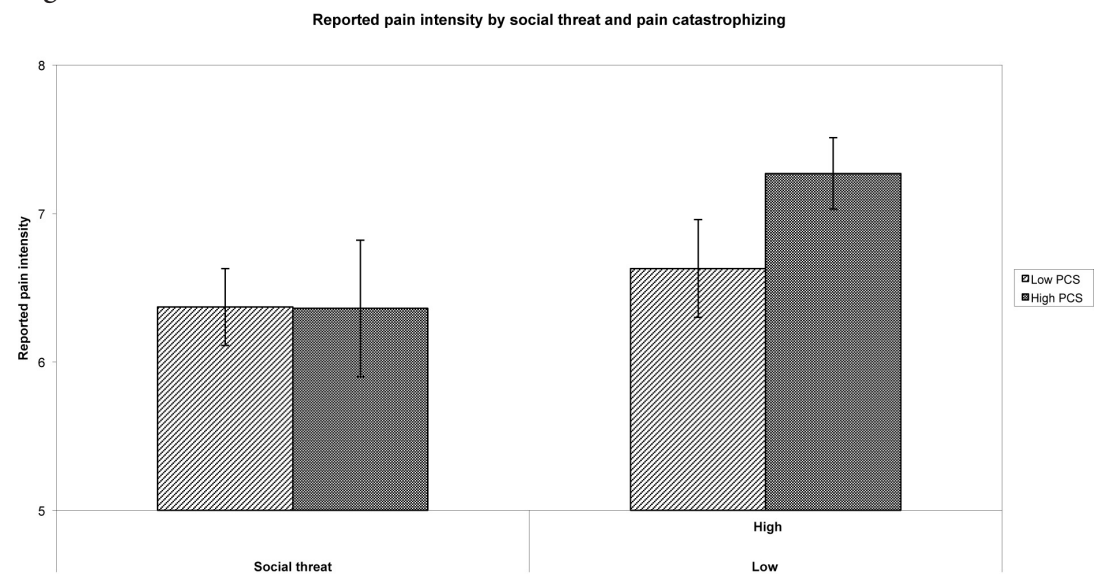

Fig 1: Reported pain intensity by pain catastrophizing and social threat based on the social threat questionnaire. Pain catastrophizing was dichotomized around a score of 16, while social threat was dichotomized around its median.

While social threat had no influence on the pain report of low pain catastrophizers, high pain catastrophizers reported increased pain when experiencing high social threat than when experiencing low social threat. These results resemble the findings of Gray and Wegner ${ }^{[12]}$, demonstrating that pain that is intentionally caused by another person hurts more than when occurring unintentionally, with the exception that the effects of social threat appear to be specific to high pain catastrophizers, a factor that was not included in their study. Pain catastrophizing has repeatedly shown to be a potent predictor of self-reported pain ${ }^{[21]}$ and the current study demonstrates that these effects not only generalize towards a socially threatening situation, but also increase under social threat. Furthermore, as both trait affect and any changes in state affect brought about by the social threat manipulation were controlled for in the present study, social threat appears to have a unique effect on reported pain over and beyond any effects it may already have through mood changes. While the present study did not include a threat manipulation, it is possible that only high 
Figure 2.

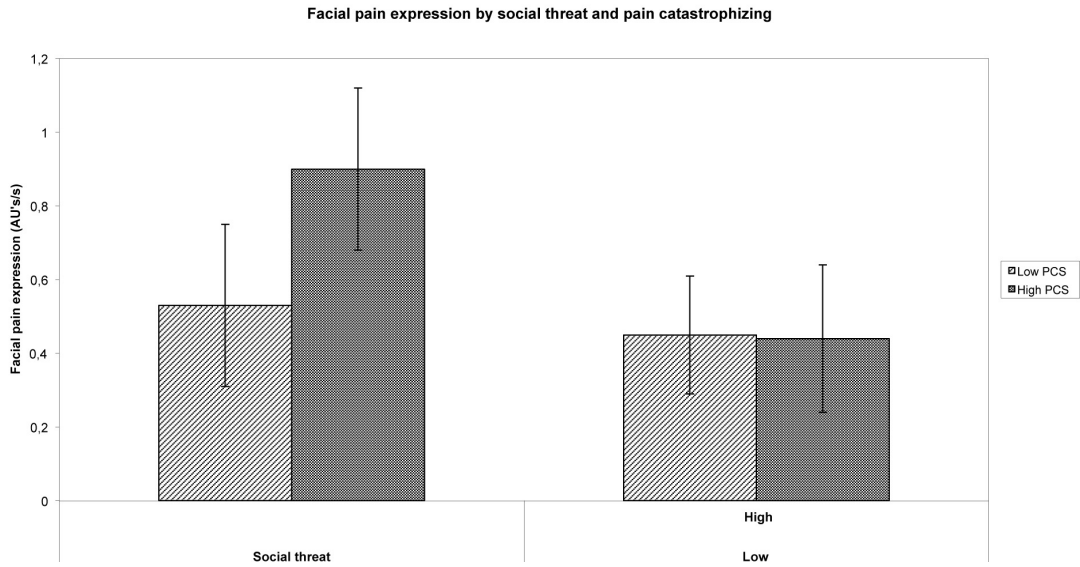

Fig 2: Facial pain expression by pain catastrophizing and social threat based on the social threat questionnaire. Pain catastrophizing was dichotomized around a score of 16 , while social threat was dichotomized around its median.

pain catastrophizers experienced the pain to be threatening enough to be influenced by the social threat cue (Pearson $r=0.46$ between pain catastrophizing and experienced threat of pain). Nevertheless, no support was found for the assumption from the safety cue hypothesis that the association between social threat and pain report is mediated by the experienced threat value of pain.

It can be hypothesized that rather than affecting the experienced threat of the pain, social threat as operationalized in the current study causes a different aspect of pain to become more aversive. For example, being intentionally hurt by another person may increase the unpleasantness of pain through its perceived social unfairness. Social influences on pain are unlikely to be limited to a single aspect of the pain experience or expression. It is likely that some social influences act through affective and cognitive mechanisms such as experienced threat, helplessness or attention, while others may act through more social mechanisms including perceived justice or social exclusion ${ }^{[7 ; 8]}$. The social threat effect on reported pain intensity found in this study is more likely to belong to the latter category. An even more elaborate investigation of different aspects of pain than the present study would be necessary to test this hypothesis.

Contrary to the results for reported pain intensity, social threat was found to decrease facial pain expression, irrespective of the level of pain catastrophizing, which is in line with predictions from the evolutionary perspective expressed by Williams ${ }^{[6]}$. According to such a perspective [11], facial pain expression, like any other expression of emotion, serves a primarily communicative function, aiming to solicit help from others. While in-group individuals, like kin, may be motivated to help an individual who expresses pain, same species competitors who wish the individual ill, may understand that a signal to solicit help also signals that the individual 
is less able to defend himself, providing an ideal opportunity to aggress. Hence, expression of pain would be more dangerous when a situation is socially threatening, causing individuals to express less pain.

While the findings support a communicative function of facial pain expression, they do not support the claim of the communal coping model [21], that high pain catastrophizing people display pain expression in a functionally different way than low pain catastrophizers. However, the lack of an effect for pain catastrophizing on facial expression may also be due to a procedural artifact. Pain stimuli were calibrated for each participant individually, and as baseline experience of threat was controlled for, individual differences in pain sensitivity may have been minimized at the start of the study. Any difference in facial expression between high and low pain catastrophizers in other studies may have been caused by a difference in the experience of the pain stimuli ${ }^{[18]}$, which causes the communication goals of high pain catastrophizers to be focused stronger on soliciting support versus protecting oneself from social threats.

The opposite effects of social threat on reported pain intensity and facial pain expression suggest different functions for both expressions of pain. While others have noted that both forms of pain expression are likely to be driven by different mechanisms for encoding pain experience ${ }^{[14]}$ and represent different adaptive functions Williams \& Craig ${ }^{[27]}$, to the knowledge of the authors the present study is the first to demonstrate a single manipulation to have opposite effects on reported intensity an facial expression. These findings underscore the necessity of studying the distinct mechanisms behind reported intensity and facial expression, and the conditions under which both forms of pain expression are likely to covary or diverge. The latter is especially important with the eye on pain assessment methods that are based (often by necessity) on only one form of pain expression, such as pain assessment based on facial pain expression in neonates ${ }^{[13]}$ or cognitively impaired adults or elderly ${ }^{[4]}$. To estimate an individuals' pain experiences, observers decode the pain expression which in turn arises from the individuals encoding of the pain experience [14]. More detailed knowledge about how these encoding processes of pain expression are influenced by environmental factors may help in the development of more sensitive pain measures.

The findings of the present study encourage further research on the effects of social threat cues on pain. It would be intriguing to investigate other kinds of social threat cues, such as in-group versus out-group differences ${ }^{[15]}$, experienced social discrimination, and the withdrawal of pre-existing social support as another form of threat, or excessive performance demands by an authority figure. Another interesting avenue of research would be to investigate other kinds of moderators of social threat effects, such as gender, sociotropy/autonomy preferences, or sensitivity to rejection. By extending the research on social threat effects, their moderators, and working mechanisms, a better understanding of various forms of pain expression may be gained in relation to the social context in which they are displayed. 


\section{References}

[1] Baron RM, Kenny DA. The moderator-mediator variable distinction in social psychological research: Conceptual, strategic and statistical considerations. Journal of Personality and Social Psychology 1986;51:1173-1182.

[2] Brown JL, Sheffield S, Leary MR, Robinson ME. Social support and experimental pain. Psychosomatic Medicine 2003;65:276-283.

[3] Chambers CT, Cassidy KL, McGrath PJ, Gilbert CA, Craig KD. Child Facial Coding System

[4] Cohen-Mansfield J. The relationship between different pain assassments in dementia. Alzheimer Disease \& Associated Disorders 2008;22(1):86-93.

[5] Craig KD. The social communication model of pain. Canadian Psychology 2009;50(1):22-32.

[6] de C Williams AC. Facial expression of pain: An evolutionary account. Behavioral and Brain Sciences 2002;25:439-488.

[7] DeWall CN, Baumeister RF. Alone but feeling no pain: Effects of social exclusion on physical pain tolerance and pain threshold, affective forecasting and interpersonal empathy. Journal of Personality and Social Psychology 2006;91(1):1 - 15 .

[8] Eisenberger NI, Lieberman MD, Williams KD. Does rejection hurt? An fMRI study of social exclusion. Science 2006;302:290-292.

[9] Ekman P, Friesen W. Investigator's guide to the Facial Action Coding System. Palo Alto, CA: Consulting Psychologists Press, 1978.

[10] Flor H, Breitenstein C, Birbaumer N, Fürst M. A psychophysiological analysis of spouse solicitousness towards pain behaviors, spouse interaction, and pain perception. Behavior Therapy 1995;26(2):255-272.

[11] Fridlund A. Evolution and facial action in reflex, social motive, and paralanguage. Biological Psychology 1991;32:3-100.

[12] Gray K, Wegner DM. The sting of intentional pain. Psychological Science 2008;19(12):1260-1262.

[13] Grunau RE, Oberlander T, Holsti L, Whitfield MF. Bedside application of the Neonatal Facial Coding System in pain assessment of premature infants. Pain 1998;76(3):277-286.

[14] Hadjistavropoulos T, Craig KD. A theoretical framework for understanding self-report and observational measures of pain: A communications model. Behaviour Research and Therapy 2002;20:551-570.

[15] Platow MJ, Voudouris NJ, Coulson M, Gilford N, Jamieson R, Najdovski L, Papaleo N, Pollard C, Terry L. In-group reassurance in a pain setting produces lower levels of physiological arousal: Direct support for a selfcategorization analysis of social influence. European Journal of Social Psychology 2007;37:649-660.

[16] Prkachin KM. The consistency of facial expressions of pain: a comparison across modalities. Pain 1992;51(3):297-306.

[17] Prkachin KM, Craig KD. Expressing pain: The communication and interpretation of facial pain signals. Journal of Nonverbal Behavior 1995;19(4):191-205. 
[18] Severeijns R, Vlaeyen JWS, van den Hout MA. Do we need a communal coping model of pain catastrophizing? An alternative explanation. Pain 2004;111(3):226-229.

[19] Sullivan MJL, Adams H, Sullivan ME. Communicative dimensions of pain catastrophizing: social cueing effects on pain behaviour and coping. Pain 2004;107:220-226.

[20] Sullivan MJL, Bishop S, Pivik J. The pain catastrophizing scale: development and validation. Psychological Assessment 1995;7:52-64.

[21] Sullivan MJL, Thorn B, Haythornthwaite JA, Keefe F, Martin M, Bradley LA, Lefebvre JC. Theoretical perspectives on the relation between catastrophizing and pain. The Clinical Journal of Pain 2001;17:52-64.

[22] Van Damme S, Crombez G, Bijttebier P, Goubert L, Van Houdenhove B. A confirmatory factor analysis of the Pain Catastrophizing Scale: Invariant factor structure across clinical and non-clinical populations. Pain 2002;96(3):319-324.

[23] Van Damme S, Crombez G, Vlaeyen JWS, Goubert L, Van den Broeck A, Van Houdenhove B. De Pain Catastrophizing Scale: psychometrische karakteristieken en normering. Gedragstherapie 2000;3:211-222.

[24] Vlaeyen JWS, Hanssen MMP, Dautzenberg A, Peters ML, Goubert L, Sullivan ML, Morley S. Threat of pain influences social context effects on verbal pain report and facial expression. Behaviour Research and Therapy 2009;47(9):774-782.

[25] Watson D, Clark LA, Tellegen A. Development and validation of brief measures of Positive and Negative Affect: The PANAS Scales. Journal of Personality and Social Psychology 1988;54:1063-1070.

[26] Williams ACdC. Facial expression of pain: An evolutionary account. Behavioral and Brain Sciences 2002;25:439-488.

[27] Williams ACdC, Craig KD. A science of pain expression? Pain 2006;125(3):202-203. 


\section{Taking into account social \\ threat: A vignette study of pain assessment}

Pim A. M. Peeters \& Johan W. S. Vlaeyen 


\begin{abstract}
Recent studies have yielded evidence that social threats increase reported pain intensity and may decrease facial pain expression on the other hand. According to an evolutionary perspective of facial pain expression, humans have evolved a capacity to understand pain expression and detect suppression and amplification. This raises the question whether social threat effects are also taken into account when assessing pain of others. To investigate this question, two vignette studies were conducted in which participants had to estimate the experienced pain intensity and facial pain expression of the lead character. The first study was conducted among students in psychology, health sciences or medicine, and consisted of vignettes that were systematically varied in social context valence and severity of injury. The second study was conducted amongst a much larger and more diverse sample of higher education students and presented less systematic, but in terms of the social threat more ecologically valid vignettes. It was hypothesized in both studies that, mirroring the experiments on social threat, a more negative social context would be associated with increased pain experience estimates but decreased pain expression estimates. The analyses yielded mixed findings, with the first study demonstrating decreased pain expression estimates for social threat contexts as hypothesized, but no significant findings for the pain intensity estimates. For the second study, increased pain intensity estimates were demonstrated for socially threatening contexts, but no significant findings for the pain expression estimates. The results are discussed with regard to the evolutionary perspective and experimental studies on social threat.
\end{abstract}




\section{Introduction}

The finding that fear of pain increases its intensity is well established ${ }^{[18 ; 7]}$. Much less is known about what happens if not the pain itself, but the social context in which it is experienced presents a threat. There is some evidence that social threats increase reported pain intensity much like threatening pain appraisals ${ }^{[5 ; 9]}$. However, it appears that social threats can also decrease the expression of pain ${ }^{[17 ; 9]}$. According to an evolutionary perspective of facial pain expression ${ }^{[19]}$, this is likely the result of suppression of pain expression, since signaling that one is vulnerable can be detrimental to survival in a threatening social context. According to the same evolutionary perspective, humans are likely to have an evolved capacity to understand pain expression and detect suppression and amplification. This suggests that social threat may not only have an effect on the experience and expression of pain, but also on how pain is understood by observers who are aware of the social threat.

Based on the empathy model of pain ${ }^{[3]}$ there are three types of factors that influence the understanding someone has of another's' pain (from here on referred to as empathy for pain); 1) top-down influences, such as observer characteristics, 2) bottom-up influences, such as the characteristics of the observed pain expression, and 3) contextual factors, which include the relation between the observer and the individual in pain. Several studies have examined the effects of contextual factors on empathy for pain. Most of these have focused on medical information, such as the absence of a medical explanation for the pain ${ }^{[13 ; 1 ; 14 ; 2]}$. It remains unclear whether the (threatening) meaning of the social context can influence empathy for pain, in the absence of any additional information about the individual in pain or his/her injury.

The present studies aimed to investigate the influence of social context valence on estimated pain experience and pain expression of others. To accurately investigate the influence of social context effects on pain experience estimates, the top-down and bottom-up influences were controlled for in the design and statistical analysis. Therefore, the present studies adopted a vignette design. By offering written descriptions of the pain eliciting situation and pain behaviour, all participants receive exactly the same bottom-up information. A vignette design has the additional advantage that it can be used to gain an estimate of pain for a situation that cannot be created in the laboratory, such as very severe injuries. Pain catastrophizing, the most obvious top-down factor, was assessed by means of a questionnaire and statistically controlled for.

Two vignette studies were conducted. The first study was conducted among students in psychology, health sciences or medicine, and consisted of vignettes that were systematically varied in social context valence and severity of injury. The second study was conducted amongst a much larger and more diverse sample of higher education students and presented less systematic, but in terms of the social threat more ecologically valid vignettes. It was hypothesized in both studies that, mirroring the 
experiments on social threat, a more negative social context would be associated with increased pain experience estimates but decreased pain expression estimates.

\section{Study 1}

To investigate the effects of social context valence on ratings of others' pain intensity and expression, a first vignette study was conducted with ninetyfive participants from the faculties of psychology and health, medicine and life sciences from Maastricht University. The vignettes were presented to the participants as part of a study into medical decision making in daily life, to draw away the attention from the actual factors under investigation.

The social context valence was varied across three conditions, by varying the presence of another character (Friend/Stranger/Foe). It was hypothesized that the presence of a foe would lead to higher pain intensity ratings and lower pain expression ratings. The suppression hypothesis of facial pain expression states that suppression occurs because showing pain towards antagonists may have undesirable results. However, when an antagonist is not actually out to cause severe physical harm, there should be a point at which the severity of an injury prioritizes soliciting help even from the antagonist, regardless of the possible undesirable effects. To investigate this hypothesized interaction between social context valence and wound severity, the severity of the injury sustained in the vignette was varied across five conditions as well (scrape/bruise/burn/ fracture/heavy trauma) (see Box 1.)

\section{Measures}

\section{Vignettes}

All vignettes presented to the participants contained men around the age of 21 as the lead character. Care was taken that, aside from the wound severity and social context, no additional information was provided that could be used to infer known bottom-up factors influencing empathy. There was a different base story for each injury severity level, in which the social context valence was varied based on the same three social context description, resulting in 18 different vignettes. Each participant received two vignettes. The presentation of the vignettes was balanced across participants so that no participant received the same injury or social context description twice, while all vignettes were completed by approximately the same number of participants. Two vignettes per participant were chosen rather than three to make the social context manipulation less obvious.

After each vignette, the participant was asked to rate how much pain the lead character was expected to experience, and how much pain this character would express, both on 1 to 10 point Likert scales (0: no pain, 10: worst pain ever experienced, and 0: no pain expression, 10: extreme pain expression). To support the cover story four questions 
were added asking about medical decisions the lead character should take on the basis of the information provided in the vignette.

Box 1.

Paul is a 26 year old student at the Maastricht Graduate School of Governance. One day he is at the city centre to buy new clothes. Carrying his new purchases he is walking back to the bicycle stall. Underway he meets his best friend Andre/Andre, a student from his tutorial group with whom Paul recently had an argument. While greeting Andre/while trying to ignore Andre, Paul trips over an uneven street tile and falls roughly on the street. He scrapes his underarms badly. Andre watches how Paul gets up, still startled by the fall. Paul wipes some dirt from his clothes and looks at his underarms, they look dirty and bloody.

1. How much pain do you expect Paul to experience?

$\begin{array}{lrrrrrrrrrr}0 & 1 & 2 & 3 & 4 & 5 & 6 & 7 & 8 & 9 & 10 \\ \text { No pain } & & & & & & & & \text { Worst pain ever }\end{array}$

2. How much pain do you expect Paul to express?

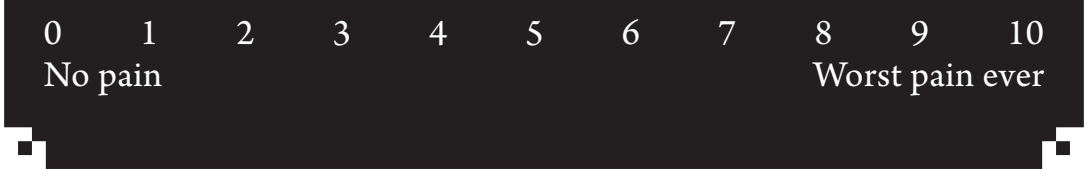

Box 1: An example of a vignette. The base story is written in normal print, the social context (friend/foe) in cursive print

\section{Pain catastrophizing}

As higher levels of pain catastrophizing are associated both with higher pain ratings for the self ${ }^{[12]}$, and higher pain estimates in others ${ }^{[10 ; 4]}$, pain catastrophizing was included as a top-down variable. Pain catastrophizing was measured with the Dutch version of the Pain Catastrophizing Scale [11]. The PCS is a 13-item self-report questionnaire that targets rumination, magnification and feelings of helplessness associated with the experience of pain. The PCS has shown to be a valid and highly reliable instrument ([Cronbach's alpha between 0.85 and 0.9116$]$ ).

\section{Statistical analyses}

In order to investigate the effects of pain catastrophizing, wound severity and the social context on the estimated pain intensity and expression, multilevel regression analyses were conducted using SPSS18 (IBM SPSS) Since there were two measures per participant, participant was chosen as 
the first level of the analyses. Pain catastrophizing, wound severity, social context condition and their interactions were entered as independent, fixed variables. A variance components matrix was chosen. A stepwise procedure was used where the model started out as an intercept only model with one level, adding first a second level, then the fixed factors and finally a random slope, provided that each next step made a significant contribution to the model. A step was considered a significant improvement based on a Chisquare significance test on the difference in -2 Log Likelihood (-2LL) between the previous and new model.

\section{Results}

\section{Pain intensity}

A two level model with intercept and fixed factors, without random slope, yielded the lowest -2LL that was a significant improvement over the previous model. A statistically significant interaction was found for pain catastrophizing and wound severity $(\beta=-0.022, p<0.005)$. Increased wound severity was associated with higher estimated pain intensity for both low and high pain catastrophizers, with high pain catastrophizers giving higher ratings than low pain catastrophizers for the relatively minor wounds. No interactions (Injury: $\beta=0.015, p=0.837$; PCS: $\beta=0.015$, $\mathrm{p}=0.842)$ or main effects $(B=-0.162, \mathrm{p}=0.196)$ were observed for the social context.

\section{Pain expression}

A two level model with intercept and fixed factors, without random slope, yielded the lowest -2LL that was a significant improvement over the previous model. No significant interactions between any of the variables were observed. A main effect was found for wound severity $(\beta=0.904, p<$ $0.001)$, such that increased wound severity lead to higher pain expression estimates. In line with our hypothesis, a main effect was also observed for social context $(B=-0.687, p<0.001)$, such that specifically the presence of a foe led to lower pain expression estimates than the stranger $(B=-1.090$, $p<0.005)$ or friend $(B=-0.626, p=0.001)$. Additionally, a main effect was found for pain catastrophizing, such that higher pain catastrophizing scores lead to higher estimated pain expression ratings $(B=0.038, \mathrm{p}=$ $0.028)$.

\section{Conclusions}

The decreased pain expression estimates in the presence of a foe, rather than in the presence of a stranger of friend, mirror the experimental findings on the influences of social threat on pain expression $[5 ; 8]$. Furthermore, this finding is in line with the suppression hypothesis of pain expression ${ }^{[19]}$, suggesting that suppression of pain expression in a socially 
threatening context is taken into account when observing pain in others. Unlike the experimental studies, no social context effect was observed on the estimated pain experience.

Contrary to expectations, there was no interaction between the social context valence and wound severity. Wound severity and pain catastrophizing were both related to higher pain experience and expression estimates, independently from the social context.

\section{Study 2}

The lack of a social context effect on estimated pain experience in study 1 is striking given the earlier findings of experimental studies. While this lack of effect may indicate that social context valence is only taken into account when judging another's pain expression, not his experience, there are some aspects of study 1 which may have occluded an effect on estimated pain intensity.

While the design of study 1 allowed for very systematic manipulation of the social context valence, the differences in valence were relatively mild. Furthermore, in the experimental studies on social threat, pain was usually actively inflicted on the participant, whereas in the vignettes pain was experienced for reasons not to be blamed on the social context. Additionally, many of the participants in study 1 were enrolled in a health(care) related curriculum, which may have an influence on empathy for pain ${ }^{[6]}$.

Therefore a second vignette study was conducted among 543 participants as part of a larger survey on bullying amongst higher education students. Alternative vignettes were used in which the social context valence was more pronouncedly varied, and in which the pain experienced by the lead character was caused by another person in the social context. The vignettes were embedded amongst other vignettes on hostile interpretation biases.

\section{Measures}

\section{Vignettes}

Each participant completed four vignettes (See Box 2.) in which the lead character experienced one of two injuries. All participants received the same four vignettes as part of a larger survey on bullying. Since the format did not allow for random assignment of vignettes to each participant, two types injuries were chosen of about the same severity to create two pairs of vignettes that described the same injury, yet varied between a neutral and negative social context. To fit the vignettes with the hostile interpretation bias vignettes in which they were embedded, the participants were asked to imagine that they were the lead character in the vignettes themselves. The dependent variables were the participants' estimates of their experienced pain intensity in the vignette, and the estimate of how much pain behavior they expected to express. 
Box 2.

You are playing a soccer match with some of your friends. When someone passes the ball to you, one of your friends enthusiastically tries to take the ball from you. Instead of hitting the ball, he kicks you hard against the shin.

When walking in the halls of your school you accidently bump into another student. He and his friends gather up around you angrily, and he kicks you hard against the shin.

1. How much pain do you expect to experience?

$\begin{array}{lrrrrrrrrrr}0 & 1 & 2 & 3 & 4 & 5 & 6 & 7 & 8 & 9 & 10 \\ \text { No pain } & & & & & & & & \text { Worst pain ever }\end{array}$

2. How much pain do you expect to express?

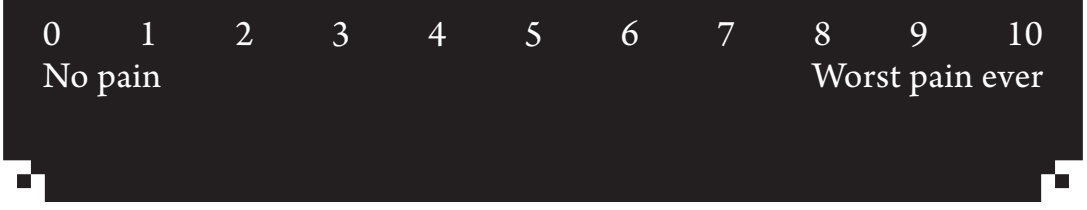

Box 2: An example of two vignettes. The social context setting is written in normal print, the wound part that is kept identical across vignettes in cursive print.

\section{Pain catastrophizing}

As in study 1, pain catastrophizing was included as a top-down variable. Pain catastrophizing was measured using the Dutch version of the Pain Catastrophizing Scale (PCS) ${ }^{[16 ; 15]}$.

\section{Statistical analyses}

In order to investigate the effect of the social context on the estimated pain intensity and expression, multilevel regression analyses were conducted. Since there were four measures per participant, participant was chosen as the first level of the analyses. Social context condition (neutral/threat) and pain catastrophizing were entered as independent, fixed variables. A variance components matrix was chosen. A stepwise procedure was used where the model started out as an intercept only model with one level, adding first a second level, then the fixed factors and finally a random slope, provided that each next step made a significant contribution to the model. A step was considered a significant improvement based on a Chi-square significance test on the difference in -2 Log Likelihood (-2LL) between the previous and new model. 


\section{Results}

\section{Pain intensity}

A two level model with intercept and fixed factors, without random slope, yielded the lowest -2LL that was a significant improvement over the previous model. The interaction between PCS and the social context was not significant $(B=0.002, p=0.726)$. A main effect was found for the social context $(B=0.487, p<0.001)$, such that threatening social context's yielded higher pain intensity scores. A main effect was also found for pain catastrophizing $(B=0.040, p<0.001)$, such that higher pain catastrophizing was associated with higher pain estimates

\section{Pain expression}

A two level model with intercept and fixed factors, without random slope, yielded the lowest -2LL that was a significant improvement over the previous model. The interaction between PCS and the social context was not significant $(B=0.112, p=0.183)$. No main effect was found for the social context $(B=-0.060, p=0.454)$. A main effect was also found for pain catastrophizing $(B=0.029, \mathrm{p}=0.001)$, such that higher pain catastrophizing was associated with higher pain expression estimates

\section{Conclusions}

The results on the estimated pain experience mirror the findings of experimental studies, with more threatening social contexts being associated with higher pain ratings. Unlike the experimental studies, no social context effect was observed on the estimated pain expression. As in study 1, pain catastrophizing was related to higher estimates of pain experience and expression, independently from the social context.

\section{Discussion}

The present studies were conducted to investigate whether the valence of the social context in which pain occurs influences estimations of experienced and expressed pain. The results show that indeed the social context influences these estimations. In line with the results of experimental studies on social threat effects on pain ${ }^{[5,8]}$, and the evolutionary account of facial pain expression, descriptions of a socially threatening setting in the first vignette study were associated with decreased estimated pain expression. Reversely, social threat in the second vignette study was associated with increased estimated pain experience. Neither vignette study demonstrated both effects though, begging the question which factors are relevant for both estimation processes.

One difference between both studies was that for the vignettes in the first study participants were asked to make estimations about another 
individual, where the second study asked to make estimations for oneself in a hypothetical situation. Although the latter is strictly not a form of estimating pain in others, the underlying process of estimating pain in others in an abstract situation with limited bottom-up information about the other is likely to be an estimation as to how oneself would react in that situation. This difference between the studies is therefore an unlikely explanation for the observed differences in effects.

An additional difference was that pain was accidently self-inflicted in the first study, while it was (accidentally or intentionally) inflicted by others in the second study. Since intentionality in inflicting pain is known to influence the subsequent pain experience ${ }^{[5]}$, this is likely the cause for the differential effects on estimated pain experience between both studies. The fact that intentionally inflicted injury is estimated to be more painful matches with the experimental studies on this topic ${ }^{[5 ; 8]}$.

However, the difference in intentionality does not explain the differential effect on pain expression. It is unlikely that suppression of pain is released in exactly those circumstances that the injury is inflicted by another. This implies that another factor is responsible for the lack of a pain expression effect in the second study. While in the first study the social context was limited to the lead character and one other person, the second study describes the injuries taking place in the presence of larger groups. It may be that the influence of a threatening individual on pain expression was evened out in this case by the presence of other, more neutral individuals. While one would do well not to show pain to an antagonist, this may be overruled by the need to communicate pain to (potential) allies. Up till now, pain expression has mostly been investigated in situations of one on one social interaction. Studies on group interactions are necessary to investigate this hypothesis.

In accordance with previous studies, pain catastrophizing was associated with higher estimates of pain experience ${ }^{[10 ; 4]}$. Similarly, more severe injuries were associated with higher pain ratings. While these topdown and bottom-up factors interacted with each other in study 1 , in no instances was an interaction observed with the social context effects. This suggests that the valence of the social context impacted pain estimates independently from these top-down and bottom-up factors.

Taking the findings of both studies together, they do parallel the findings from experimental studies. There appears to be a dissociation between the effect of the social context on pain experience and pain expression [8]. A more negative social context appears to be associated with higher pain intensity estimates, and lower non-verbal pain expression estimates. Converging evidence amongst experimental studies and the current vignette study suggests that people take social context effects into account when estimating pain in others. An intriguing question is whether this occurs on a conscious or automatic level.

Taking social context effects into account when assessing pain is particularly important given the possible dissociation between pain experience and expression. Especially so in a health care setting, where 
pain assessment forms the basis of pain treatment. Depending on the level of automaticity that is involved in taking the social context into account when assessing pain, different strategies are likely to be more successful at educating/training people to do this.

It should be mentioned that the results of this study are based on a vignette study, in which the injuries and social context were verbally described, rather than actually observed by the assessor. The actual observing of wounds and pain expressions may lead to much more affective engagement than reading a vignette ${ }^{[3]}$. The somewhat more abstract nature of assessing a vignette may be the reason for the absence of a statistical interaction between wound severity and the social context valence in then first study.

In sum, to the knowledge of the authors this is the first study to demonstrate social contextual effects on the estimation of pain intensity and pain expression. These effects appear to be similar to ones found in experimental studies on social context effects on pain. To investigate if similar assessment effects occur when observing actual wounds and pain expression, more ecologically valid experimental studies are recommended. 


\section{References}

[1] Chibnall JT, Tait RC. Observer perception of low back pain: effects of pain report and other contextual factors. journal of Applied Social Psychology 1995;25:418-439.

[2] Chibnall JT, Tait RC. Social and medical influences on attributions and evaluations of chronic pain. Psychology \& Health 1999; 14:719-729.

[3] Goubert L, Craig KD, Vervoort T, Morley S, Sullivan MJL, Williams ACdC, Cano A, Crombez G. Facing others in pain: the effects of empathy. Pain 2005; 118:285-288.

[4] Goubert L, vervoort T, Cano A, Crombez G. Catastrophizing about their children's pain is related to higher parent-child congruency in pain ratings: an experimental investigation. European Journal of Pain 2009; 13:196-201.

[5] Gray K, Wegner DM. The sting of intentional pain. Psychological Science $2008 ; 19(12): 1260-1262$.

[6] Hojat M, Vergare MJ, Maxwell K, Brainard G, Herrine SK, Isenberg GA, Veloski J, Gonnella JS. The Devil is in the Third Year: A Longitudinal Study of Erosion of Empathy in Medical School. Academic Medicine 2009;84(9):1182-1191.

[7] Jackson T, Pope L, Nagasaka T, Fritch A, Iezzi T, Chen H. The impact of threatening information about pain on coping and pain tolerance.

British Journal of Health Psychology 2005; 10:441-451.

[8] Peeters PAM, Vlaeyen JWS. Feeling more pain, yet showing less: The influence of social threat on pain. Journal of Pain 2011.

[9] Peeters PAM, Vlaeyen JWS. Feeling more pain, yet showing less: The influence of social threat on pain. In preparation.

[10] Sullivan ME, Martel MO, Tripp D, Savard A, Crombez G. Catastrophic thinking and heightened perception of pain in others. Pain 2006;123:37-44.

[11] Sullivan MJL, Bishop S, Pivik J. The pain catastrophizing scale: development and validation. Psychological Assessment 1995;7:52-64.

[12] Sullivan MJL, Thorn B, Haythornthwaite JA, Keefe F, Martin M, Bradley LA, Lefebvre JC. Theoretical perspectives on the relation between catastrophizing and pain. The Clinical Journal of Pain 2001;17:52-64.

[13] Tait RC, Chibnall JT. Observer perceptions of chronic low back pain. Journal of Applied Social Psychology 1994;24:415-431.

[14] Tait RC, Chibnall JT. Physician judgments of chronic pain patients. Social Science \& Medicine 1997;45:1199-1205.

[15] Van Damme S, Crombez G, Bijttebier P, Goubert L, Van Houdenhove B. A confirmatory factor analysis of the Pain Catastrophizing Scale: Invariant factor structure across clinical and non-clinical populations. Pain 2002;96(3):319-324.

[16] Van Damme S, Crombez G, Vlaeyen JWS, Goubert L, Van den Broeck A, Van Houdenhove B. De Pain Catastrophizing Scale: psychometrische karakteristieken en normering. Gedragstherapie 2000;3:211-222. 
[17] Vervoort T, Goubert L, Eccleston C, Verhoeven K, De Clercq A, Buysse A, Crombez $\mathrm{G}$. The effects of parental presence upon the facial expression of pain: The moderating role of child pain catastrophizing. Pain 2008; 138:277-285.

[18] Vlaeyen JWS, Linton SJ. Fear-avoidance and its consequences in chronic musculoskeletal pain: A state of the art. Pain 2000;85(3):317-332.

[19] Williams ACdC. Facial expression of pain: An evolutionary account. Behavioral and Brain Sciences 2002;25:439-488. 


\section{The impact of}

a social threat

to psychosocial

integrity on

reported pain

intensity and facial

pain expression

Pim A. M. Peeters \&

Johan W. S. Vlaeyen 


\begin{abstract}
Recent studies have demonstrated that social threats, such as when pain is intentionally inflicted by others, increased reported pain intensity, and possibly decrease facial pain expression at the same time. Whether other forms of social threat have a similar impact remains unclear. The present study focused on another form of social threat, aiming to investigate the influence of experienced injustice on reported pain intensity and facial pain expression. Healthy participants $(\mathrm{N}=62)$ took part in an experiment where they competed in an intelligence quiz for a monetary reward. The experimenter would obviously favour one participant over the other to manipulate the level of injustice experienced by both participants. After the quiz, participants completed a one minute cold pressor task during which they had to report experienced pain intensity and their facial pain expression were videotaped and coded. Since both favoured and disfavoured participants experienced injustice as a result of the manipulation, a questionnaire measure of interpersonal threat was used as independent variable in the analyses. The results on reported pain intensity showed a cross-over pattern, with low interpersonal threat being associated with higher pain reports in high pain catastrophizers. On the other hand, high interpersonal threat was associated with higher pain reports for low pain catastrophizers as compared to high pain catastrophizers. High interpersonal threat was also associated with increased facial pain expression for both low and high pain catastrophizers. These results are discussed with regard to the previous studies on social threat and psychological models of pain.
\end{abstract}




\section{Introduction}

As social beings we are affected in different ways depending on the valence of the social context in which we find ourselves. In pain research, most attention has focused on positive influences, such as social support ${ }^{[2]}$. However, individuals in pain may also experience social situations as threatening, such as when pain is inflicted by another or when one is treated unjustly. The threat value of pain itself is well established as an important intrapersonal factor influencing pain experience ${ }^{[9]}$, as the threat value increases, the pain experience intensifies. However, what happens when not the pain itself, but the interpersonal context in which pain is experienced presents a threat is much less clear.

Interpersonal threat can take the form of pain being inflicted on the individual by another. Gray and Wegner ${ }^{[8]}$ demonstrated that intentionally inflicted pain is associated with higher pain reports than unintentionally inflicted pain. Similarly, Peeters and Vlaeyen ${ }^{[11]}$ found that the experience that someone administers more pain stimuli than necessary is associated with higher pain reports for individuals that catastrophize about pain, and less facial pain expression for all individuals. These findings suggest that an interpersonal threat increases pain intensity, while decreasing the communication of pain.

Alternatively, the interpersonal threat can also be unrelated to the cause of the pain itself, but present a threat to psychosocial integrity. Since brain areas processing physical pain and 'social pain' overlap ${ }^{[6]}$, threats to psychosocial integrity may also affect pain experience ${ }^{[1]}$. The experience of unnecessary psychological suffering as a result of another's actions is likely to give rise to feelings of injustice ${ }^{[10]}$. Feelings of injustice have shown to predict poor (chronic) pain-related outcomes, such as lower return to work status ${ }^{[14]}$. These observations make it likely that this form of interpersonal threat may also have a direct effect on pain. Therefore the present study aimed to investigate the direct effects of feelings of injustice on reported pain intensity and facial pain expression.

Possible mechanisms for injustice effects on pain were taken into account in the investigation. According to the cognitive appraisal model of pain (CAM) ${ }^{[13]}$, interpersonal threat may influence the appraisal of the pain itself, making it more threatening and hence experienced more intensely. Alternatively, the need-threat theory (NTT) of social exclusion when applied to injustice predicts an initial, direct negative impact on mood and pain sensitivity as injustice threatens the social needs of the individual ${ }^{[23 ; 24]}$. If coping is unsuccessful, this leads to depletion of coping resources and social, emotional, and physical numbing causing decreased pain sensitivity.

pecifically for pain expression, communicative models of pain such as the communal coping model (CCM $)^{[17]}$ or an evolutionary account of pain expression ${ }^{[22]}$ predict that social threat should decrease pain expression, as communicating weakness towards an antagonist is undesirable. Based on the CCM, this effect should be exclusive to or larger for individuals scoring 
high on pain catastrophizing. To test this hypothesis, pain catastrophizing was included as a moderator.

\section{Methods}

\section{Design}

A between subjects design with two conditions (high/low injustice) was used in this study. Two participants were present during each experiment session, of whom one would be assigned each experimental condition. Both participants underwent a cold pressor task after performing a quiz that was developed to induce feelings of injustice to one participant. The dependent variables were reported pain intensity and facial pain expressions. The ethical committee of the faculty of Psychology and Educational Sciences of the University of Leuven, Belgium, approved this study.

\section{Participants}

Participants (N=62, 26 male, mean age 20.7) were recruited from first year psychology students at Leuven University, Belgium, who were invited to participate in a study on the relationship between logical reasoning and pain. Exclusion criteria were any form of heart condition, neuromuscular diseases, epilepsy or pregnancy. Participants were selected so that they had had no prior interaction with each other.

\section{Apparatus}

A cold pressor apparatus was used to induce pain. Cold pressor pain is considered to be an analogue for various naturally occurring acute pains [4]. The cold pressor apparatus consisted of a refrigerated unit filled with circulating water $(30 \mathrm{~h}-50 \mathrm{l}-30 \mathrm{~d} \mathrm{~cm})$ that maintained the water temperature at $2^{\circ}$ to $4^{\circ}$ Celsius. Prior to the cold pressor test, participants immersed their hand in a unit that contained water at approximately room temperature $\left(21^{\circ}\right.$ Celsius $)$ for 5 minutes in order to assure comparable baseline skin temperatures across participants.

\section{Manipulation of injustice}

To create two injustice conditions, a quiz was played by the two participants in each experiment session in which one participant would be favoured by the experimenter leading the quiz, while the other would be disadvantaged. The quiz itself consisted of twenty numerical sequences for which the participants had to complete the final missing number (e. g. $013610 \ldots$ ? [correct answer: 15$]$ ), and was introduced to the participants as a measure of logical reasoning capability. As an additional motivation, the quiz' winner would receive a $€ 5$ reward.

The experimenter leading the quiz favored the participant in the low injustice condition by assigning relatively easy number sequences, providing additional tips to solve the sequence, and by being more lenient 
with the time limit. The disadvantaged participant received more complex sequences, received no tips or time limit extensions, while regularly being told by the experimenter to be an underachiever. As a result of this differential treatment the advantaged participant would usually win the quiz and the additional $€ 5$ reward.

\section{Measurements}

\section{Pain Catastrophizing}

Pain catastrophizing, the tendency to interpret pain as excessively negative, was measured with the Dutch version of the Pain Catastrophizing Scale (PCS) ${ }^{[18]}$. The PCS consists of 13 items that measure thoughts and feelings that are associated with the experience of pain. The PCS has shown to be a valid and highly reliable instrument (Cronbach's alpha between .85 and .91) ${ }^{[19]}$.

\section{Interpersonal threat}

Interpersonal threat was measured by a 14-item questionnaire in which characteristics of the experimenter, including perceptions of his behaviour as being just/unjust, were evaluated ${ }^{[11]}$. Items are scored on an 11 point Likert scale ranging from 0 to 10 or -5 to +5 depending on the specific item (e.g 'the experimenter treated me unjustly' $0=$ completely disagree, $10=$ completely agree; 'I rate the experimenter as: $-5=$ unfair, $+5=$ fair). Reliability analyses of the scale yielded a sufficient internal reliability for this study (Cronbach's Alpha $=.70$ ).

\section{Threat value of the pain}

The threat value of the pain was measured with a threat questionnaire based on a questionnaire by Vlaeyen et al. ${ }^{[20]}$ for a cold pressor task. It consists of five statements describing threatening pain appraisals that have to be rated on an 11 point Likert scale ranging from 0 (completely disagree) to 10 (completely agree). Reliability analysis on the items of the threat questionnaire yielded a good internal consistency (Cronbach's Alpha $=.91)^{[20]}$.

\section{State positive and negative affect}

State positive and negative affect were measured to correct for possible confounding of the effects of the unjust treatment on pain. Affect measures were taken with the state version of the Positive and Negative Affect Schedule (PANAS-t/-s) ${ }^{[21]}$, before and after the injustice manipulation. The PANAS-s measures the present mood state of the participant by having him/her rate 20 adjectives describing mood states on a 5-point scale ranging from 1 (completely does not apply to me) to 5 (completely applies to me).

\section{Reported Pain Intensity}

Reported Pain Intensity was measured by letting the participants write down a score from 0 (no pain at all) to 10 (this is the worst pain ever 
experienced) at three times during the cold pressor task at a 20s, 40s and 60 s interval. After the task the three ratings were averaged to obtain an overall measure of pain intensity.

\section{Facial Pain Expression}

Facial Pain Expression was coded using an abridged version ${ }^{[11]}$ of the Child Facial Coding System (CFCS) ${ }^{[3]}$ which has also been successfully used in coding pain of adults ${ }^{[20]}$. Six facial actions were scored on three different levels (not present, slightly present, distinct/maximally present): brow lowering, eye squint, eye squeeze, nose wrinkle, cheek raiser, and upper lip raise. Videotaped fragments of the participants' faces were divided into 60 parts of one second each. All parts were coded by one of two coders who coded a random sample of the fragments with $20 \%$ overlap between the coders to determine inter-rater reliability. Inter-rater reliability was calculated in accordance with the formula provided by Ekman and Friesen ${ }^{[7]}$ and was .84.

\section{Procedure}

At the start of the experiment both participants were introduced to the study by the experimenter. They were seated on one side of the room, visually divided by a screen and completed the PCS, PANAS-s, and pain threat questionnaire. The experimenter was seated such that he was visible to both participants and started the injustice manipulation quiz. The quiz was presented on a computer screen visible to both participants, which was controlled by the experimenter After the quiz, both participants remained seated and filled in the PANAS-s and pain threat questionnaire again. Subsequently they simultaneously underwent a cold pressor task, during which they had to hold their hands in a personal tank with circulating water of $\pm 2{ }^{\circ} \mathrm{C}$ for one minute. Video recordings of the faces of both participants were made during this minute. The cold pressor task was followed by completing the interpersonal threat questionnaire. Thereafter participants were debriefed and rewarded for their participation, including an additional $€ 5$ reward for both the winner and loser of the quiz.

\section{Statistical analyses}

As a manipulation check regression analyses were conducted on the scores of the quiz and separately on the interpersonal threat questionnaire scores with condition as independent variable. Separate linear regression analyses were conducted for reported pain intensity and average facial pain expression as dependent variables. Experienced interpersonal threat and pain catastrophizing were entered as independent variables. Experienced interpersonal threat as reported in the interpersonal threat questionnaire was chosen over condition as independent variable, as favoured participants often still viewed the experimenter as unjust for his treatment of the other participant. Gender and mood prior to the cold pressor task were entered as covariates to account for their influences on pain. All variables 
were centered for the purpose of the analyses. VIF factors did not exceed 2 , indicating no problematic multicollinearity.

\section{Results}

\section{Participant characteristics}

A total sample of 62 participants completed the study. All participants successfully completed the cold pressor task. One participant was excluded from the analyses because of a large outlier value on pain catastrophizing. Data from another participant had to be excluded from the study due to technical problems with videotaping for facial expression coding. The total sample that was included into the analyses contained 60 participants, 35 women and 25 men (see Table 1 for descriptive statistics).

Table 1 .

\begin{tabular}{lll}
\hline & Low injustice & High injustice \\
\hline Positive affect (post-CPT) & $30.93(8.05)$ & $28.07(6.95)$ \\
Negative affect (post-CPT) & $16.17(4.71)$ & $15.07(4.93)$ \\
Pain threat (post-CPT) & $11.31(12.00)$ & $9.13(6.78)$ \\
Pain catastrophizing & $18.14(7.23)$ & $18.43(6.38)$ \\
Quiz score & $8.17(1.58)$ & $4.67(1.49)$ \\
Interpersonal threat & $72.83(17.22)$ & $67.67(17.16)$ \\
\hline
\end{tabular}

Table 1: Means and standard deviations on the studies most important independent variables

\section{Manipulation checks}

Regression analyses of the quiz scores between conditions yield significantly higher scores in the advantaged group versus the disadvantaged group ( $B$ $=-0.757 ; \mathrm{p}<0.001)$. The advantaged participants won the quiz 25 out of 30 times, the disadvantaged participants winning four times and one quiz ending in a draw. This clear effect of the unjust treatment on quiz performance (and thereby reward) also lead participates in the advantaged condition to perceive interpersonal threat, which is reflected by a nonsignificant effect of condition on the interpersonal threat questionnaire ( $\beta$ $=-0.151$; n.s.). Since the experienced injustice did vary among participants, however not based on condition, experienced interpersonal threat was chosen as an independent variable to examine its effect on reported pain intensity and facial pain expression.

\section{Pain report}

Analyses on reported pain intensity yielded a significant interaction between interpersonal threat and pain catastrophizing $(B=0.359 ; \mathrm{p}<0.01)$. Further 
analyses on the simple effects showed that high pain catastrophizers gave lower pain scores than low pain catastrophizers when experiencing high interpersonal threat $(B=-0.490 ; p<0.05)$, while they gave higher pain scores than low pain catastrophizers while experiencing low interpersonal threat $(B=0.433 ; \mathrm{p}<0.05)$ (see Figure 1.).

\section{Non-verbal facial pain expression}

No main effect for pain catastrophizing $(B=0.165$; n.s. $)$ nor an interaction effect with interpersonal threat were observed on the analyses on facial pain expression, however a main effect for interpersonal threat was found $(B=-0.311 ; \mathrm{p}<0.05)$ such that low interpersonal threat lead to higher facial pain display (see Figure 2.).

Figure 1 .

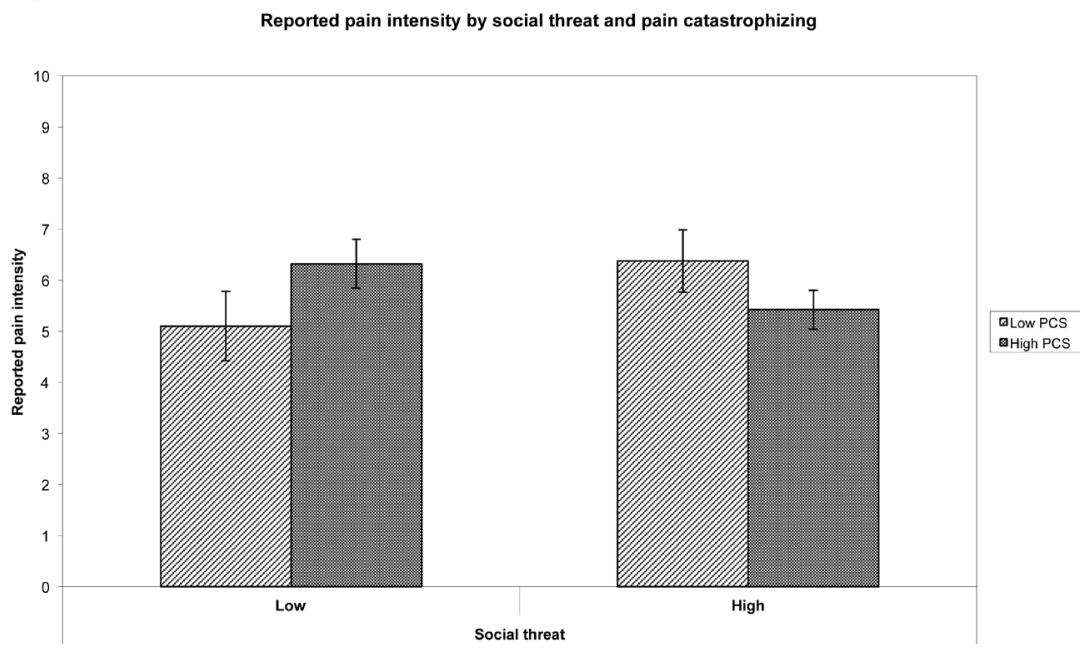

Fig 1: Reported pain intensity by pain catastrophizing and social threat based on the social threat questionnaire. Pain catastrophizing was dichotomized around a score of 16, while social threat was dichotomized around its median.

\section{Discussion}

The present study aimed to investigate the influence of unjust treatment on reported pain intensity and facial expressions of pain. The results demonstrate that experienced interpersonal threat as a result of unjust behaviour, impacted reported pain intensity and facial expressions differently depending on the individual level of pain catastrophizing. The predictions of the CAM and NTT, that reported pain intensity should increase in response to interpersonal threat, are not supported by the data. Similarly, an increase in facial pain expression was found in response to interpersonal threat, rather than the decrease predicted by the CCM.

All analyses were conducted with the measured experience of 
interpersonal threat, rather than condition, since the latter was no reliable predictor of how much interpersonal threat was experienced by the participants. It appears as though the participants who were not unjustly treated by the experimenter often experienced him as an interpersonal

Figure 2.

Facial pain expression by social threat and pain catastrophizing

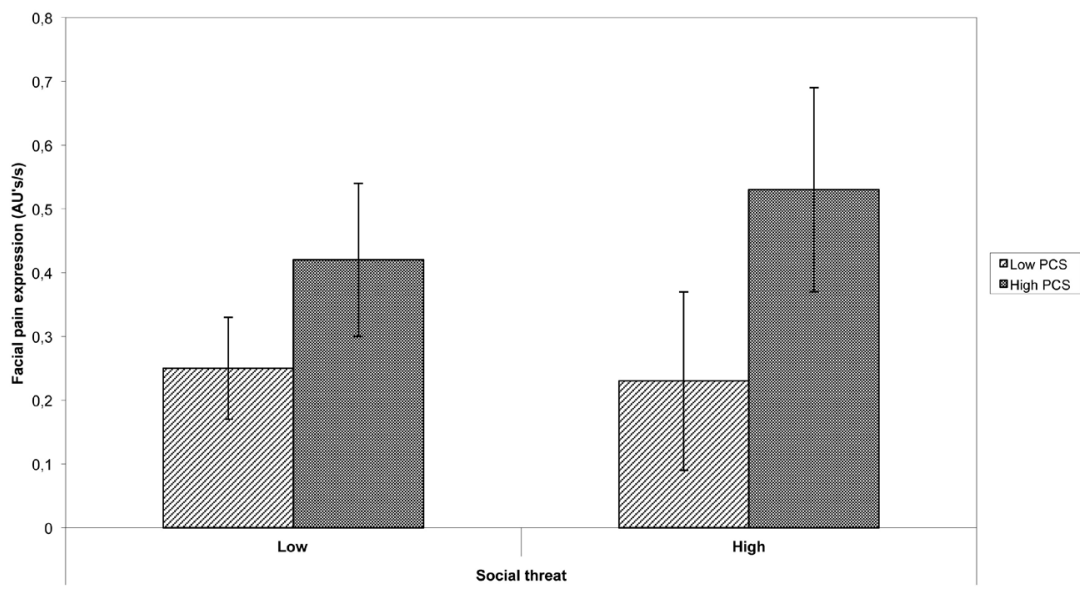

Fig 2: Facial pain expression by pain catastrophizing and social threat based on the social threat questionnaire. Pain catastrophizing was dichotomized around a score of 16, while social threat was dichotomized around its median.

threat because of his unjust treatment of the other participant. The observation that there was enough variation in the levels of experienced interpersonal threat suggests that individuals differ in their sensitivity to injustice. This sensitivity is likely to be a trait related to the sensitivity to befallen injustice ${ }^{[12]}$, although the present results imply that this sensitivity may extend to the unjust treatments of others as well.

The results on reported pain intensity show a cross-over pattern, with low interpersonal threat being associated with higher pain reports in high pain catastrophizers. On the other hand, high interpersonal threat is associated with higher pain reports for low pain catastrophizers as compared to high pain catastrophizers. In turn, high pain catastrophizers generally report more pain in response to pain tasks than low pain catastrophizers ${ }^{[17]}$, with some studies suggesting that this is more pronounced when pain is experienced in a social context ${ }^{[15 ; 16]}$. The same appears to be the case in the present study only for those individuals experiencing low interpersonal threat.

The reverse pattern being observed for individuals experiencing high interpersonal threat appears to reflect both an increase in pain sensitivity for low pain catastrophizers and a decrease in pain sensitivity for high pain catastrophizers. Based on both the CAM and NTT, only an increase in pain 
experience is to be expected. It could be hypothesized that since high pain catastrophizers appear to be more responsive to the social context, they are more severely affected by unjust treatment, leading to a numbing for pain, analogue to emotional numbing ${ }^{[5]}$. However, given the relatively mild nature of the social threat manipulation, this explanation appears to be unlikely.

The results on the facial expression of pain show an increased expression of pain when experiencing high social threat, for both low and high pain catastrophizers. In general, these results do not fit with the communicative pain models, which predict decreased pain expression in the presence of an interpersonal threat. Furthermore, the lack of moderation by pain catastrophizing goes against the hypothesis of the CCM that high pain catastrophizers should be more responsive to the social context.

This lack of any clear support for any of the investigated theoretical models suggests that the mechanism(s) underlying the effects of the interpersonal context on pain are still poorly understood. This is all the more striking since the predictions of the CAM and communicative pain models do fit to some degree with the results of the studies on inflicted pain ${ }^{[8 ; 11]}$. Different mechanisms may be playing a role depending on the exact nature of the interpersonal threat. Instances in which the interpersonal threat is closely related the inflicting or worsening of pain may be better explained by traditional models of pain than instances in which the interpersonal threat is related to the loss of psychosocial integrity.

Overall, the present study found that unjust treatment caused differences in reported pain intensity, (moderated by pain catastrophizing), and increased facial pain expression. The observed patterns run opposite to the studies on intentionally inflicted pain ${ }^{[8 ; 11]}$, suggesting differential effects and mechanisms for diverse forms of injustice. These results lend no clear support to existing theoretical models of pain and pain expression. Further studies on the effects of injustice, and how it is experienced differently by low and high pain catastrophizers are recommended. 


\section{References}

[1] Bernstein MJ, Claypool HM. Social Exclusion and Pain Sensitivity: Why Exclusion Sometimes Hurts and Sometimes Numbs. Psychological Bulletin 2011:1 - 12.

[2] Brown JL, Sheffield S, Leary MR, Robinson ME. Social support and experimental pain. Psychosomatic Medicine 2003;65:276-283.

[3] Chambers CT, Cassidy KL, McGrath PJ, Gilbert CA, Craig KD. Child Facial Coding System

[4] Chen ACN, Dworkin SF, Haug J, Gehrig J. Human responsivity in a tonic pain model: psychological determinants. Pain 1989;37(2):143-160.

[5] DeWall CN, Baumeister RF. Alone but feeling no pain: Effects of social exclusion on physical pain tolerance and pain threshold, affective forecasting and interpersonal empathy. Journal of Personality and Social Psychology 2006;91(1):1 - 15 .

[6] Eisenberger NI, Lieberman MD, Williams KD. Does rejection hurt? An fMRI study of social exclusion. Science 2003;302:290 - 292.

[7] Ekman P, Friesen W. Investigator's guide to the Facial Action Coding System. Palo Alto, CA: Consulting Psychologists Press, 1978.

[8] Gray K, Wegner DM. The sting of intentional pain. Psychological Science 2008;19(12):1260-1262.

[9] Jackson T, Pope L, Nagasaka T, Fritch A, Iezzi T, Chen H. The impact of threatening information about pain on coping and pain tolerance. British Journal of Health Psychology 2005; 10:441-451.

[10] Miller DT. Disrespect and the experience of injustice. 2001;52(Annual Review of Psychology):527-553.

[11] Peeters PAM, Vlaeyen JWS. Feeling more pain, yet showing less: The influence of social threat on pain. Journal of Pain 2011.

[12] Schmitt MJ, Neumann R, Montada L. Dispositional Sensitivity to Befallen Injustice. Social Justice Research, Vol 8, No 4, 1995 1995;8(4):385-407.

[13] Severeijns R, Vlaeyen JWS, van den Hout MA. Do we need a communal coping model of pain catastrophizing? An alternative explanation. Pain 2004;111(3):226-229.

[14] Sullivan MJL, Adams H, Horan S, Maher D, Boland D, Gross R. The Role of Perceived Injustice in the Experience of Chronic Pain and Disability: Scale Development and Validation. Journal Occupational Rehabilitation 2008; 18(3):249-261.

[15] Sullivan MJL, Adams H, Sullivan ME. Communicative dimensions of pain catastrophizing: social cueing effects on pain behaviour and coping. Pain 2004; 107:220-226.

[16] Sullivan MJL, Martel MO, Tripp D, Savard A, Crombez G. The relation between catastrophizing and the communication of pain experience. Pain 2006;122:282-288.

[17] Sullivan MJL, Thorn B, Haythornthwaite JA, Keefe F, Martin M, Bradley LA, Lefebvre JC. Theoretical perspectives on the relation between catastrophizing and pain. The Clinical Journal of Pain 2001;17:52-64. 
[18] Van Damme S, Crombez G, Bijttebier P, Goubert L, Van Houdenhove B. A confirmatory factor analysis of the Pain Catastrophizing Scale: Invariant factor structure across clinical and non-clinical populations.

Pain 2002;96(3):319-324.

[19] Van Damme S, Crombez G, Vlaeyen JWS, Goubert L, Van den Broeck A, Van Houdenhove B. De Pain Catastrophizing Scale: psychometrische karakteristieken en normering. Gedragstherapie 2000;3:211-222.

[20] Vlaeyen JWS, Hanssen MMP, Dautzenberg A, Peters ML, Goubert L, Sullivan ML, Morley S. Threat of pain influences social context effects on verbal pain report and facial expression. Behaviour Research and Therapy 2009;47(9):774-782.

[21] Watson D, Clark LA, Tellegen A. Development and validation of brief measures of Positive and Negative Affect: The PANAS Scales. Journal of Personality and Social Psychology 1988;54:1063-1070.

[22] Williams ACdC. Facial expression of pain: An evolutionary account. Behavioral and Brain Sciences 2002;25:439-488.

[23] Williams KD. Ostracism: The power of silence. New York: Guilford Press., 2001.

[24] Williams KD. Chapter 6 Ostracism: A Temporal Need Threat Model. Advances in Experimental Social Psychology 2009;41:275-314. 
THE IMPACT OF A SOCIAL THREAT TO PSYCHOSOCIAL INTEGRITY ON

REPORTED PAIN INTENSITY AND FACIAL PAIN EXPRESSION 
8 


\section{General Discussion}


While threat and fear have received a lot of attention in pain research, the focus has mainly been on intrapersonal threat of pain and its relation to catastrophic interpretations of pain ${ }^{[32]}$, attention and hypervigilance ${ }^{[5]}$, fear avoidance ${ }^{[4,20,40]}$ and motivation ${ }^{[4,36]}$. Overall it appears that as the threat of pain increases, so does its experience become more aversive [15], and safety behaviour more elaborate ${ }^{[33]}$. Whether a similar principle applies to interpersonal threat, rather than intrapersonal threat, remains largely unclear.

Increasing evidence from social and health psychology suggests that social threats can indeed have a severe impact on our physical and

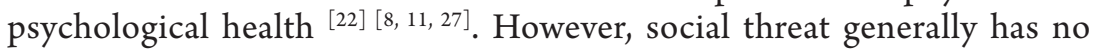
place in the existing models of pain. Most research on social influences on pain have focused on the communication of pain from the sufferer to an observer/assessor ${ }^{[12,13,24]}$, with relatively little research having been conducted on how behaviour of others can influence the pain experience and behaviour of the sufferer. Aside from studies on negative spouse interactions of chronic pain patients ${ }^{[21]}$, no systematic effort has been made to investigate the influence of social threats on pain and possible underlying mechanisms. Information on social threat influences on pain experience and expression would further our insights in how interacting with chronic pain patients affects their pain experience and expression

The present dissertation aimed to offer the start for a systematic investigation of social threat influences on pain experience and expression. The review and studies in this dissertation focused on the effects of social threats to both physical and psychological integrity on reported pain intensity and facial pain expression. Furthermore it was investigated whether social threat affects people differently depending on their level of pain catastrophizing and whether social threat is taken into account when judging the pain of others.

To structure the discussion of this dissertation it has been divided in several subheadings. First a summary will be presented about the most important findings of each of the studies described in the previous chapters and how these relate to each other. We subsequently discuss the most important limitations that were encountered in and across studies, before moving on to the implications of the findings from both a theoretical and practical/clinical standpoint. The discussion ends with a number of conclusions.

\section{Summary of the findings}

This dissertation started with an introduction (Ch1) and topical review (Ch2) that identified a lack of systematic research on how threats originating from the social context impact pain experience and expression. To lend structure to the interpretation of existing findings on social threat and future investigations, a theoretical distinction of four social threat subtypes was suggested. These distinctions are based on the target and the 
nature of the social threat. The target refers to whether the social threat is aimed at physical or psychosocial integrity, whereas the nature refers to whether the social threat implies direct or indirect harm to integrity. Based on these subtypes several existing findings were discussed in the context of models that appear to be promising to social threat research. Due to time constraints the studies in this dissertation only focused on direct forms of social threat. The relevant models identified for each subtype were taken into account in these studies.

Rather than focusing on the effect of social threat on pain experience and expression, the first two experimental studies described in this thesis dealt with more methodological questions regarding factors influencing social context effects on reported pain intensity and facial pain expression. The first of these studies focused on the influence of observer control (Ch3), investigating whether the effects of the presence of an observer on pain experience and pain expression were amplified by the observer having control over the pain stimulus. The second study investigated whether reported pain intensity and facial pain expression were influenced by the possibility to effectively communicate pain verbally, visually or both (Ch4). By varying both communication options it was also possible to investigate whether one form of pain communication would be favoured over the other when both are available.

Both of these studies yielded no significant effects for condition, implying that in these studies there were no influences of observer control or available communication options on reported pain intensity or facial pain expression. Whether these factors truly have no influence on pain measures is hard to establish, as no statistical tests exist to confirm equality of two conditions. To make a credible claim about equality, a manifold larger sample would have been necessary, to the point of practical impossibility ${ }^{[25]}$. Rather, the lack of an effect in these studies suggest that any possible effects of these factors are so small that they do not significantly influence these specific pain measures given the used sample size. As the pain outcome measures and sample sizes of these studies match the other studies in this dissertation, this suggests that it was not necessary to take these factors into account in the design of these studies.

The other three experimental studies described in this dissertation focus more specifically on social threat. The first of these studies investigated the influence of a direct social threat to physical integrity on reported pain intensity and facial pain expression (Ch5). The experience of social threat was found to influence reported pain intensity and facial expression in opposite manners. While increasing the pain report of high pain catastrophizers, it was associated with a decrease in facial pain expression of all participants. This finding is unique in that it demonstrates a dissociation between report of pain and the non-verbal expression of pain in the same individuals at one single instance.

This dissociation matches with the findings of the following study, which investigated the influence of social threats on estimating pain experience and expression of others (Ch6). In this vignette study, descriptions of 
more threatening social contexts led to higher pain experience estimates and lower pain expression estimates compared to neutral or positive social context descriptions. This suggests that the dissociation observed in the previous study is apparently taken into account when judging the pain of others.

The final experimental study focused on the effect of a direct social threat to psychosocial integrity on reported pain intensity and facial pain expression ( $\mathrm{Ch} 7$ ). This study yielded remarkably different findings than the previous experiments. High social threat was associated with higher pain reports for low pain catastrophizers. However, high pain catastrophizers displayed a reversed pattern, with higher pain reports when experiencing low social threat. Furthermore, high social threat was associated with increased facial pain expression, rather than decreased facial pain expression as in the other studies. This suggests that social threats to physical and to psychosocial integrity may impact pain through altogether different mechanisms.

\section{Limitations}

While most limitations are study specific and are described in the discussion sections of the respective chapters, some limitations warrant attention in the discussion of this whole dissertation. This is mostly because they proved to be problematic across multiple studies and can in some cases be considered a finding in and by itself, although not necessarily of the same empirical quality.

The main problem that was encountered across the studies in which the social context was manipulated in a laboratory, is that there appears to be a fine balance between the effectiveness of a social context manipulation and its credibility to the participants. In several pilot studies on social context manipulations that were not included in this dissertation, one of both factors disqualified the specific manipulation for use in a study. More so than other social context manipulations perhaps, participants appear to be very sensitive to social threat manipulations. Many participants quickly suspect manipulation when a clear social threat is presented in a laboratory setting. This can also be seen in the study described in chapter 5 , where $16 \%$ of the original sample had to be excluded because they were suspicious about the confederate's role.

To make the social threat manipulation more credible, it appears it has to be toned down somewhat as to provide a social threat that does not raise suspicion in a research setting. However, while pilot studies in which this was attempted were largely successful at lowering dropout rates due to suspicion, it appears that the more credible social threat was also no longer potent enough to yield measurable effects on reported pain intensity and expression. Therefore a balance has to be struck between both, to develop an effective social threat manipulation that is credible to a majority of the participants. 
Even in the studies described in chapter 5 and 7, where an acceptable balance between both appears to have been managed, the social context manipulation yielded some difficulties. The study on a direct social threat to physical integrity initially included a third neutral condition, which was intended to serve as a contrast to the more threatening and safe contexts. However, rather than resulting in a neutral context, the lack of social information provided by the social context manipulation appears to have led to participants using other, unintended clues to asses the social context. This is supported by the much larger spread on the scores on the social threat manipulation check in the neutral condition than in the threatening and safe condition, with experienced social threat scores overlapping with both the threatening and safe condition.

Excluding the neutral condition altogether would result in a too small sample size for analyses, so an alternative approach was chosen. By using the experienced social threat scores as independent variable, rather than the conditions, the effect of the experienced social threat on reported pain intensity and facial pain expression could be investigated. Technically, the study no longer used an experimental design, as observed scores are used rather than predefined conditions. Although this means that an observational design was employed, the finding that the standardized beta of a comparison between the threatening and safe conditions matched the beta of the experienced social threat scale supports the notion that the in the analysis based on an observational design was similar to the one in an experimental design.

Even though in the end there was a statistically acceptable solution to analyze the findings of this study, the problems with the neutral condition again demonstrated one of the difficulties of social context manipulations. While some information provided by the social context manipulation may appear to be clear, it can still be interpreted differently amongst participants. It appears that this tendency by personal interpretation is amplified by ambiguity, providing yet another factor to take into account when constructing a social context manipulation.

A similar, but harder to solve problem with participants' interpretations appears to have occurred in the study on a direct threat to psychosocial integrity. Whereas the experimenter in that study clearly favoured one participant over the other to create a social context that is threatening to one participant and safe to the other, this did not appear to reflect the way participants experienced the manipulation. Witnessing the experimenter treating the other participant unjustly, apparently led the favoured participants to conclude that while the experimenter may behave nicely to themselves, he is in fact not a pleasant person. This was reflected in the lack of a significant difference in experienced social threat scores between conditions.

Although compared to other studies only one extra participant was present, this already made the social context so complex that it is was hard to direct what each individual actually experienced. Participants did not only experience the behaviour of the observer towards themselves, but also 
the behaviour of the observer towards others and the behaviour of these others as well. Even though such complex social situations probably have a higher ecological validity, the investigation of social threat effects and their underlying mechanisms in the laboratory are likely to be better served by first expanding the investigation of social treat in one-on-one interaction before expanding to more complex social situations. Additionally, studies on social threat effects are likely to be better conducted using betweensubjects designs, in which there is more control over each participant's experiences.

As in the previous study, the decision was made to use the experienced social threat scores as an alternative independent variable to the conditions. However, with no analyses based on conditions as a reference for the effect sizes such as in the previous study, this means that the analyses in this observational design cannot be validated against experimental conditions. It should therefore be taken into account that it is unclear what exactly drove the experienced social threat.

Summing up the use of social threat manipulations in a laboratory setting seem to be complicated by limited effectiveness and/or credibility, and ambiguity, even more so when multiple participants are involved in one session. The latter can be relatively easily solved by focusing on oneon-one interactions and strictly using between-subjects designs. The other factors are however less simple to take into account, and seem to rely on a fragile balance. Alternatively to trying to balance out these factors in a highly controlled social context manipulation in the laboratory, it may be a more promising approach to use more ecologically valid manipulations that build in part on previous experiences of the participants. This would mean relinquishing some experimental control to create a more naturalistic setting, which is likely to lead to much more credible, less ambiguous, and more effective social context manipulations as it mimics situations that participants actually experience in daily life. This had the added advantage of generating results that are more generalizable to everyday situations.

An example of such a manipulation could be to expose high school-aged adolescents to a protocolized form of (cyber)bullying, such as excluding them from social interaction. This manipulation is likely to become more powerful if conducted with adolescents with a history of being bullied, at the cost of a fully randomized design. Furthermore, being excluded from social interaction by peers rather than strangers is also likely to be more effective, though at the cost of some experimental control as each participant will not be excluded by exactly the same persons.

More ecologically valid social threat paradigms like the one described are likely to raise ethical concerns. Due to the very nature of social threat its' investigation will always take place near the limit of what is ethically acceptable. However, under the assumption that increased knowledge on social threat processes may help the development of programs to reduce the occurrence of social threat in some settings, or programs to help people to better deal with social threats, research on the topic should not be abandoned. A continuing discussion on the ethics of social threat research 
should take place with ethical comities, other researchers and relevant stakeholders such as anti-bullying organizations, in order to ensure that no ethical lines are crossed while making progress in social threat research.

\section{Implications: Theoretical models}

Regardless of the mentioned limitations, the studies described in this dissertation have several implications. Most of these implications concern the validity of predictions based on the pain models described in chapter two. Additional implications on the basis of these findings will be discussed in the next paragraph. As outlined in Chapter 2, several pain models make predictions about how social threat should impact pain. Since not all suggested subtypes of social threat were investigated in this dissertation, only those models shall be discussed that are assumed to be related to the social threat subtypes that were investigated.

\section{Cognitive Appraisal Model}

The cognitive appraisal model of pain (CAM) is a theory that was formulated as a possible explanation for the relation between pain catastrophizing and pain ${ }^{[16,34]}$. The CAM is based on the work of Lazarus and Folkman ${ }^{[19]}$, distinguishing between primary and secondary appraisal. It states that information and beliefs about pain influence the appraisal of the threat value of pain, thereby determining for a large part how intensely the pain is experienced and dealt with.

Originally, the CAM was constructed to better understand the influences of cognitive, mostly intrapersonal, factors on pain ${ }^{[28]}$. However, more recently the CAM has also been used to explain more social contexts effects on pain. Vlaeyen et al. ${ }^{[14]}$ found that the presence of a neutral observer during a painful task lead to decreased pain ratings and facial pain expression compared to an alone condition. This relation was found to be mediated by the experienced threat value of the pain. The authors explained this by means of the CAM, suggesting that the presence of others can serve as safety information, thereby decreasing the threatening appraisals of pain.

In Chapter 2 of this dissertation it was argued that this same argumentation should also be applicable to social threat. If social safety signals reduce the threatening appraisal of pain, thereby reducing its intensity, following the same logic social threat signals should increase the threatening appraisal of pain, and thereby increase its intensity. This hypothesis was specifically investigated in Chapter 5. The CAM was also investigated in the study on a direct threat to psychosocial integrity (Ch7).

Overall the findings of these studies lend no support to the CAM. Even though in some cases social threat was associated with an increase in reported pain intensity as predicted by the CAM, the crucial mediation by the experienced threat value of the pain found by Vlaeyen et al. [39] could not be replicated. The same failure to replicate applies to the study 
described in Chapter 3, on the influence of observer control. As in the study by Vlaeyen et al. ${ }^{[39]}$ this study focused on safety rather than threat information. Also in this study the social context condition was not found to influence the experienced threat value of the pain.

It appears that the CAM does not apply to social threats as operationalized in the studies in this dissertation. It is possible that for a social threat to affect the appraised threat value of the pain as proposed by the CAM, it needs to provide information about the pain stimulus itself, rather than the context in which it is experienced. Even in the study on a direct social threat to physical integrity, the threat was mostly in the number of pain stimuli administered rather than in the nature of the pain stimulus itself. Therefore it is possible that the CAM still applies in situations that provide or implicate information more related to the pain stimulus itself. An example of such a situation could be to have participants complete a pain task in the presence of a (passive) observer that is explained to be a medical doctor to the participants in one condition. Especially to those fearful of pain this could signal that the procedure is not entirely safe, thereby increasing the threat value of the pain.

While the CAM may still apply to some specific cases of social threat, it does not appear to hold for the forms of social threat investigated in this thesis. This implies that for a majority of the forms of social threat, it is unlikely to be of much predictive value. The more a social threat targets psychosocial integrity rather than physical integrity, the less likely the CAM is to be applicable for that situation. As the other models that are discussed below mostly deal with pain expression rather than experience, this means that as of yet there is no model that accurately predicts the effects of social threat on pain experience.

\section{Evolutionary theory of pain expression}

In a seminal paper on the evolutionary basis of pain expression, Williams ${ }^{[42]}$ made a strong point for evolved propensities in especially facial pain expression. According to this evolutionary model, facial pain expression serves to inform close others that one is in pain, to enable these others to lend help. Facial pain expression is assumed to be a largely automatic response to pain that can be suppressed when the need to do so arises. While suppression of facial pain expression takes effort, there are situations where this cost in effort is lower than the potential hazards of expressing pain. In the presence of antagonists that are likely to abuse the weakness of the individual in pain, facial pain expression is expected to be suppressed.

The findings of the studies in this dissertation are mixed with regard to the evolutionary model. The findings of the study on a direct social threat to physical integrity (Ch5) seem to support this hypothesis. In this study, social threat was associated with a decrease in facial pain expression. However, the study on a direct social threat to psychosocial integrity found an association between social threat and increased facial pain expression. Due to the limitations of the latter study, it is possible that the facial pain expression in this study was confounded by other, unknown factors as 
well. Additionally, a study conducted by Vervoort et al. ${ }^{[38]}$ demonstrated suppression of pain expression for low pain catastrophizing children in the presence of a stranger. The overall evidence therefore rules slightly in favour of the evolutionary model of pain expression.

It is also interesting to note that the vignette study in Chapter 6 found evidence, albeit indirectly, for people taking into account a decrease in facial pain expression in social threatening contexts. It appears that to some degree people are aware of the evolved propensity to suppress pain in the presence of antagonists. Whether this is explicit knowledge that can be applied or more implicit knowledge that is itself an evolutionary product remains unclear. In the case of more implicit tendencies to take social threats into account when assessing pain, explicitly informing people about social threat effects may further improve the quality of pain assessment.

\section{Communal coping model}

A communal coping model of pain catastrophizing (CCM) was formalized in a review article by Sullivan et al. ${ }^{[32]}$. The CCM suggests that catastrophizing itself may serve as a coping style, in which the pain sufferer exaggerates pain behaviour to solicit support from others. It is therefore to be expected that people who catastrophize about pain should be (more) reactive to different social contexts.

This is supported by studies that imply that people who catastrophize about pain may react to pain in a qualitatively different way, depending on the social context ${ }^{[29,31]}$. To investigate this hypothesis, most studies in this dissertation included pain catastrophizing as a potential moderator of pain experience and facial pain expression.

Overall the results of the studies do not support the main hypothesis of the CCM. In none of the studies pain catastrophizing was found to be a moderator for social threat effects on pain expression. While some main effects show that high pain catastrophizers display more facial pain expression overall, the lack of interaction with the social context conditions does not support the notion of a qualitatively different reaction to pain depending on the social context. Rather, pain catastrophizing appears to be associated with a 'quantitatively bigger' reaction to pain, that acts independently, on top of the social context mechanisms.

The finding that pain catastrophizing does not seem to drive a social coping mechanism is supported by several other recent studies. In the study by Vlaeyen et al. ${ }^{[14]}$, pain catastrophizing was associated with higher facial pain expression, but did not serve as a moderator of social context effects. In two different studies in children, Vervoort ${ }^{[37,38]}$ even found the high pain catastrophizing children to be less sensitive to the specific interpersonal context than low pain catastrophizing children. In these studies high pain catastrophizing was associated with higher facial pain expression overall, regardless of the social context, whereas low catastrophizing children showed more pain to a parent than to a stranger.

It has been suggested that the increased facial pain expression of high 
pain catastrophizers is in fact driven by a more aversive pain experience resulting from increased pain fears ${ }^{[28]}$. In support of this hypothesis, Kunz, Chatelle, Lautenbacher, and Rainville ${ }^{[17]}$ found that facial pain expression does not differ between low and high pain catastrophizers when a controlled pain stimulus is individually calibrated to be equally painful for all recipients. Although with a different purpose in mind, in the study presented in this dissertation that used electric stimuli ( $\mathrm{Ch} 5$ ) the pain intensity was also calibrated to a standard value. It is interesting to note that also in this study no interaction or main effects were found of pain catastrophizing on facial pain expression. While no relation between pain catastrophizing and electrical stimulus intensity could be demonstrated, this is likely due to the overall large variance in electrical stimulus intensity making it hard to reach statistical significance given the sample size. These findings do suggest that differences in pain between low and high pain catastrophizers are caused by differences in experiencing the pain stimulus rather than differences in reactions to the social context.

Additional to the lack of empirical evidence for the CCM's predictions, the model also appears to feed a conceptual unclarity on the nature of pain catastrophizing. By framing pain catastrophizing itself as a coping style, it implies that pain catastrophizing is the exaggeration of pain behaviour. However, in other models pain catastrophizing is generally viewed as a more cognitive/emotional construct. This conceptualization seems to fit better with the instruments that are used to measure pain catastrophizing $[26,30]$. Items on these questionnaires usually reflect thoughts and emotions in reaction to pain. While this conceptualization of pain catastrophizing does not reject the possibility of pain catastrophizing affecting coping, it does not equate it to coping. Doing so runs the risk of misinterpreting high scores on instruments measuring pain catastrophizing as indicative of an individual using pain expression instrumentally, simply trying to solicit support.

In sum, aside from a couple of studies, the majority of studies investigating pain catastrophizing as a moderator of social context effects on facial pain expression fail to support to the CCM, occasionally yielding even directly opposing findings. Additionally, the current framing of the CCM appears to be confusing at best, or else conceptually disruptive. Both points raise serious doubts about the usefulness of the CCM.

\section{Future models incorporating social threat effects on pain}

The finding that most existing pain models at best only partially explain social threat effects on pain and do not appear to apply to a majority of the forms of social threat that can be conceived, begs for alternative theories and models. Several promising theories and models can be identified in the existing literature in other fields of research as was outlined in the review (Ch2). These will likely have to be adapted to some degree when applied to social threat effects on pain.

The need-threat model from the social exclusion, rejection and ostracism research ${ }^{[43,44]}$ is one of these models that with minimal changes 
could be applied to social threat in the context of pain. The need-threat model distinguishes between three phases in the consequences of social exclusion. First is the immediate/reflexive phase in which four fundamental needs are threatened by the exclusion; belongingness, control, self-esteem, and meaningful existence. This has a negative impact on the individual, regardless of the exact nature of the exclusion and the context in which it occurs. Then follows the coping/reflective phase in which the individual attempts to compensate for the threat to their needs either by trying to get socially included again or find other sources for their needs. If coping attempts are unsuccessful and social exclusion goes into the long-term/ resignation phase, coping resources become depleted and individuals start feeling depressed, unworthy and hopeless.

While there is some evidence relating social exclusion to pain ${ }^{[6][2][7]}$, it would be even more interesting to take this research a bit further and relate not only pain experience, but also pain expression to the various stages of the need-threat model. Applying the reasoning of the need-threat model to pain, it could be predicted that in the initial phase of social exclusion pain sensitivity would be increased, mediated by the experienced threats to the basic needs of belonging, self esteem, control and a meaningful existence. On the long term, unsuccessful coping with pain would lead to a resignation phase in which depleted coping resources and depressive feelings further impact on pain experience and expression. This is especially salient in the context of chronic pain where individuals continually need to cope with pain, and are therefore much more likely to reach the resignation phase.

The need-threat model, but also other empirical studies outlined in the review (Ch2) all stress the importance of considering social threat from a motivational perspective ${ }^{[36]}$. Socials threats are only one of the problems that people suffering from pain have to deal with in their attempts to lead a valued life, which itself constitutes something different for each individual. To more fully understand the influence of social threat on pain experience, it is necessary to understand which kinds of goals and behaviours it motivates and with which others goals and behaviours it competes. In many cases chronic pain patients are likely to experience a conflict between dealing with a social threat, such as disproving stigmatization, and dealing with pain, such as stopping with work before overstraining occurs. These conflicts themselves are likely to be stressful and may in themselves serve as a burden of disease. Additional to goal conflicts, from a motivational perspective it can also be investigated to which degree stereotype threats ${ }^{[18]}$ and loss of control ${ }^{[1,3]}$ play a role in social threat effects on pain.

\section{Implications: Practical/Clinical}

Aside from what can be learned about the theoretical models of pain, there are some more practical implications based on this dissertation as well. These concern research as well as clinical practice. The most important shall be discussed below. 


\section{Dissociation between pain experience and expression}

One of the most interesting findings across the studies described in this dissertation is that on multiple occasions a dissociation was found between reported pain intensity and facial pain expression (or their estimates), driven by social threat. Although it is known that verbal and non-verbal indices of pain generally correlate only moderately, to the knowledge of the author the presented studies are the first to demonstrate manipulations that yield opposite effects for indices of pain experience and expression.

On a theoretical level, this implies that the mechanisms underlying pain experience and non-verbal pain expression may be even more separate than was assumed up till now. The demonstration of a dissociation between measures of pain experience and expression stresses the need for using multiple indices of pain in pain research as well as clinical practice. To determine under which circumstances measures of pain experience and expression correlate well or poorly, more research into the underlying mechanisms is necessary.

From a more practical viewpoint, a dissociation between pain experience and expression implies that observations of pain behaviour are an even poorer indication of experienced pain than previously assumed. Pain assessment is often based largely on observations of non-verbal pain expressions ${ }^{[12]}$. While education about the possible dissociation between experience and expression could decrease the reliance on non-verbal expression, this is not possible for all groups. Pain assessment for groups that have difficulties of communicating pain verbally, such as children and people with a cognitive impairment, by necessity relies on behavioural observations. To ensure reliable pain assessment in these cases, care has to be taken to create a social context in which the individual that is being assessed feels comfortable, so as to ensure that pain expressions are not being suppressed.

\section{Social threat in practice}

Unfortunately, several forms of social threat commonly occur in everyday life to varying degrees. Bullying is common amongst elementary school children ${ }^{[9,35,41]}$, but also prevalent amongst working adults ${ }^{[23]}$. Similarly, minority groups often experience discrimination on the basis of their minority status ${ }^{[10]}$. While a number of observational studies have already demonstrated associations between these forms of social threat and pain or more generally health problems, the studies in the present dissertation suggest that each instance of bullying or discrimination can already have a short-term impact on pain.

Additionally, the found dissociation between pain report and facial pain expression suggests that communication of increased pain resulting from these forms of social threat may be (in part) suppressed. This fits with the finding that children often do not communicate about being bullied [9], making it difficult for parents and teachers to recognize the problem. The problems resulting from bullying are often only identified after the school 
results and social life of the bullied child have suffered noticeably.

It is very well possible that a dissociation between experienced and expressed pain cause a similar process to take place in the relation between bullying/discrimination and health problems. The pain complaints associated with these forms of social threat could be the result of longterm sensitization to pain caused by the repeated short-term sensitization to pain. These short-term sensitizations are however unlikely to be communicated by the individual until the point where the pain complaints have become too problematic to not seek help or be noticed by others. This threshold for seeking help is therefore expected to be higher.

Additional research would be necessary to confirm the hypotheses outlined above. Observational studies on reported pain thresholds for seeking help for bullied children and discriminated individuals complemented with experimental studies on the underlying mechanisms of increased pain experience and decreased communication could help to determine to which degree such processes apply to the relation between social threat and pain in everyday life.

\section{Social threat research}

As was shown in the topical review in Chapter 2, there is a large gap of knowledge concerning social threat effects on pain. Due to time constraints, this dissertation has focused only on the direct forms of social threat, leaving out the indirect forms of social threat. Even so, this dissertation should be viewed as an exploratory attempt to investigate social threat effects on pain.

The topical review demonstrates that a distinction between various forms of social threat can be made and that various models from pain research, but also from other fields, may be useful at predicting the impact of social threats on pain. The applicability of social threat manipulations in the laboratory is confirmed in the experimental studies. The studies in Chapter 3 and 4 rule out two possible confounders. The experimental studies in Chapter 5 and 7 demonstrate that, in spite of the difficulties with social threat manipulations as outlined under the limitations, interesting information can be gleaned from these designs. The next step should be to apply a similar methodology to investigate the effects of indirect social threat and make direct comparisons between various forms of social threat. In addition, the limitations of the studies suggest that it is valuable to extend the research on social threat effects to more ecologically valid, albeit less controllable situations. These could investigate the suggested situations in the previous paragraph, such as the influences of bullying, discrimination and social threat during painful medical procedures. The combination of both laboratory and field experiments could both broaden en deepen the knowledge about social threat effects on pain and the possible underlying mechanisms. 


\section{Conclusions}

In sum, the present dissertation outlined a number of exploratory experiments on the relation between social threat and pain. Regardless of difficulties with creating credible and effective social threat manipulations, the studies yielded interesting results. The most prominent finding is that social threat seems to drive a dissociation between reported pain intensity and facial pain expression. None of the existing models of pain seem to offer a suitable explanation for this dissociation. Alternative theories and models from other fields of research may prove to be more successful at explained social threat effects on pain. Future research should first focus on replicating the dissociation between reported pain intensity and facial pain expression. Social threat manipulations have proven to be difficult, the use of more ecologically valid designs is advised to tackle the believability/effectiveness problem and additionally to close the gap between laboratory studies and (clinical) practice. 


\section{References}

[1] Arntz, A, Schmidt, AJM. Perceived control and the experience of pain. In A Steptoe and A Appels. Stress, personal control and health.

Chichester:Wiley, 1989. pp. 131-162

[2] Bernstein, MJ, Claypool, HM. Social Exclusion and Pain Sensitivity:

Why Exclusion Sometimes Hurts and Sometimes Numbs.

Psychological Bulletin. 2011:1-12

[3] Crombez, G, Eccleston, C, De Vlieger, P, van Damme, S, De Clercq, A. Is it better to have controlled and lost than never to have controlled at all? An experimental investigation of control over pain. Pain. 2008; 137:631-639

[4] Crombez, G, Eccleston, C, Van Damme, S, Vlaeyen, JWS, Karoly, P. Fear-avoidance model of chronic pain: The next generation. Clinical Journal of Pain. 2012;28:475-483

[5] Crombez, G, van Damme, S, Eccleston, C. Hypervigilance to pain: an experimental and clinical analysis. Pain. 2005; 116:4-7

[6] DeWall, CN, Baumeister, RF. Alone but feeling no pain: Effects of social exclusion on physical pain tolerance and pain threshold, affective forecasting and interpersonal empathy. Journal of Personality and Social Psychology. 2006;91(1):1 - 15

[7] Eisenberger, NI, Jarcho, JM, Lieberman, MD, Naliboff, BD. An experimental study of shared sensitivity to physical pain and social rejection.

Pain. 2006; 126:132-138

[8] Fekkes, M, Pijpers, FIM, Fredriks, AM, Vogels, T, Verloove-Vanhorick, SP. Do bullied children get ill, or do ill children get bullied? A prospective cohort study on the relationship between bullying and health-related symptoms. Pediatrics. 2006;117(5):1568 - 1574

[9] Fekkes, M, Pijpers, FIM, Verloove-Vanhorick, SP. Bullying: who does what, when and where? Involvement of children, teachers and parents in bullying behavior. Health Education Research. 2005;20(1):81 - 91

[10] Fuller-Rowell, TE, Evans, GW, Ong, AD. Poverty and Health: The Mediating Role of Perceived Discrimination. Psychological Science. 2012:

[11] Gini, G, Pozzoli, T. Association between bullying and psychosomatic problems: a meta-analysis. Pediatrics. 2009;123(3):1059 - 1065

[12] Hadjistavropoulos, T, Craig, KD. A theoretical framework for understanding self-report and observational measures of pain: A communications model. Behaviour Research and Therapy. 2002;20:551-570

[13] Hadjistavropoulos, T, Craig, KD, Duck, S, Cano, A, Goubert, L, et al. A biopsychosocial formulation of pain communication. Psychological Bulletin. 2011;137(6):910-939

[15] Jackson, T, Pope, L, Nagasaka, T, Fritch, A, Iezzi, T, et al. The impact of threatening information about pain on coping and pain tolerance. British Journal of Health Psychology. 2005; 10:441-451

[16] Jensen, MP, al., e. Coping with chronic pain: a critical review of the literature. Pain. 1991;47:249-283 
[17] Kunz, M, Chatelle, C, Lautenbacher, S, Rainville, P.

The relation between catastrophizing and facial responsiveness to pain. Pain. 2008;140(1):127-134

[18] L., SJ. Understanding the Process of Stereotype Threat: A Review of Mediational Variables and New Performance Goal Directions. Educational Psychology Review. 2004;16(3):177-206

[19] Lazarus, RS, Folkman, S. Stress, Appraisal and Coping. New York:Springer, 1984

[20] Leeuw, M, Goossens, MEJB, Linton, SJ, Crombez, G, Boersma, K, et al. The fearavoidance model of musculoskeletal pain: current state of scientific evidence. Behavioural Medicine. 2007;30:77-94

[21] Leonard, MT, Cano, A, Johansen, AB. Chronic pain in a couples context: a review and integration of theoretical models and empirical evidence. Journal of Pain. 2006;7(6):377-390

[22] Miller, GE, Chen, E, Parker, KJ. Psychological stress in childhood and susceptibility to the chronic diseases of aging: moving toward a model of behavioral and biological mechanisms. Psychological Bulletin. 2011;137(6):959-997

[23] Parent-Thirion, A, Fernández Macías, E, Hurley, J, Vermeylen, G. Fourth European Working Conditions Survey. Luxembourg:European Foundation for the Improvement of Living and Working Conditions, 2007

[24] Prkachin, KM, Craig, KD. Expressing pain: The communication and interpretation of facial pain signals. Journal of Nonverbal Behavior. 1995;19(4):191-205

[25] Quertemont, E. How to statistically show the absence of an effect. Psychologica Belgica. 2011;51(2):109-128

[26] Rosenstiel, AK, Keefe, FJ. The use of coping strategies in chronic low back pain patients: relationship to patient characteristics and current adjustment. Pain. 1983; 17:33-44

[27] Saastamoinen, P, Laaksonen, M, Leino-Arjas, P, Lahelma, E. Psychosocial risk factors of pain among employees. European Journal of Pain. 2009; 13(1):102-108

[28] Severeijns, R, Vlaeyen, JWS, van den Hout, MA. Do we need a communal coping model of pain catastrophizing? An alternative explanation.

Pain. 2004;111(3):226-229

[29] Sullivan, MJL, Adams, H, Sullivan, ME. Communicative dimensions of pain catastrophizing: social cueing effects on pain behaviour and coping. Pain. 2004; 107:220-226

[30] Sullivan, MJL, Bishop, S, Pivik, J. The pain catastrophizing scale: development and validation. Psychological Assessment. 1995;7:52-64

[31] Sullivan, MJL, Martel, MO, Tripp, D, Savard, A, Crombez, G. The relation between catastrophizing and the communication of pain experience. Pain. 2006; 122:282-288

[32] Sullivan, MJL, Thorn, B, Haythornthwaite, JA, Keefe, F, Martin, M, et al. Theoretical perspectives on the relation between catastrophizing and pain. The Clinical Journal of Pain. 2001;17:52-64 
[33] Tang, NK, Salkovskis, PM, Poplavskaya, E, Wright, KJ, Hanna, M, et al. Increased use of safety-seeking behaviors in chronic back pain patients with high health anxiety. Behavior Research and Therapy. 2007;45(12):

[34] Thorn, BE, Rich, MA, Boothby, JL. Pain beliefs and coping attempts: conceptual model building. Pain Forum 1999;8:169-171

[35] Undheim, AM, Sund, AM. Prevalence of bullying and aggressive behavior and their relationship to mental health problems among 12- to 15-year-old Norwegian adolescents. Eur Child Adolesc Psychiatry. 2010;19(11):803 - 811

[36] van Damme, S, Crombez, G, Eccleston, C. Coping with pain: A motivational perspective. Pain. 2008;139:1-4

[37] Vervoort, T, Goubert, L, Eccleston, C, Vandenhende, M, Claeys, O, et al. Expressive dimensions of pain catastrophizing: An observational study in adolescents with chronic pain. Pain.In Press, Corrected Proof:

[38] Vervoort, T, Goubert, L, Eccleston, C, Verhoeven, K, De Clercq, A, et al. The effects of parental presence upon the facial expression of pain: The moderating role of child pain catastrophizing. Pain. 2008;138:277-285

[39] Vlaeyen, JWS, Hanssen, MMP, Dautzenberg, A, Peters, ML, Goubert, L, et al. Threat of pain influences social context effects on verbal pain report and facial expression. Behaviour Research and Therapy. 2009;47(9):774-782

[40] Vlaeyen, JWS, Linton, SJ. Fear-avoidance and its consequences in chronic musculoskeletal pain: A state of the art. Pain. 2000;85(3):317-332

[41] Wang, J, Iannotti, RJ, Nansel, TR. School bullying among adolescents in the United States: physical, verbal, relational, and cyber. J Adolesc Health. 2009;45(4):368 - 375

[42] Williams, ACdC. Facial expression of pain: An evolutionary account. Behavioral and Brain Sciences. 2002;25:439-488

[43] Williams, KD. Ostracism: The power of silence. New York: Guilford Press., 2001

[44] Williams, KD. Chapter 6 Ostracism: A Temporal Need Threat Model. Advances in Experimental Social Psychology. 2009;41:275-314 


\section{Summary}


This dissertation presents an exploratory investigation of social threat effects on pain experience and expression and their underlying mechanisms. The main research question of this dissertation is: What is the effect of social threat on pain report and facial expression?

In Chapter 2 a topical review is presented in which different forms of social threat are related to existing models of pain. Four forms of social threat are distinguished on the basis of the target and nature of the social threat. The evidence for an effect of each form of social threat effects on pain are reviewed in the light of the existing models. Suggestions are made for alternative models from other fields of research that may prove useful in investigating and explaining social threat effects on pain.

Chapter 3 presents a study that aimed to investigate the communal coping and social safety cueing hypotheses by examining the roles of observer presence and the threat value of pain. Participants $(\mathrm{N}=92)$ completed a one minute cold pressor task, either alone or in the presence of an observer who explicitly stated to be able to control the painfulness of the cold pressor task when necessary (observer/control condition) or who would not interfere with the task (observer/no control condition). High pain catastrophizers reported more pain than low pain catastrophizers, and independently, participants in the observer conditions reported less pain than those in the alone condition. Contrary to the social safety cueing hypothesis, the effects of observer presence on pain expression were not mediated by perceived threat of pain Further analyses indicated that high pain catastrophizers displayed more facial pain expression than low pain catastrophizers, however no social context effects were found. These results contrast with earlier studies on social context effects on pain and are not adequately explained by the communal coping or social safety cueing hypotheses, stressing the need for more elaborate studies and models of social context effects on pain.

In Chapter 4 a study is presented that investigated the hypothesis that the way pain is expressed depends on which form of pain expression most effectively communicates pain to others in the specific situation. Healthy subjects $(\mathrm{N}=82)$ completed a one minute cold pressor task during which they verbally reported pain intensity. The available communication channels were manipulated by telling the subjects that they could or could not be heard by the experimenter (auditory channel) and could or could not be seen by the experimenter (visual channel). The faces of participants were recorded in all conditions and scored for facial pain expression. In contrast with the hypothesis, the analyses yielded no significant results for the conditions on either reported pain intensity and facial pain expression. These results suggest that the availability of communication channels does not have a (large) influence on the way in which pain is expressed. Implications for communicative models of pain and research on social context effects are discussed.

Chapter 5 presents a study that investigated the effects of social threat to physical integrity on reported pain and facial pain expression. Predictions of a cognitive appraisal model and a communicative perspective on pain 
expression were compared. Participants $(\mathrm{N}=67)$ received five electric pain stimuli administered by a confederate. They were lead to believe that five pain stimuli were the minimum, a fixed amount, or the maximum number of pain stimuli allowed, thereby varying the social threat posed by the confederate. Reported pain and facial pain expression were recorded during the delivery of pain stimuli. Increased perceived social threat lead to an increase of reported pain, specifically for high pain catastrophizing participants, while it lead to a reduction of facial pain expression. This is the first study to demonstrate that a social threat manipulation has opposite effects on reported pain and facial expression, suggesting differences in adaptive function for both forms of pain expression.

In $\underline{\text { Chapter } 6}$ a study is presented that investigated whether social threat effects are also taken into account when assessing pain of others. two vignette studies were conducted in which participants had to estimate the experienced pain intensity and facial pain expression of the lead character. The first study was conducted among students in psychology, health sciences or medicine, and consisted of vignettes that were systematically varied in social context valence and severity of injury. The second study was conducted amongst a much larger and more diverse sample of higher education students and presented less systematic, but in terms of the social threat more ecologically valid vignettes. It was hypothesized in both studies that, mirroring the experiments on social threat, a more negative social context would be associated with increased pain experience estimates but decreased pain expression estimates. The analyses yielded mixed findings, with the first study demonstrating decreased pain expression estimates for social threat contexts as hypothesized, but no significant findings for the pain intensity estimates. For the second study, increased pain intensity estimates were demonstrated for socially threatening contexts, but no significant findings for the pain expression estimates. The results are discussed with regard to the evolutionary perspective and experimental studies on social threat.

The study presented in Chapter 7 focused on another form of social threat, aiming to investigate the influence of experienced injustice on reported pain intensity and facial pain expression. Healthy participants $(\mathrm{N}=62)$ took part in an experiment where they competed in an intelligence quiz for a monetary reward. The experimenter would obviously favour one participant over the other to manipulate the level of injustice experienced by both participants. After the quiz, participants completed a one minute cold pressor task during which they had to report experienced pain intensity and their facial pain expression were videotaped and coded. Since both favoured and disfavoured participants experienced injustice as a result of the manipulation, a questionnaire measure of interpersonal threat was used as independent variable in the analyses. The results on reported pain intensity showed a cross-over pattern, with low interpersonal threat being associated with higher pain reports in high pain catastrophizers. On the other hand, high interpersonal threat was associated with higher pain reports for low pain catastrophizers as 
compared to high pain catastrophizers. High interpersonal threat was also associated with increased facial pain expression for both low and high pain catastrophizers. These results are discussed with regard to the previous studies on social threat and psychological models of pain.

In sum, the present dissertation outlined a number of exploratory experiments on the relation between social threat and pain. Regardless of difficulties with creating credible and effective social threat manipulations, the studies yielded interesting results. The most prominent finding is that social threat seems to drive a dissociation between reported pain intensity and facial pain expression. None of the existing models of pain seem to offer a suitable explanation for this dissociation. Alternative theories and models from other fields of research may prove to be more successful at explained social threat effects on pain. Future research should first focus on replicating the dissociation between reported pain intensity and facial pain expression. Social threat manipulations have proven to be difficult, the use of more ecologically valid designs is advised to tackle the believability/effectiveness problem and additionally to close the gap between laboratory studies and (clinical) practice. 
123 


\section{Samenvatting}


Dit proefschrift presenteert exploratieve studies naar de invloed van sociale dreiging op pijnervaring en pijncommunicatie en de onderliggende mechanismes van deze invloed. De hoofdvraag van dit proefschrift is: Wat is de invloed van sociale dreiging op pijnrapportage en gezichtsexpressies van pijn?

Hoofdstuk 2 bestaat uit een topical review waarin verschillende vormen van sociale dreiging gerelateerd worden aan bestaande pijnmodellen. Onderscheid wordt gemaakt tussen vier vormen van sociale dreiging op basis van het doel en de aard van de sociale dreiging. Het bewijs voor effecten van iedere vorm van sociale dreiging op pijn wordt samengevat in het licht van de bestaande pijnmodellen. Alternatieve modellen uit andere onderzoeksvelden worden aangedragen als mogelijk bruikbare modellen voor het onderzoeken en verklaren van sociale dreiging effecten op pijn.

In Hoofdstuk 3 wordt een studie beschreven dat als doel had het communal coping model en de social safety cueing hypothese te onderzoeken aan de hand van de aanwezigheid van observanten en de dreigwaarde van de pijn. Deelnemers $(\mathrm{N}=92)$ namen deel aan een één minuut durende koudwatertaak. Zij deden dit alleen of in het bijzijn van een observant die of duidelijk maakte dat hij de pijnlijkheid van de taak zo nodig aan kon passen (observant/controle), of duidelijk maakte dat hij geen invloed had op het beloop van de taak (observant/geen controle). Hoog pijncatastroferende deelnemers rapporteerden meer pijn dan laag pijncatastroferende deelnemers. Onafhankelijk hiervan rapporteerden deelnemers in de observant condities minder pijn dan in de alleen conditie. Tegen de verwachtingen van de social safety cueing hypothese in werd de invloed van de observant niet gemedieerd door de dreigwaarde van de pijn. Verdere analyse wees uit dat hoog pijncatastroferende deelnemers meer gezichtsexpressie van pijn vertoonden dan laag pijncatastroferende deelnemers. Er werd geen effect van de sociale context gevonden op de gezichtsexpressie van pijn. Deze resultaten staan in contrast tot eerdere studies naar sociale context effecten op pijn en kunnen niet adequaat verklaard worden door het communal coping model of de social safety cueing hypothese. Dit benadrukt de noodzaak voor meer uitgebreide modellen van en studies naar sociale context effecten op pijn.

In Hoofdstuk 4 wordt een onderzoek gepresenteerd dat de hypothese onderzocht dat de wijze waarop pijn wordt geuit afhangt van welke vorm van pijnuitdrukking het meest effectief pijn communiceert naar anderen in die specifieke situatie. Gezonde proefpersonen $(\mathrm{N}=82)$ voltooiden een één minuut durende koudwatertaak waarbij zij mondeling de pijnintensiteit rapporteerden. De beschikbare communicatiekanalen werden gemanipuleerd door de deelnemers te vertellen dat ze wel of niet door de onderzoeker werden gehoord (auditieve kanaal) en wel of niet door de onderzoeker werden gezien (visuele kanaal). De gezichten van de deelnemers werden in alle omstandigheden opgenomen en gescoord op gezichtsexpressies van pijn. In tegenstelling tot de hypothese leverde de analyses geen significante resultaten voor de condities op gerapporteerde pijnintensiteit nog op gezichtsexpressie van pijn. Deze resultaten 
suggereren dat de beschikbaarheid van communicatiekanalen geen (grote) invloed heeft op de wijze waarop pijn geuit wordt. Implicaties voor communicatieve modellen van pijn en onderzoek naar sociale context effecten worden besproken.

Hoofdstuk 5 presenteert een studie die de effecten van een sociale dreiging voor de fysieke integriteit op de gerapporteerde pijn en gezichtsexpressie van pijn onderzocht. Voorspellingen van een cognitive appraisal model en een communicatief perspectief op pijnuitdrukking werden vergeleken. Deelnemers $(\mathrm{N}=67)$ kregen vijf elektrische pijnprikkels toegediend door een medewerker van het onderzoek die aan hen gepresenteerd was als een andere deelnemer. Ze werden verteld dat vijf pijnprikkels het minimum, een vastgesteld, of het maximale aantal pijnprikkels was dat werd toegestaan, waardoor de sociale dreiging die uitging van de medewerker werd gevarieerd. Gerapporteerde pijn en gezichtsexpressie van pijn werden opgenomen tijdens de toediening van pijnprikkels. Verhoogde ervaren sociale dreiging leidde tot een toename van de gerapporteerde pijn, specifiek voor hoog pijncatastroferende deelnemers, terwijl het leidde tot een vermindering van gezichtsexpressie van pijn. Dit is de eerste studie waarin werd aangetoond dat een sociale dreiging manipulatie het tegenovergestelde effect heeft op gerapporteerde pijn en gezichtsexpressie van pijn, wat suggereert dat beide vormen van pijn expressie verschillen in hun adaptieve functie.

In Hoofdstuk 6 wordt een studie gepresenteerd die onderzocht of met sociale dreigingeffecten rekening wordt gehouden bij het beoordelen van andermans pijn. Twee vignet studies werden uitgevoerd waarbij de deelnemers de ervaren pijnintensiteit en gezichtsexpressie van pijn moesten schatten van het hoofdpersonage. De eerste studie werd uitgevoerd onder psychologie-, gezondheidswetenschappen- en geneeskundestudenten, en bestond uit vignetten waarin de sociale context valentie en de ernst van het letsel systematisch werden gevarieerd. De tweede studie werd uitgevoerd bij een veel grotere en meer diverse steekproef van studenten in het hoger onderwijs en met minder systematische, maar in termen van de sociale dreiging meer ecologisch valide, vignetten. De hypothese was dat in beide studies, net als in de experimenten naar sociale dreiging, een meer negatieve sociale context zou worden geassocieerd met een verhoogde schatting van pijnbeleving, maar een lagere schatting van gezichtsexpressies van pijn. De analyses leverden gemengde resultaten op. In de eerste studie werd in lijn met de hypothese een lagere schatting van gezichtsexpressie van pijn gevonden voor de sociale dreiging context, maar geen effect op geschatte pijnintensiteit. In de tweede studie werd eveneens in lijn met de hypothese een hogere geschatte pijnintensiteit gevonden voor sociaal dreigende contexten, maar er was geen significant verschil tussen de gezichtsexpressies van pijn. Deze resultaten worden besproken met betrekking tot het evolutionaire perspectief op pijnuitingen en experimentele studies naar sociale dreiging.

De studie beschreven in Hoofdstuk 7 richtte zich op een andere vorm van sociale bedreiging; de invloed van ervaren onrecht op gerapporteerde 
pijnintensiteit en gezichtsexpressie van pijn. Gezonde deelnemers $(\mathrm{N}=62)$ namen deel aan een experiment waarin zij in een intelligentie quiz streden voor een financiële beloning. De onderzoeker bevoordeelde openlijk één van beide deelnemers om zo het ervaren onrecht van beide deelnemers te manipuleren. Na de quiz ondergingen de deelnemers een één minuut durende koudwatertaak waarbij ze de ervaren pijnintensiteit rapporteerden en hun gezichtsexpressie van pijn werd gefilmd en gecodeerd. Aangezien zowel de begunstigde en benadeelde deelnemers onrecht ervaarden als gevolg van de manipulatie is een vragenlijstmeting van ervaren interpersoonlijke bedreiging als onafhankelijke variabele ingevoerd in de analyses. De resultaten op gerapporteerde pijnintensiteit toonden een cross-over patroon, waarbij een lage interpersoonlijke dreiging werd geassocieerd met hogere pijnrapportage voor hoog pijncatastroferende deelnemers. Anderzijds werd een hoge interpersoonlijke dreiging geassocieerd met hogere pijnrapportage voor laag pijncatastroferende deelnemers in vergelijking met de hoog pijncatastroferende deelnemers. Hoge interpersoonlijke dreiging werd ook geassocieerd met een verhoogde gezichtsexpressie van voor zowel laag als hoog pijncatastroferende deelnemers. Deze resultaten worden besproken met betrekking tot de eerdere studies naar social dreiging en psychologische modellen van pijn.

Samengevat beschrijft dit proefschrift een aantal exploratieve experimenten naar de relatie tussen sociale dreiging en pijn. Ongeacht de moeilijkheden met het creëren van geloofwaardige en effectieve sociale dreiging manipulaties leverden de studies interessante resultaten op. De meest opvallende bevinding is dat sociale dreiging een dissociatie tussen gerapporteerde pijnintensiteit en gezichtexpressie van pijn lijkt te veroorzaken. Geen van de bestaande modellen van pijn lijken een geschikte verklaring voor deze dissociatie bieden. Alternatieve theorieën en modellen uit andere onderzoeksgebieden kunnen een betere verklaring bieden voor de sociale dreiging effecten op pijn. Toekomstig onderzoek zou zich allereerst moeten richten op het repliceren van de dissociatie tussen de gerapporteerde pijnintensiteit en de gezichtexpressie van pijn. Sociale dreiging manipulaties hebben bewezen moeilijk te zijn. Het wordt daarom geadviseerd meer ecologisch valide designs te gebruiken om het probleem met geloofwaardigheid en effectiviteit aan te pakken, en bovendien het gat tussen laboratorium onderzoek en de (klinische) praktijk te dichten. 
About the author 
Pim Antonius Maria Peeters was born in Eindhoven, The Netherlands on January 2, 1985. In 2003 he graduated from secondary school Van Maerlant Lyceum, in Eindhoven. The same year he started studying Psychology at Maastricht University. He received his bachelor's and honours degree, both cum laude, in 2006. He enrolled in the research master program Abnormal Psychology, Neuropsychology and Cognitive Neuroscience, in the Abnormal Psychology track. During his research internship he wrote a toptalent grant proposal for the Dutch organization of scientific research (NWO) to fund his own PhD project. Directly after graduating cum laude in 2008, the grant proposal was awarded the toptalent grant. He started on the PhD project at Maastricht University and quickly after also at the Catholic University Leuven. Since June 2012 he has held a position as lecturer at the Avans University of Applied Science.

\section{Publications}

Journal Articles

Peeters, P. A. M. \& Vlaeyen, J. W. S. (2011). Feeling more pain, yet showing less: The influence of social threat on pain. Journal of Pain, 12(12), 12551261.

Keulemans, K., \& Peeters, P. A. M (2012). Pijn in een interpersoonlijke context. De Psycholoog, 47(11), 17 - 25.

\section{Conference Abstracts}

Peeters, P. A. M. \& Vlaeyen, J. W. S. Pain control 'by proxy' moderates the effects of the experienced threat value of pain on pain expression. Abstract $\# 329,6^{\text {th }}$ Congress of the European Federation of IASP chapters (EFIC), Lissabon (2009)

Vandebroek, N., Peeters, P., \& Vlaeyen, J. Social threat hurts! A withinsubjects study on the influence of pain-specific social threat on pain report. Abstract PT486, $13^{\text {th }}$ World Congress on Pain, Montreal (2010)

Peeters, P., Helsen, K., \& Vlaeyen, J. Social threat hurts! Te influence of pain-spcific social threat on pain expression. Abstract PW033, 13 ${ }^{\text {th }}$ World Congress on Pain, 
ABOUT THE AUTHOR

133 
Dankwoord 


\section{A few words of thanks}

I've always believed that gratitude is expressed more in the way one behaves rather than in the words of thanks that are spoken. I therefore hope that this chapter is redundant and that everybody who has supported me in some way is aware that I am thankful for it. If you are reading this chapter, it is very likely that I have something to thank you for as well.

During the four years that I worked as a $\mathrm{PhD}$ student at Maastricht University and the Catholic University Leuven I have received support from too many people to name them all individually. Rather than naming some and by their absence sending others the wrong message, I've chosen to thank all who have contributed to this dissertation by their contribution instead of their name.

I would like to thank all who have advised me on the studies I conducted and the articles that I wrote. I have become a better researcher by it and for me that was always the primary reason for becoming a $\mathrm{PhD}$ student.

I would like to thank all who helped in practical matters ranging from technical support, administration, finances, data collection, experimental manipulation, study participation, and much more. Without all this help it would never have been possible to conduct the studies included, and the many studies that were not included, in this dissertation.

I would like to thank all that provided me with social support. Whether allowing me to vent the inevitable frustrations, musing about contributions to a better world, or simply taking my mind of the work for a couple of moments, without all of this I would have had a very unhappy four years.

I would like to thank those with whom I share my personal life. The way you have shaped and are shaping my life, the love you share, and in some special cases simply your presence, make me into a better man, and inevitably a better scientist.

And finally I would like to thank you, the reader. Aside from any support you lend me during my four years, the fact that you are reading this dissertation, even if only this section, flatters me.

Overall I am grateful for the way I was able to spend the last couple of years of my life on this research project with so many people involved. I feel richer for the experience. A high standard for enjoyment has been set, it is time for a new challenge. 
DANKWOORD 
